University of Texas at El Paso

\title{
DigitalCommons@UTEP
}

Open Access Theses \& Dissertations

2012-01-01

\section{Development of Thermoelectric Temperature Sensors}

Jennifer Jazmin Kuchle Ituarte

University of Texas at El Paso, jenny.jazmin@gmail.com

Follow this and additional works at: https://digitalcommons.utep.edu/open_etd

Part of the Mechanical Engineering Commons

\section{Recommended Citation}

Kuchle Ituarte, Jennifer Jazmin, "Development of Thermoelectric Temperature Sensors" (2012). Open Access Theses \& Dissertations. 1855.

https://digitalcommons.utep.edu/open_etd/1855

This is brought to you for free and open access by DigitalCommons@UTEP. It has been accepted for inclusion in Open Access Theses \& Dissertations by an authorized administrator of DigitalCommons@UTEP. For more information, please contact lweber@utep.edu. 


\title{
DEVELOPMENT OF THERMOELECTRIC TEMPERATURE SENSORS
}

\author{
JENNIFER JAZMIN KUCHLE ITUARTE
}

Department of Mechanical Engineering

\section{APPROVED:}

Norman Love, Ph.D., Chair

Ahsan Choudhuri, Ph.D.

Eric MacDonald, Ph.D.

Benjamin C. Flores, Ph.D.

Dean of the Graduate School 
Copyright (C)

by

Jennifer Jazmin Kuchle Ituarte

2012 


\section{Dedication}

This thesis is dedicated to my family and all their support, and my close friends that helped me through the hardest times. I love you all dearly. 


\title{
DEVELOPMENT OF THERMOELECTRIC TEMPERATURE SENSORS
}

by

JENNIFER JAZMIN KUCHLE ITUARTE, B.S. Mechanical Engineering

\section{THESIS}

\author{
Presented to the Faculty of the Graduate School of \\ The University of Texas at El Paso \\ in Partial Fulfillment \\ of the Requirements \\ for the Degree of
}

\section{MASTER OF SCIENCE}

Department of Mechanical Engineering THE UNIVERSITY OF TEXAS AT EL PASO

December 2012 


\section{Acknowledgements}

First and foremost I would like to thank God for filling my life with love, physical health, and for giving me the strength and perseverance to achieve my goals.

I would also like to thank my family for guiding me along the road of life and for their

continuous support through my life and career endeavors. I would like to give special thanks to my mother for being always a role model for me and an example of hard work and dedication.

I would like to acknowledge my committee members, Dr. Norman Love, Dr. Ahsan Choudhuri and Dr. Eric MacDonald for their guidance.

A special acknowledgement goes to my professor and mentor Dr. Norman Love for always sharing his knowledge and expertise with me, helping me develop my technical skills, and allowing me the opportunity to work under his guidance. I would like to express my sincere gratitude for all his teachings but mainly for the valuable advice he has given me, and that I will apply to my life.

I would like to thank Dr. Ahsan Choudhuri for the opportunity to conduct this research at the Center for Space Exploration Technology Research (cSETR) labs, and Dr. Virgilio Gonzalez for his helpful collaboration and teachings.

I would also like to acknowledge all my colleagues at cSETR for their help in my research, with a special recognition to Kazi Hassan and Rodolfo Aguirre.

Finally, the financial support by A. Loya innovation fund is gratefully acknowledged. 


\begin{abstract}
Temperature measurements in power generation systems can provide useful information on the performance parameters of the units. This paper presents a conceptual measurement technique using a simulated thermoelectric loop (signal transmitter). The transmitter simulates the induced current and magnetic field emanating from the center of an $\mathrm{n}$ and $\mathrm{p}$ loop. The receiver used in this study is a Hall Effect sensing device which measures the magnetic flux density produced by the transmitter. Three experimental setups were designed and built for the measurements. The first setup used a pendulum to move a coil simulating a loop thermoelectric generator thereby creating a magnetic field. A second generation setup was also constructed that produced more accurate and repeatable results. Finally, a third setup was built using a heated thermoelectric generator device (adding temperature as a new variable) in order to see the relation between the temperature gradient, the induced magnetic flux, and the Hall sensor's response. Results obtained in this study from the three generations of experiments are presented in this paper along with the filtering process utilized to reduce the noise of the signal. Results show that measurements of temperature wirelessly using thermoelectrics are feasible and may be used in future advanced power generation technologies.
\end{abstract}




\section{Table of Contents}

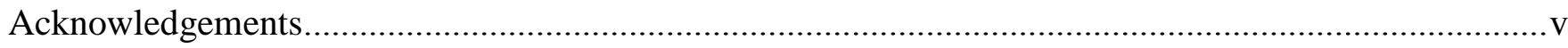

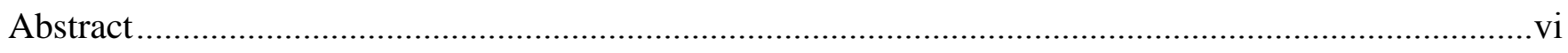

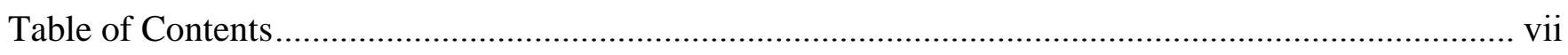

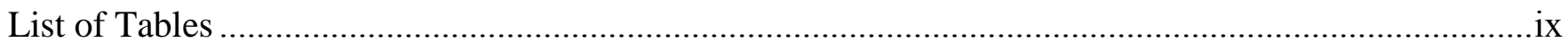

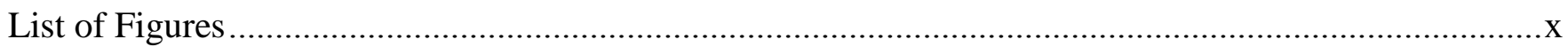

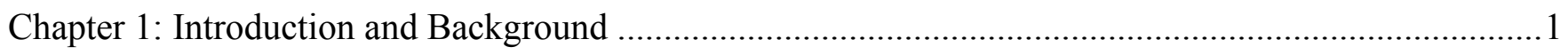

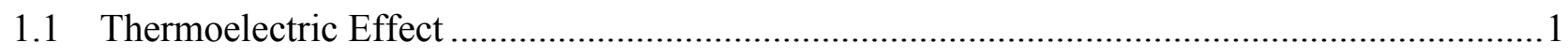

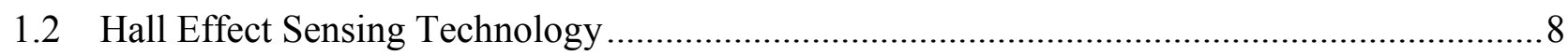

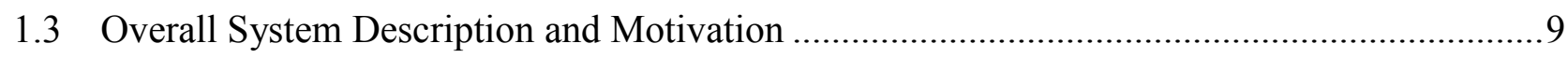

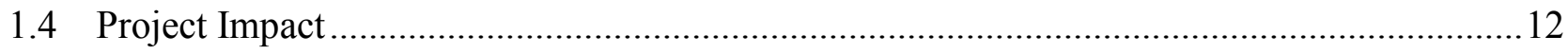

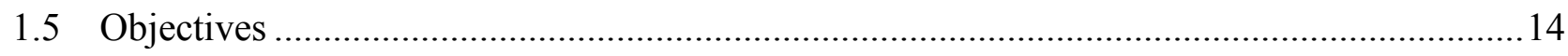

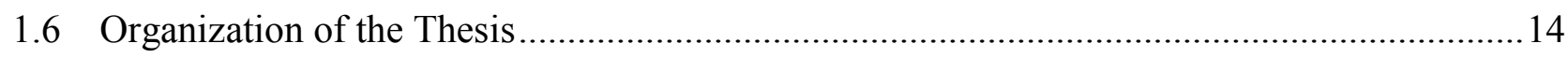

Chapter 2: Instrumentation and Experimental Procedure .......................................................... 16

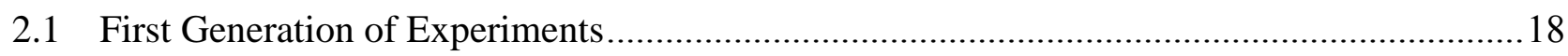

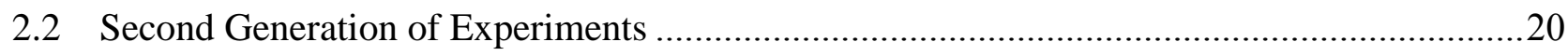

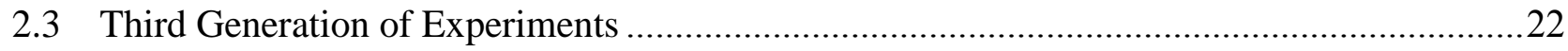

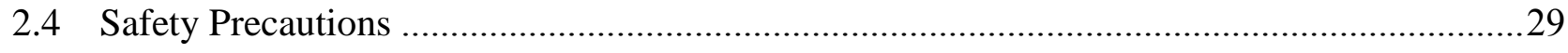

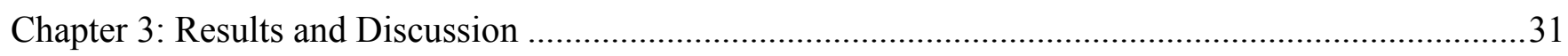

3.1 First Generation Experimental Results ............................................................. 31

3.2 Second Generation Experimental Results ............................................................ 33

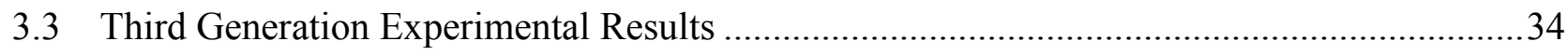

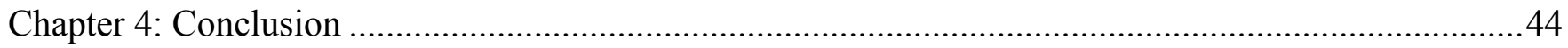

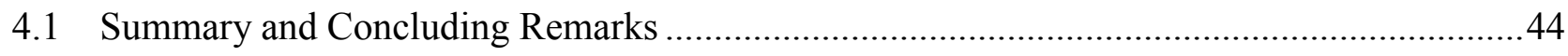

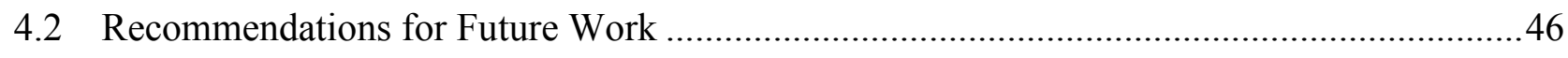




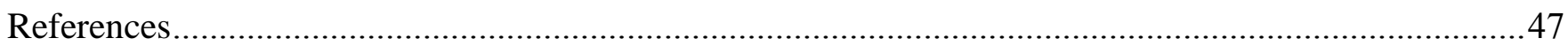

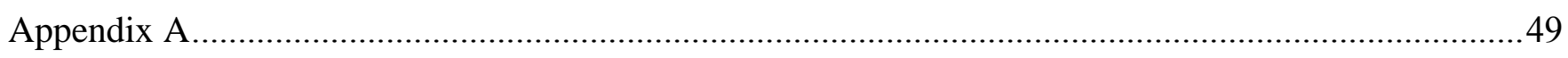

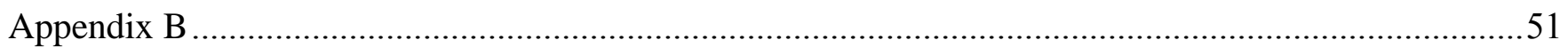

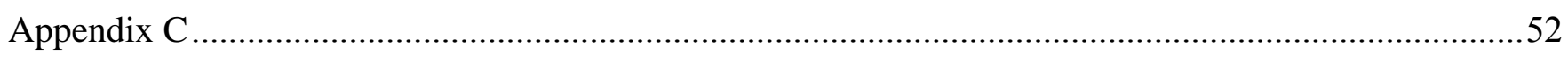

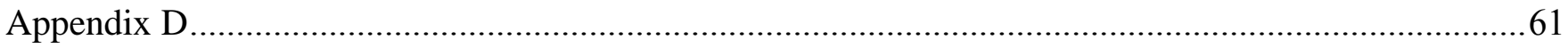

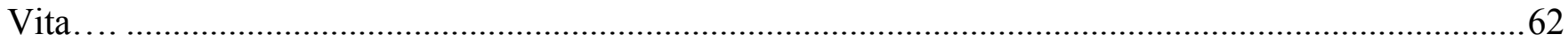




\section{List of Tables}

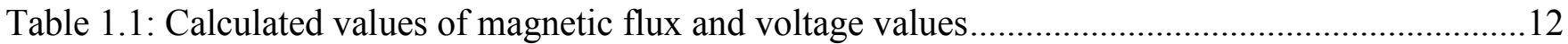

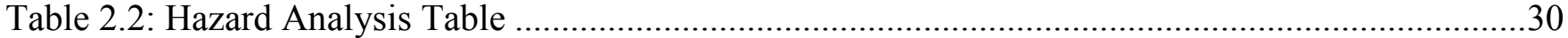

Table 3.1: Measured values for the voltage generated from a single thermoelectric element .................38 


\section{List of Figures}

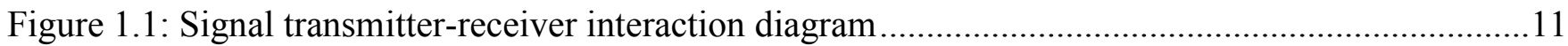

Figure 2.1: Block diagram showing experimental procedure ..............................................................17

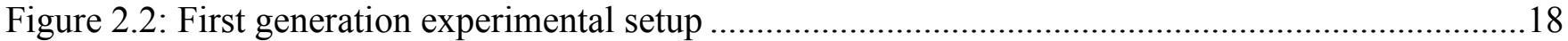

Figure 2.3: Circuit diagram representation of $1^{\text {st }}$ generation setup .......................................................19

Figure 2.4: (Left) Second generation experimental setup (Right) Hall Effect sensing device ...................20

Figure 2.5: Circuit diagram representation of 2nd generation setup .........................................................20

Figure 2.6: Positioning of the sensor with respect to the solenoid .........................................................22

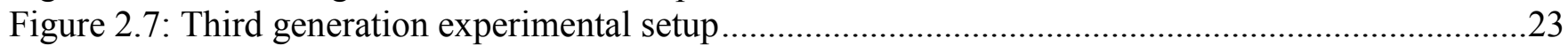

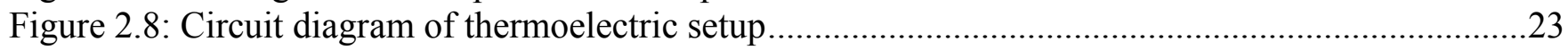

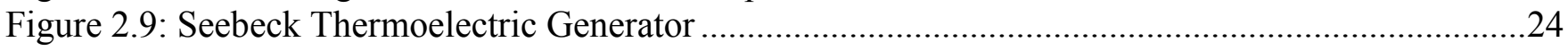

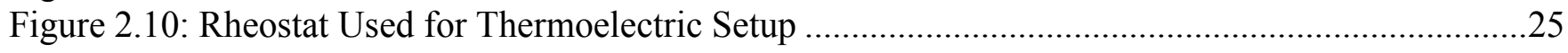

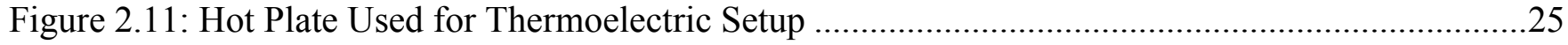

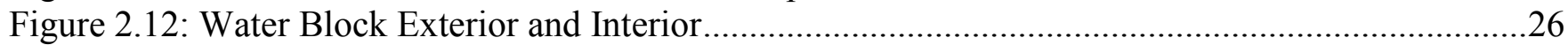

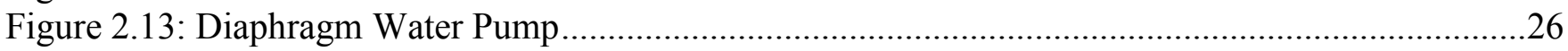

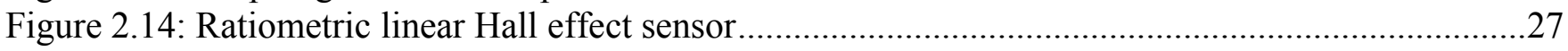

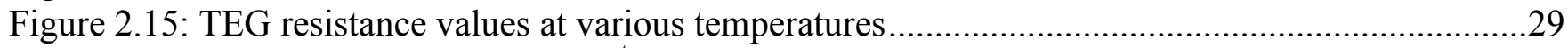

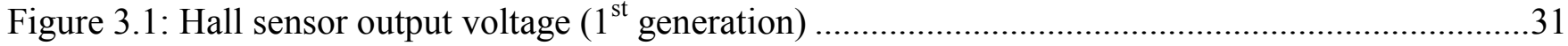

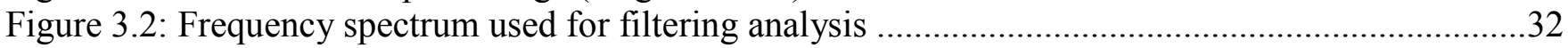

Figure 3.3: Comparison between unfiltered and filtered signals ...........................................................32

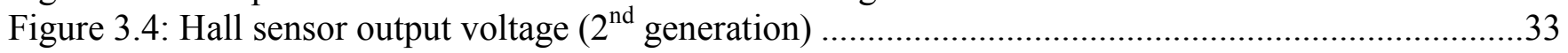

Figure 3.5: Temperatures on surfaces of heated thermoelectric element .................................................34

Figure 3.6: Hall sensor output voltage and temperature gradient $\left(3^{\text {rd }}\right.$ generation) ......................................35

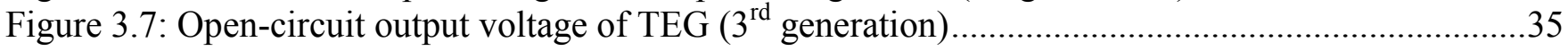

Figure 3.8: Temperatures on surfaces of heated thermoelectric element ..................................................36

Figure 3.9: Hall sensor output voltage and temperature gradient ( ${ }^{\text {rd }}$ generation) .....................................

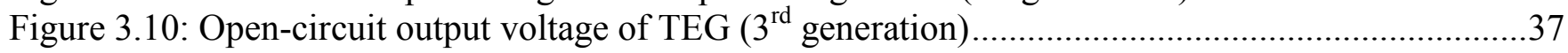

Figure 3.11: LabVIEW VI block diagram of 4-way valve system............................................................39

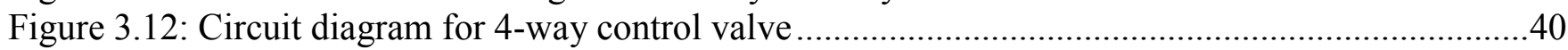

Figure 3.13: Temperatures on surfaces of heated thermoelectric element ................................................40

Figure 3.14: Hall sensor output voltage $\left(3^{\text {rd }}\right.$ generation, dynamic system $)$.............................................4

Figure 3.15: Open-circuit output voltage of TEG $\left(3^{\text {rd }}\right.$ generation, dynamic system $) \ldots \ldots \ldots \ldots \ldots \ldots \ldots \ldots \ldots \ldots . . . . . . . . . . . . . . .11$

Figure 3.16: Temperature on surfaces of heated thermoelectric element..............................................42

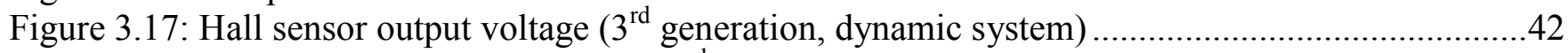

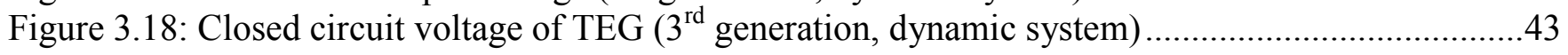




\section{Chapter 1: Introduction and Background}

The increasing awareness of the harmful effect of global warming as well as the development of new and environmentally-friendly electrical power sources have led to a substantial increasing interest in the thermoelectrics field of study.

This introductory chapter provides a general overview of the major technologies used in this project (thermoelectric and Hall Effect sensing technologies). The literature pertaining to the recent investigation in this field, as well as the statement of the problem, project impact, objectives, and organization of the content are also included.

\subsection{THERMOELECTRIC EFFECT}

\subsubsection{General Principle: Seebeck Effect}

Thermoelectric phenomena arise out of the intercoupled electrical and thermal currents in a material. According to the Seebeck effect, the temperature gradient $(\Delta T)$ applied to a conductor material cause a voltage gradient $(\Delta V)$ proportional to it. The principle is described by the equation,

$$
\Delta V=S \Delta T
$$

The Seebeck effect can be explained using a thermocouple as an example, (the simplest form of a thermoelectric generator) which is formed by making an electrical connection of an $n$-type conductor with a $p$-type conductor. When the junction is heated, electrons become excited and pass from the material in which the electrons have the lower energy into that in which their energy is higher, giving rise to an electromotive force [1]. This project uses this principle and shorts the two ends of the $n$ and $p$ type conductors or semiconductors in a loop. Additionally, this project attempts to use the magnitude of the current generated to a temperature difference between the two connection points.

\subsubsection{Applications}

Using the Seebeck effect, a temperature difference between the two sides of a thermoelectric can be utilized to convert thermal energy into electrical energy. In general, thermoelectric power generators 
have attracted the attention of researchers due to the notable advantages they offer over other power generation technologies. Thermoelectric power generators can be reliable since they do not contain any moving mechanical parts, are suited for small-scale and remote applications, are environmentally friendly, are not-position dependent, are silent in operation, and require significantly less maintenance $[2]$.

A limitation, however, of thermoelectrics, is their efficiency which still remains well below 10\%, prompting their use for other applications such as waste heat recovery and space applications. Thermoelectrics have also been used to power sensor devices and have been applied to many currently existing power generation units. Many research studies have been conducted for this purpose, some of which are presented in the following sections. A novel study is presented here that uses the thermoelectric technology to directly be used as a sensing device.

\section{Waste Heat Recovery}

Traditional usage of thermoelectrics is for waste heat recovery applications. Since the discovery of the Seebeck effect, thermoelectric modules have been studied for more than 180 years. Optimizations in the design and materials used for power generation systems have been made by researchers in order to make use of all the heat available in such systems and generate electricity. An example of this is the numerical model created by Crane and Jackson which was used to integrate a thermoelectric heat exchanger in a cross flow configuration and compared their results with previous studies done on general counter flow heat exchangers [3]. The results revealed that heat exchanger design on both sides of the thermoelectric generators significantly impacts the thermal efficiency of the system.

Furthermore, with the increasing concern of global warming, thermoelectric devices have been used in conjunction with carbon dioxide reduction techniques. In the study conducted by Mori et al., a 2 L gasoline vehicle was utilized as a study case and the effect of a thermoelectric system was evaluated based on the fuel economy, adopting commercially available thermoelectric materials and common industrial techniques [4]. As part of their investigation, they also saw the application of thermoelectrics along with carbon capture methods to further reduce greenhouse gas emissions and support environmental sustainability. During the same year, Ismail and Ahmed conducted a study where they 
presented some of the most relevant patents and applications reviewed remarking their importance as an available alternative green technology [5].

Some other works in the waste heat recovery area include the study performed by Love et al., where several thermoelectric devices were tested on a simulated automotive exhaust heat recovery system. An experimental investigation was completed in order to see the effect of clean and fouled heat exchangers of different materials and their impact for exhaust heat recovery [6]. From their results, they could observe a direct correlation between the increasing power generated through the thermoelectric devices and the elevation of the temperature of the exhaust gases. Also, higher power generation rates were perceived with the decrement of the cooling fluid temperature as well as with the increment of the mass flow rate of the heated gas.

A similar work was conducted by Baker and Shi. During their study, they investigated the characteristics of a conceptual heat exchanger design from a diesel exhaust for thermoelectric waste heat recovery purposes [7].

\section{Power Generation for Sensing Devices}

Moreover the extensive set of studies found on the thermoelectric usage for waste heat recovery applications, several studies have been found on their utilization as a means to supply power to a variety of sensors used in the industry. For instance, Schilz monitored the absorption of an infrared light beam

utilizing the perceived changes in the electrical conductivity induced by infrared radiation [8]. As a result, he developed a system of thermoelectric infrared sensors which were used as gas detectors during his research studies.

In 2007, the first autonomous health monitoring sensors powered by thermoelectric systems were reported. An example of this is presented in the research conducted by Torfs et al. where they designed and developed a wireless autonomous pulse oximeter consisting of a thermoelectric power supply and a pulse oximetry finger sensor [9]. Their studies served as a fundamental basis for future research work made on thin-film and MEMS thermopiles. 
In the same area, as part of their investigation in thermoelectricity, Leonov et al. developed a wireless electroencephalograph (EEG) monitoring system powered by a headband-type thermoelectric generator based on temperature differences between the skin and the ambient temperatures [10].

Dalola made use of thermoelectric devices to supply an autonomous system which interfaced with a temperature sensor and transmitted the signal via an RF link [11].

Thermoelectric devices have been widely used to power sensors in remote locations and enclosed spaces where a more conventional source of power is not available.

Sardini and Serpelloni developed a power harvesting system supplied by an electromagnetic field used as a communication support in order to obtain the electric power required to make the sensors work and take remote measurements [12]. As part of their investigation, they placed the sensors on hot pipes and powered them using a thermoelectric generator. The sensor periodically performed temperature measurements and saved all the data in non-volatile memory.

Using a similar technique, Sordiashie developed an electromagnetic harvesting method to power energy management sensors in the built environment. The designed system consisted of a small prototype harvesting device used in the experiments which was mounted on the current carrying conductor at a node and wired to an energy management sensor [13].

In more recent studies regarding power generation for sensors, the study led by Cartens can be found also as part of the literature in this field. He conducted experiments using thermoelectric generators to power radio frequency modules in order to monitor the fuel being spent during dry-cask storage. The temperature distribution in a thermoelectric generator and heat sink was calculated using Finite Element Analysis (FEA) software. From the data obtained, the power produced by the generator was determined as a function of the service life of the dry-cask storage system [14].

\section{Other Studies}

As seen in most of the aforementioned studies, thermoelectrics are nowadays being used to power sensing devices. The research study presented here is intended to prove the concept that thermoelectric technology can be used as a sensing device itself. More precisely, it is proposed to 
demonstrate that temperature measurements may be recorded on the surface of a material making use of thermoelectrics only.

At laboratory scale, ultrasonic intensity sensors have been developed and analyzed. Romdhane et al. conducted initial experiments in this area using a thermocouple embedded in silicone [15]. The thermocouple was mounted on a rack gear and was allowed horizontal and vertical displacement. During the heating, the increasing temperature of the silicone was linked to the increased transmittance of the ultrasound, and vice versa. The changes in temperature signal allowed the establishment of a relation between the temperature signal response and ultrasound intensity.

Thin film thermoelectric sensors have also been investigated and fabricated as thermal sensors for radiation, electrical AC and DC power, and low vacuum, which can be integrated in microelectronics. A work related to this application was presented by Völklein et al. [16].

Another study was conducted by Haruyama where he utilized a Peltier element as a heat flux sensor at cryogenic temperatures $(200 \mathrm{~K}$ down to $60 \mathrm{~K})$ in order to prove its ability to take in situ radiant heat flux measurements. The results showed the sensitivity of the cryogenic heat flux sensor was still large enough even at $60 \mathrm{~K}$, demonstrating a promising future for this application [17].

Thermoelectrics have also been used in the last decades for aerospace applications. Radioisotope thermoelectric generators (RTGs) have been built for power generation from radioactive decay using the heat released by the decay of radioactive materials and converting it into electricity by the Seebeck effect principle. The major components of thermoelectric unicouples used nowadays are Silicon Germanium alloys. However, recent investigations have suggested the use of more efficient segmented thermoelectric unicouples for aerospace power applications. In the study conducted by El-Genk et al., the use of skutterudite segmented thermoelectric materials at temperatures of $\sim 970 \mathrm{~K}$ was used instead of common used materials in order to increase the conversion efficiency of space nuclear reactor power systems by $41 \%$. Similarly, an increment in the useful lifetime of the power system was observed [18].

A more recent study was presented in 2010 at the $56^{\text {th }}$ International Instrumentation Symposium. Gregory et al. developed a passive wireless temperature sensor which was embedded on a gas turbine 
blade. The sensor was intended to determine surface temperatures and heat flux measurements for heat engine applications [19]. Further implementation of this device is still being investigated.

Their research work means a significant progress over the current wired sensor technology where the main challenges on designing temperature sensors are met. However, their research project has little to do with the utilization of the thermoelectric technology available, which is the main scope of this project.

The novel study presented here investigates the potential of using thermoelectric loops for temperature and temperature difference measurements that allow remote data to be obtained and recorded in a wireless configuration.

\subsubsection{Thermoelectric Materials}

The main foci of researchers in this field are the study, design, development, and implementation of new thermoelectric materials in mechanical systems. Its primary importance lies in the implementation of thermoelectric technology which can be used to increase efficiencies of many systems in this configuration. A driving effort has been made to maximize the efficiency of the thermoelectric generators $\left(\dot{W}_{\text {out }} / \mathrm{Q}_{\text {in }}\right)$, shown by the equation,

$$
\eta=\frac{\Delta T}{T_{h}} \cdot \frac{\sqrt{1+Z T_{a v g}}-1}{\sqrt{1+z T_{a v g}}+\frac{T_{C}}{T_{h}}}
$$

which is restricted by the Carnot efficiency $\left(\Delta T / T_{h}\right)$, and the thermoelectric properties of the material itself. Typical solids of interest used to improve the thermoelectric efficiencies are metals and semiconductors.

The material properties of major interest in the analysis of a thermoelectric material include the electrical conductivity, $\sigma$, the thermal conductivity, $\lambda$, and the Seebeck coefficient (commonly known as thermopower), $S$. These material properties govern the thermoelectric performance and add important 
and valuable information on the efficiency of a device over alternative thermoelectric choices. These properties are included in the so called figure of merit in the following equation,

$$
Z=\frac{\sigma s^{2}}{\lambda}
$$

As seen from Eq. 1.3, the efficiency of the thermoelectric becomes the Carnot efficiency as the figure of merit ZT approaches infinity. A higher ZT value generally means a higher efficiency but it also implies a higher electrical resistivity value, which results in additional challenges for researchers and engineers to overcome. In general, the dimensionless value of the figure of merit, $Z T$, is aimed to be increased by raising the electrical conductivity and lowering the thermal conductivity through the application of advanced material development and innovative manufacturing, ultimately enabling more widespread use of thermoelectric systems. This parameter is widely used in the thermoelectric community and will be used as a performance metric in the current study.

In terms of the selection of thermoelectric materials, several studies can be found as part of the literature. An example of this is the investigation made by researcher LaGrandeur et al. where they developed a computer aided simulation of an automotive vehicle exhaust, and used series of segmented elements comprised of different materials (skutterudite, TAGS, $\mathrm{PbTe}$, and $\mathrm{Bi}_{2} \mathrm{Te}_{3}$ ) as the thermoelectric generators. The materials were chosen to achieve the highest average figure of merit (ZT) over the total operating temperature range [20].

Brown et al. performed an exhaustive research on the bulk material $\mathrm{Yb}_{14} \mathrm{MnSb}_{11}$. They tested it and proved its capability as a new high efficiency thermoelectric material for power generation applications [21].

In the article presented by Snyder and Toberer, some of the most recent advances, challenges and strategies researchers have implemented to produce high-efficiency thermoelectric materials are presented [22].

Definitely, a deep understanding of solid-state chemistry and physics along with hightemperature electronics and thermal transport properties background are required for the appropriate 
research and development of new thermoelectric materials. Advances in this field are evident but there is still a long road ahead in this area.

\subsection{Hall EfFect Sensing Technology}

This section describes Hall Sensor technologies which were used as the primary measurement tool for the current project.

\subsubsection{Theory}

The Hall Effect principle refers to the voltage generated when a current-carrying conductor is placed into a magnetic field. When a magnetic field is present, a Lorentz force is exerted on the current. This force disturbs the current distribution and, consequently, an output voltage is generated. The voltage produced is perpendicular to both current direction and magnetic field and is proportional to the vector cross product of the current and magnetic field as described by,

$$
V_{H} \propto \mathrm{I} \times \mathrm{B}
$$

The Hall sensor provides an output voltage that is proportional to the magnetic field to which it is exposed.

The two important parameters when selecting a Hall Effect sensor for this project were sensitivity and null offset. The sensitivity refers to the change in the output voltage with respect to the change in the input. The null offset is the output voltage from the sensor when no magnetic field is present. For this study, the Hall sensor chosen has a sensitivity of $5 \mathrm{mV} /$ Gauss and a null offset of half of the voltage supply (presented in more detail in Chapter 2).

\subsubsection{Sensing Devices and Applications}

Hall Effect sensors can be used for a wide range of applications. For instance, some of the flow rate sensors used nowadays employ this technology. By mounting magnets on the impeller blade in a pump, a digital Hall output sensor can be used to measure the magnetic field produced when a certain fluid level is reached. This technology has also enabled the user to create proximity sensors for accurate 
positioning applications [23]. Printers, copiers, and almost any commonly used office machine can be mechanically operated using Hall Effect sensors. Cameras, valve actuators and dampers' exact position can also be determined with this system.

Likewise, current sensing devices used to measure large amounts of current around voltage lines in power plants apply the Hall Effect. Linear output Hall Effect sensing devices belong to this type of sensors, which is the area of interest for this study. When a linear sensor is placed near a currentcarrying conductor, the output voltage developed is proportional to the magnetic field surrounding the conductor.

The selected Hall-based sensing device for this study is a ratiometric linear Hall Effect sensor. This type of sensor is constructed using a silicon steel or ferrite core and a Hall integrated circuit which are mounted in a plastic housing. The term ratiometric indicates that the initial reading of the output voltage (when no external magnetic field is present) will be half of the supply voltage.

The Hall sensing device, as the majority of the sensors, is sensitive to variations in temperature. For this reason, the Hall sensor used was held at ambient temperature conditions during the duration of the study.

\subsection{OVERAll System Description AND Motivation}

Since the system that will be tested will generate a magnetic flux, it is important to use the appropriate tool to measure the magnetic flux density. The magnetic flux density describes the intensity of the magnetic field at a particular point in space. This concept is one of the most important terms in this study because it represents the input of the Hall sensing device. Using the following equation, the magnetic flux can be computed analytically,

$$
\varphi=\frac{\mu_{0} N_{i} A}{l}
$$

The current-carrying conductor used to generate a magnetic field that could be detected by the Hall sensor was a solenoid wrapped around a plastic core. In magnetic cores, the magnetization curve indicates the relation between the magnetizing force and the magnetic flux density is not linear. With a 
gradually increasing magnetizing force, the flux density increases from zero to a maximum point indicating the core is magnetically saturated. For the selected solenoid core (non-magnetic material), the magnetizing curve reflects a straight line with the slope being the permeability constant, $\mu_{0}$.

The coil's length, cross sectional area, shape and the coil and core materials used are some factors that affect the magnetic flux density produced by the solenoid created. In order to minimize the number of variables and simplify the overall system, the material, solenoid's area and the number of turns were set constant. In addition, the solenoid's core permeability was allowed to be almost the same value as the permeability constant due to the solenoid's plastic core, allowing the magnetic field induced in the coil to be only altered by the changes in current.

The described system is validated by the Biot-Savart law which gives magnetic flux density around the conductor (solenoid) to be directly proportional to the current flowing through it and inversely proportional to the distance of that specific point from the conductor [24]. In other words, if the proposed magnet (solenoid with a supplied/induced current and magnetic field) faces the sensor from the North pole and it is located at some distance $d$ from point $P$ from the sensor as illustrated in Figure 1, the equation that describes the magnitude of the field perceived is,

$$
B_{N} \propto 1 / d^{2}
$$

whereas if it faces the South pole the equation becomes the equation,

$$
B_{S} \propto 1 /(d+L)^{2}
$$

In the system, the signal transmitter (solenoid) is intended to move in a horizontal plane in front of the receiver's sensing face in a continuous reciprocating motion (motion with directional reversal). The maximum peak of the magnetic flux is reached as the gap becomes smaller. The gap between the Hall sensor face and the solenoid was set to a constant value of $1.3 \mathrm{~cm}$. 


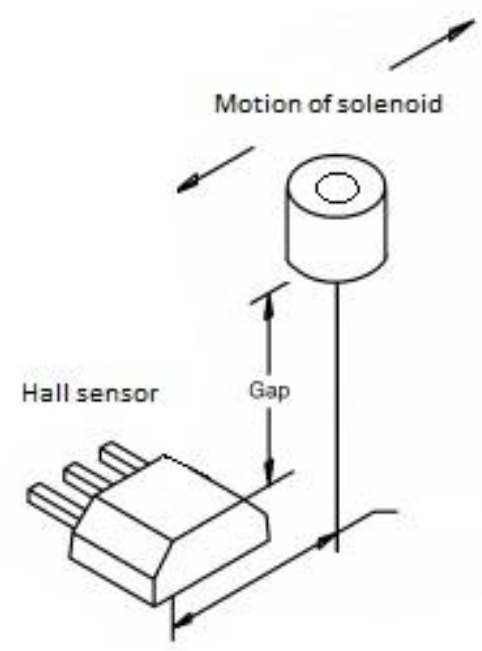

Figure 1.1: Signal transmitter-receiver interaction diagram

The equations mentioned above describing the magnitude of the field perceived at a given distance from the sensor can be approximated also with the following equation [25] used for magnetic field density at a given distance in the z-axis,

$$
B_{Z}=\frac{\mu_{0} N I}{2 l}\left\{\frac{1-\frac{2 z}{l}}{\left[\left(\frac{2 r}{l}\right)^{2}+\left(\frac{2 r}{l}-1\right)^{2}\right]^{\frac{1}{2}}}+\frac{1+\frac{2 z}{l}}{\left[\left(\frac{2 r}{l}\right)^{2}+\left(\frac{2 z}{l}+1\right)^{2}\right]^{\frac{1}{2}}}\right\}
$$

where $z$ is any point on the z-axis away from the center of the current-carrying conductor (solenoid), $r$ is the radius of the solenoid and $l$ is the length of the solenoid.

Equating Eq. 1.8 with the following equation (used to relate distance in $\mathrm{z}$ and the relative signal intensity $\mathrm{V}_{\text {out }}$ from the Hall Effect sensing device), an estimate of the output voltage reading from the sensor can be obtained from the computed theoretical values.

$$
\frac{\mu_{0} K}{2}\left\{\frac{1-\frac{2(z)}{l}}{\left[\left(\frac{2 r}{l}\right)^{2}+\left(\frac{2(z)}{l}-1\right)^{2}\right]^{1 / 2}}+\frac{1+\frac{2(z)}{l}}{\left[\left(\frac{2 r}{l}\right)^{2}+\left(\frac{2(z)}{l}+1\right)^{2}\right]^{1 / 2}}\right\}=\frac{1000\left(V_{B}-V_{0}\right)}{\operatorname{Sens}}
$$

Solving for $\mathrm{V}_{\mathrm{B}}$ the following equation is obtained, 


$$
\left\{(\text { Sens }) \frac{\mu_{0} K}{2}\right\} \frac{\left\{\frac{1-\frac{2(z)}{l}}{\left[\left(\frac{2 r}{l}\right)^{2}+\left(\frac{2(z)}{l}-1\right)^{2}\right]^{1 / 2}}+\frac{1+\frac{2(z)}{l}}{\left[\left(\frac{2 r}{l}\right)^{2}+\left(\frac{2(z)}{l}+1\right)^{2}\right]^{1 / 2}}\right\}}{1000}+V_{0}=V_{B},
$$

where "Sens" is the sensitivity of the Hall sensor, $\mathrm{V}_{0}$ is the initial voltage when no external magnetic field is sensed (2.5 Volts) and $\mathrm{V}_{\mathrm{B}}$ is the corresponding output voltage when a magnetic field is sensed.

Table 1.1 shows some of the calculated values of magnetic flux in Gauss, as well as the output voltage values at different distances from the Hall sensor. More details are shown in Appendix A.

Table 1.1: Calculated values of magnetic flux and voltage values

\begin{tabular}{ccc}
\hline Distance z-axis (m) & $\mathbf{B}$ (Gauss) & $\mathbf{V}_{\text {out }}$ \\
\hline $\mathbf{0 . 0 1 3}$ & 135 & 2.84 \\
$\mathbf{0 . 0 1 5}$ & 114 & 2.79 \\
$\mathbf{0 . 0 1 7}$ & 86.7 & 2.71 \\
$\mathbf{0 . 0 1 9}$ & 75.3 & 2.69 \\
$\mathbf{0 . 0 2 1}$ & 61.5 & 2.65 \\
\hline
\end{tabular}

\subsection{ProjeCt IMPACT}

For this project, the magnetic field in the solenoid was induced by a continuous current which was supplied by a power supply for the first experimentation and then induced by means of a thermoelectric generator.

The receiver or Hall sensor's output voltage, in turn, was set by the supply voltage and varied in accordance to the strength of the magnetic field perceived. Since the magnetic flux is proportional to the temperature gradient on the surface of a substrate, the relation obtained between the sensor's output and temperature difference from the thermoelectric module surfaces was used to determine the feasibility of the proposed system for the desired objectives described in Section 1.5. 
The study presented in this paper is motivated by the importance of an improved characterization and monitoring of the operating temperatures of mechanical systems such as gas turbines that allows to an increase in the efficiency and overall performance of such systems. This project is also motivated by the revolution of the new generation of electronic devices that do not need an external power supply or battery. The present study is intended to make a contribution in this area presenting a self-powered signal transmitter (thermoelectric attached to solenoid) which will be powered due to the temperature differences in the thermoelectric element.

Even when higher efficiencies can be obtained at higher operating temperatures, the materials used still impose limits and constraint the viability of the final goal forcing to set the safety margins to higher values to prevent fatigue and failure and the operating temperatures to lower than optimum values. It is intended to develop a system where both thermoelectricity and Hall Effect technologies can be coupled to work together and used to provide real-time temperature data while equipment is working.

Thermoelectricity has been studied for its use in numerous technologies, primarily for power generation for military, civilian and industrial uses. However, advancements and exhaustive investigation have still to be done on these fields to:

1. Utilize thermoelectric materials as sensing devices in the power generation industry

- Sensors are needed in the industry for direct measurement of physical properties on systems such as turbines and combustors. The characterization and incorporation of thermoelectric materials to wireless sensor technologies need to be investigated in order to obtain valuable information on the performance of the units. The results of the investigation presented in this paper are intended to make a future impact on this field.

2. Select the appropriate thermoelectric materials for their use in mechanical systems

- The parameters of different materials should be investigated exhaustively in order to determine the best materials that can increase the efficiency of the thermoelectric system 
and at the same time stand and take advantage of the high temperatures and harsh environments of some mechanical devices without degradation.

3. Produce and test a new generation of thermoelectric materials

- Even though the range of elements and compounds that can be classified as thermoelectric materials is wide and most of them follow similar properties, new compounds and generation of materials is needed that can work on a broader range of temperature operation without increasing the lattice thermal conductivity nor lowering the figure of merit and overall performance of the thermoelectric materials.

\subsection{OBJECTIVES}

This thesis will present the study being done on:

- The demonstration and applicability of a sensor, capable of receiving an electric signal produced by a thermoelectric device when exposed to a temperature gradient.

- The determination of a relation among crucial variables such as temperature gradient, induced current and magnetic flux density, and sensor's response (output voltage) for their future use in temperature measurements.

\subsection{Organization OF THE Thesis}

A brief introduction to the general mean topics related to this study is presented in Chapter 1, as well as the project impact and main objectives of the research conducted. This chapter includes some of the previous works in the thermoelectric area of study and its current applications.

Chapter 2 presents the experimental setup and equipment used for the first, second and third generation set of experiments.

Chapter 3 presents the results and numerical data obtained for the three generation of experiments. Analysis and discussion of the results are presented in this chapter. 
Chapter 4 gives a general summary of the results obtained and proposes recommendations for future work. 


\section{Chapter 2: Instrumentation and Experimental Procedure}

The experimental procedure was divided into three generations of experiments. For the first generation experimental setup, the capability of the receiver of detecting the magnetic flux density in a moving solenoid (attached to a pendulum) was tested supplying a continuous direct current of 4.3 Amperes to the coil. This value was previously calculated and selected as a constant parameter for the first two sets of experiments assuming n-type and p-type bismuth telluride thermoelectric strips were spray casted in a moving part of a power generation unit (e.g. turbine blade) in order to form a thermoelectric loop. In order to get the resistance of the thermoelectric loop, the following equation was used,

$$
\mathrm{R}=\frac{\mathrm{l}}{\sigma \mathrm{A}},
$$

where the total path length, 1, was predetermined to be $0.45 \mathrm{~m}$ ( $3 \mathrm{~cm}$ per strip, 15 turns), the electrical conductivity $(\sigma)$ used was $833 \times 10^{6} \Omega-{ }^{1} \mathrm{~m}^{-}{ }^{1}$, assuming an $\mathrm{n} \&$ p-type $\mathrm{Si} / \mathrm{Si}_{0.8} \mathrm{Ge}_{0.2}$ quantum well thermoelectric material spraycasted around a gas turbine blade. Even though the feasibility of quantum well thermoelectric materials on power generation units is under investigation, studies have demonstrated a significantly increase in the efficiency as well as in the thermopower measured.

This technology proposes not only a hypothetical basis for purposes of the experimental setup of this project, but also a vast field in what is expected to become the new era of thermoelectrics development for high temperature power generation applications (up to $1000^{\circ} \mathrm{C}$ ) [26].

The values of thermopower and cross sectional area of thermoelectric film strip (A) were $1500 \mathrm{x}$ $10^{-6}$ and $0.001 \mathrm{~m}^{2}$, respectively. The dimensions of the strip were from where the cross sectional area was calculated to be $0.45 \mathrm{~m}$ in length (accounting for the total number of turns), $15 \mathrm{~cm}$ in height and 6 $\mathrm{mm}$ in width. Since the required height of the thermoelectric strip was calculated to be $15 \mathrm{~cm}$, a medium or large size turbine blade is preferred for further implementation in power systems. With this information, the induced current in the thermoelectric loop was obtained with the equation 


$$
\mathrm{I}=\frac{S}{R}
$$

Based on the results obtained in this generation, a second generation rig was developed setting the intensity of the current (4.3 A) to a constant value as well. For this setup the coil moved horizontally attached to a pneumatic reciprocating cylinder rod. The transmissibility and reception of the signal were tested again. The third generation setup was built for the last generation of experiments presented in this paper. The solenoid was attached to the leads of a thermoelectric generator (TEG) device, allowing the current to be induced due to the temperature difference between the two sides of the thermoelectric. The process was repeated holding the coil static, and in moving positions. The block diagram shown in Figure 2.1 condenses the three generation of experiments and presents the relation and differences between them.

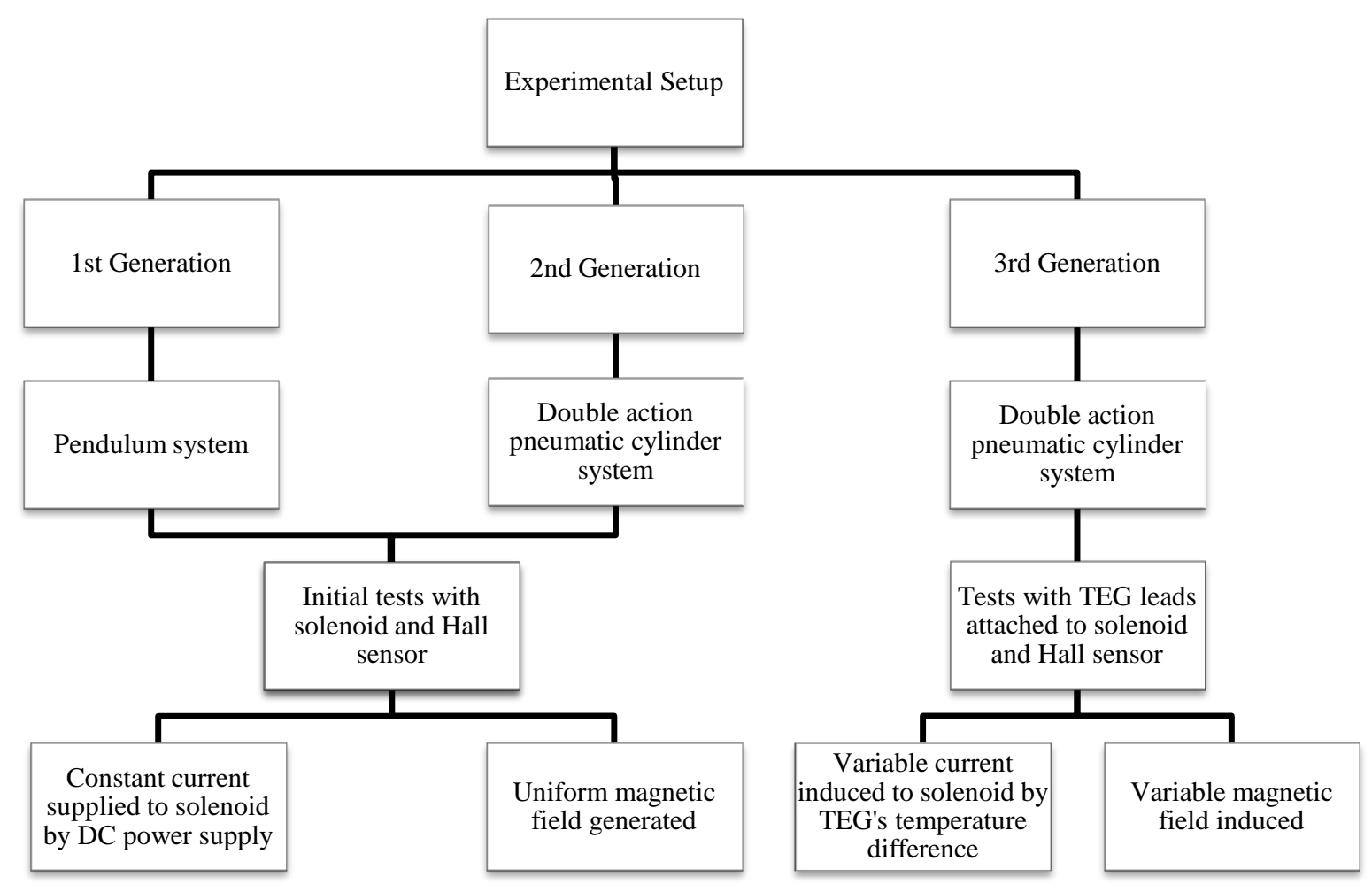

Figure 2.1: Block diagram showing experimental procedure 


\subsection{First GENERATION OF EXPERIMENTS}

The first generation of experiments included the testing of the Hall effect sensor as the signal receiver and a coil (solenoid) treated as the signal transmitter. The wireless transmission of the signal between the source and the receiver was intended to be detected followed by the governing laws of electromagnetism, as remarked in Chapter 1. The first experimental setup consisted of a wiper motor driven pendulum (104 rpm), 22-gauge magnet wire solenoid (155 turns at 4.3 A), a DC power supply, 8ohm resistor, a Hall Effect sensor (5 V), along with the data acquisition system.

The winded coil with a plastic core with a radius of $1.4 \mathrm{~cm}$ was attached at the end of a pendulum driven by a wiper motor. A continuous direct current of 4.3 Amperes was supplied to the coil by a power supply. The pendulum's arm with the attached coil was allowed to move in front of the sensor. A $5.0 \mathrm{mV} /$ Gauss ratiometric linear analog Hall Effect sensing device for relatively high temperature operation $\left(\sim 150^{\circ} \mathrm{C}\right)$ was utilized. The initial output voltage reading was $2.5 \mathrm{~V}$. Changes in the output voltage reading were visible in accordance to the changes in the magnetic field present. A picture of the experimental setup and its respective circuit diagram are shown in Figures 2.2 and 2.3, respectively.

The sensor was tested several times at a distance of $1.3 \mathrm{~cm}$ away from the solenoid. The data obtained was recorded using LabVIEW.

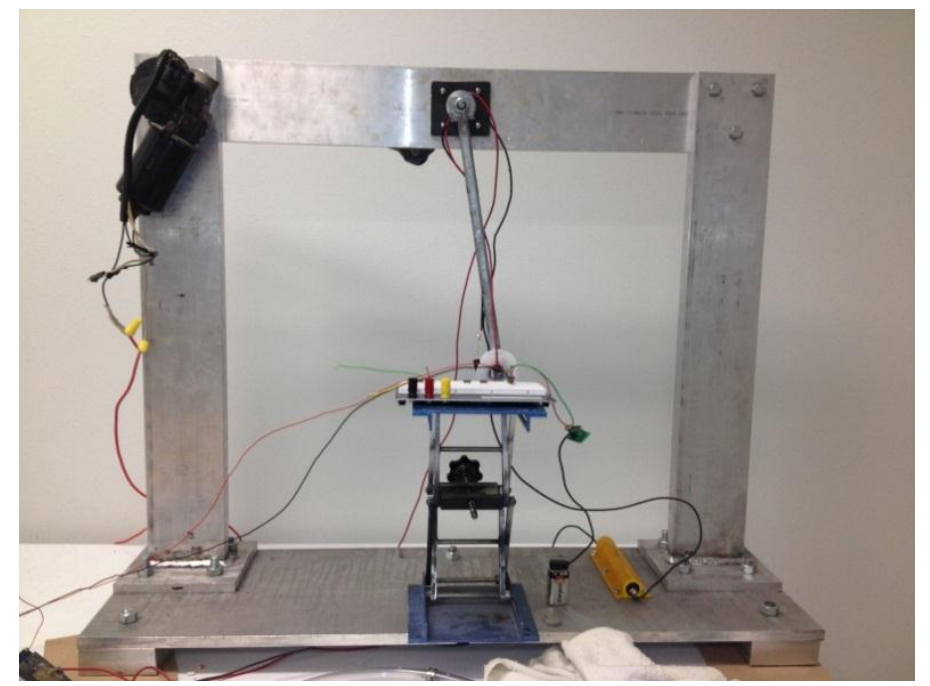

Figure 2.2: First generation experimental setup 


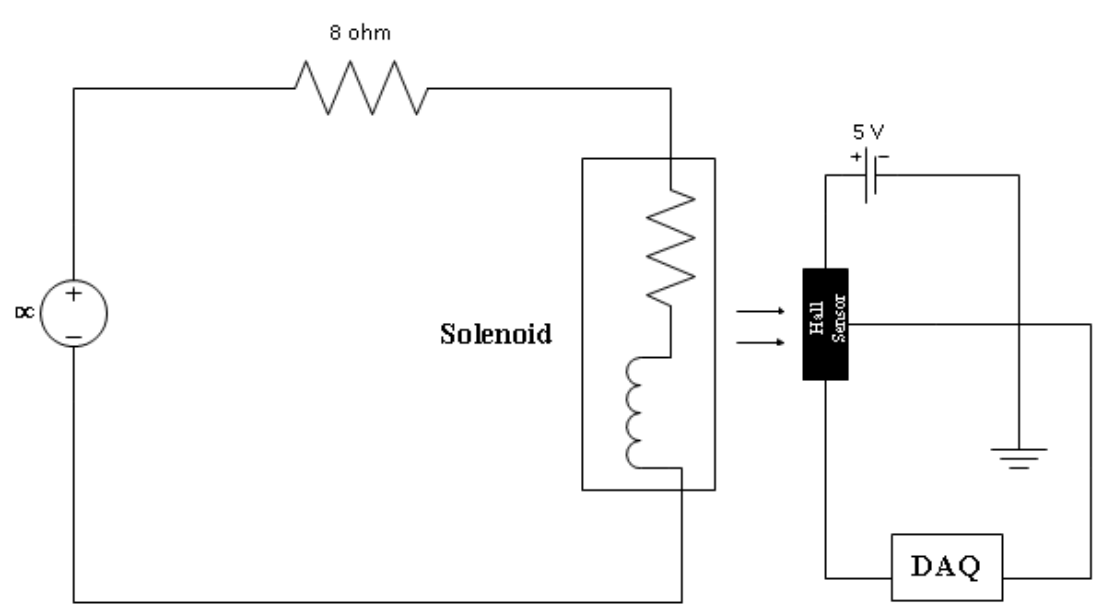

Figure 2.3: Circuit diagram representation of $1^{\text {st }}$ generation setup

\subsubsection{Filtering System}

For the filtering process of the analog signal, a Discrete Fourier Transform (DFT) function was used and a determined number of samples were evaluated. For instance, based on the results obtained in the first set of experiments, a filtering method was chosen and the analysis was made in accordance with the requirements of the system. In this case, a DFT algorithm was developed in a worksheet in Mathcad. A total of 1,630 samples, $N$, were evaluated in the filtering process. Then, the maximum and minimum frequencies were determined. The original signal was converted from the time domain to the frequency domain from which the full range of frequencies of the input signal was revealed. The cutoff frequency and bandwidth were determined by the lowest allowable frequency (pendulum's frequency) and the third highest peak in the frequency spectral .These values were 1.7 and $20 \mathrm{~Hz}$, respectively. The worksheet created in Mathcad is shown in Appendix B. Under this function, 60\% of the total noise was filtered, without any compromise in fidelity as presented in the next chapter. As presented in detail in the next chapter, the peaks' amplitude was not the same each time the coil was allowed to pass in front of the Hall sensing device. In addition to this, the inertial mass and the whole system vibrations were found significant. For these reasons, not only the filtering system was employed in further experiments but also an improved setup was developed and a second generation of tests was conducted. 


\subsection{SECOND GENERATION OF EXPERIMENTS}

The second experimental setup and its respective circuit diagram are shown in Figures 2.4 and 2.5, respectively. The instrumentation for the new setup included a double-action pneumatic cylinder, a 4-way air solenoid valve, a $5 \mathrm{~V}$ input relay, Hall effect sensor, a voltage regulator, a smoothing capacitor, DC power supply and the high pressure air delivery line, along with the data acquisition board used for the first set of experiments.
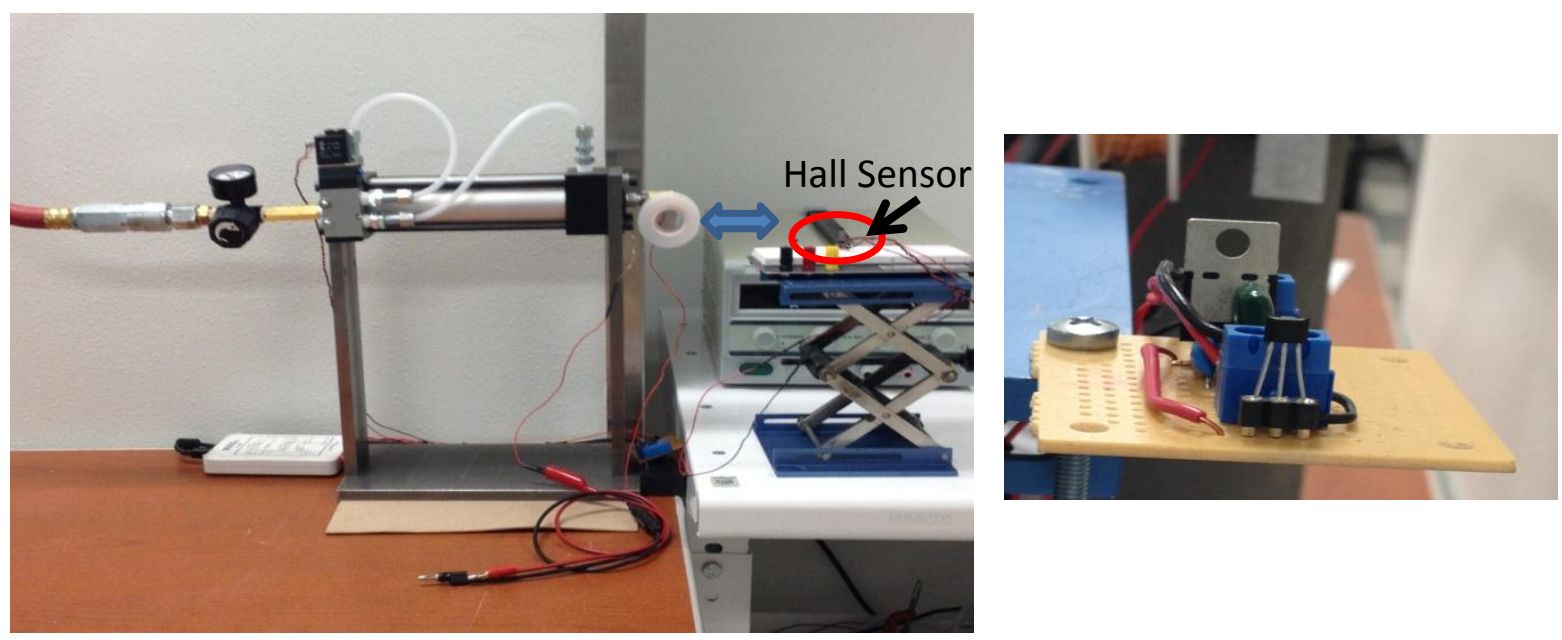

Figure 2.4: (Left) Second generation experimental setup (Right) Hall Effect sensing device
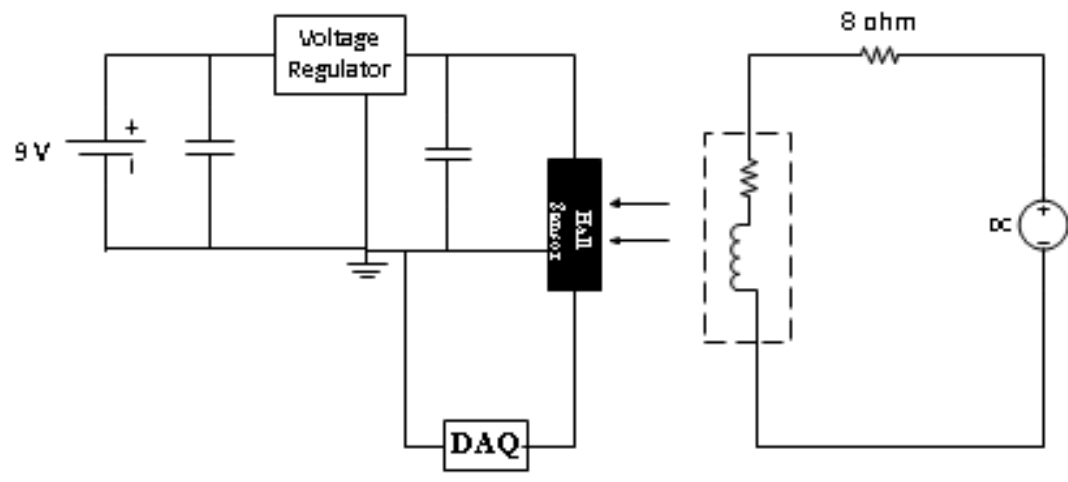

Figure 2.5: Circuit diagram representation of 2nd generation setup 
For the experiments conducted at this stage, a laser displacement sensor was also implemented and mounted on the Hall sensor's bench. The laser displacement sensor OptoNCDT 1402 located at the laboratory facilities was used.

The instantaneous velocity of the coil at the time its location was orthogonal to the Hall device position and at any given instant, was monitored with the help of the laser displacement sensor. The information obtained was relevant in the determination of the causes for the variations in the amplitudes from peak-to-peak in the acquired signal.

The 4-way valve was set to open and close at a frequency of $0.5 \mathrm{~Hz}$ at the time the sensor's analog signal was being recorded in LabVIEW. Furthermore, the relation between distance and time from the displacement sensor when the laser was pointing towards the rod's center (viewed from the moving direction) was logged. Then, the same relation was obtained placing the laser sensor in front of the attached coil (perpendicular to the rod's moving direction). Each test was run several times for 10 seconds, approximately. Figure 2.6 shows a schematic diagram of the two positions of the laser sensor relative to the Hall Effect sensor and pneumatic cylinder rod.

As displayed in Figure 2.6, the measuring range of the displacement sensor used was $10 \mathrm{~cm}$ and the start measuring range was $5 \mathrm{~cm}$ away from the object. The sensor was fixed on the Hall sensor's bench $5 \mathrm{~cm}$ away from the object. The data obtained showed the relation between displacement with respect to time. In order to find the velocity, the positive and negative slope curves of the plot were approximated to second order polynomial equations. The velocity and acceleration of the rod at the time the coil was passing just in front of the sensor were obtained by calculating the first and second derivatives of the displacement equations, respectively. Results from the tests with the displacement sensor showed the acceleration of the rod was not constant for the entire distance traveled in front of the Hall sensor. In addition, due to vibrations in the pneumatic cylinder's bench, some displacement of the rod was detected moving closer to the Hall Effect sensor. For these reasons, the amplitude of the signal at the time the solenoid passed in front of the Hall sensor was slightly different each time. 


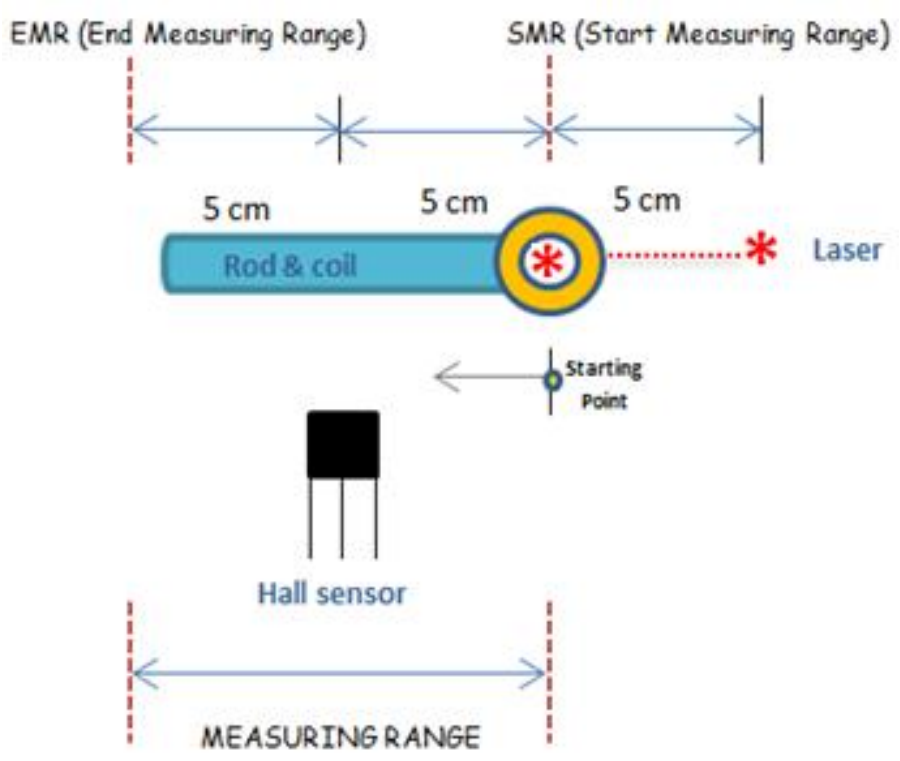

Figure 2.6: Positioning of the sensor with respect to the solenoid

Once the setup was complete, several tests were run moving the cylinder rod back and forth in front of the Hall sensing device. The Hall sensor's response (Vout) was recorded in LabVIEW. The filtering process of the signal used in the first generation of experiments was followed for this generation, as well.

\subsection{THIRD GENERATION OF EXPERIMENTS}

After the first generation of experiments was completed, a third generation of experiments, also called thermoelectric setup, took place connecting the solenoid to a thermoelectric generator and applying a thermal gradient between the hot and cold sides of the thermoelectric module.

The instrumentation for the new generation of experiment was the same as the second. A Seebeck thermoelectric generator (TEG), rheostat (0-3 $\Omega, 25 \mathrm{~W})$, hot plate (heater), water block (cooler), water container, diaphragm water pump (12 VDC, $3.3 \mathrm{gpm}$ ), tygon tubing and k-type thermocouples were also used.

The experimental setup and its respective circuit diagram with all components are presented in Figures 2.7 and 2.8, respectively. The main components are described in detail in the subsequent sections. 


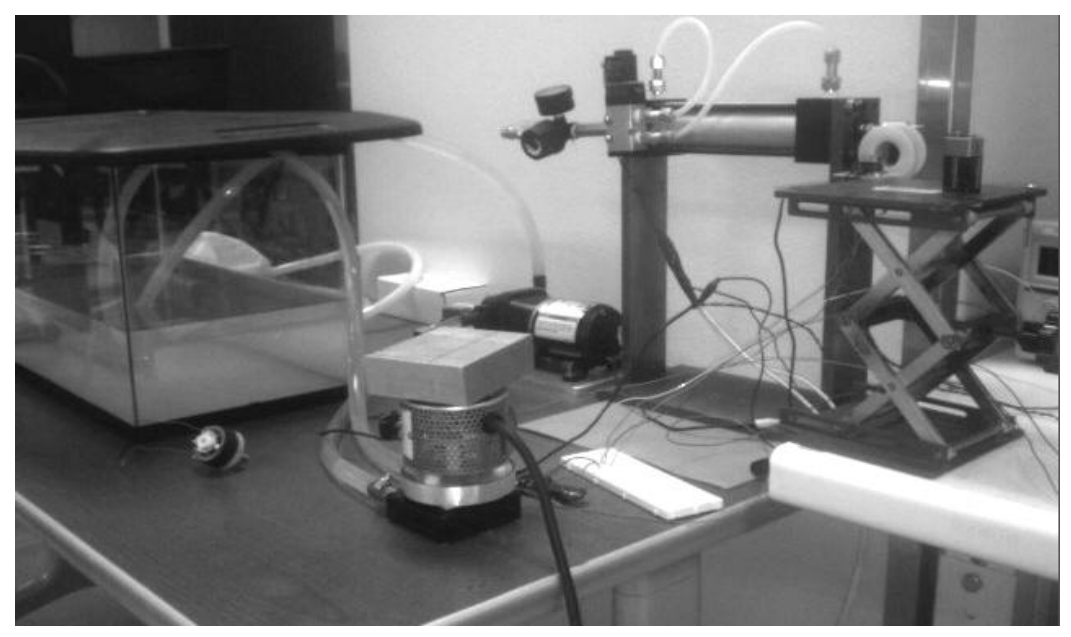

Figure 2.7: Third generation experimental setup

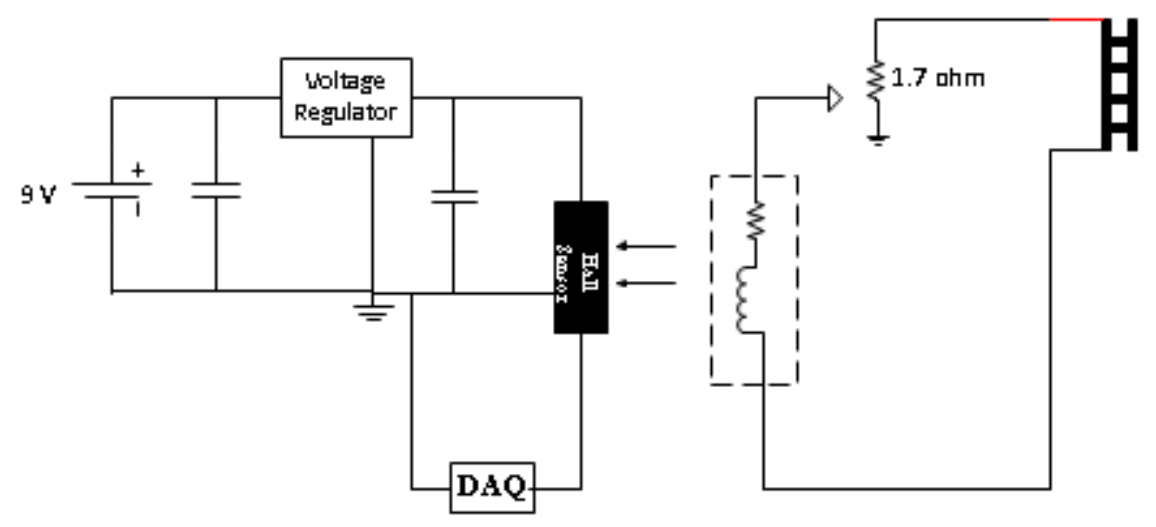

Figure 2.8: Circuit diagram of thermoelectric setup

\subsubsection{Seebeck Thermoelectric Generator (TEG)}

The thermoelectric generator 1261G-7L31-24CX1, designed and manufactured by Custom Thermoelectric Inc., was utilized for the third experimental setup. The dimensions of the thermoelectric were 2.205 in. x 2.205 in. and its width was 0.181 inches. The TEG is represented in Figure 2.9. The hot side surface was rated to a maximum of $300{ }^{\circ} \mathrm{C}$ and the cold side to a maximum limit of $180{ }^{\circ} \mathrm{C}$. Both 
sides of the TEG had a graphite foil pre-applied as a thermal interface material. The initial resistance of the thermoelectric element was 0.38 ohms at ambient temperature having small variations as temperature changes were experienced.
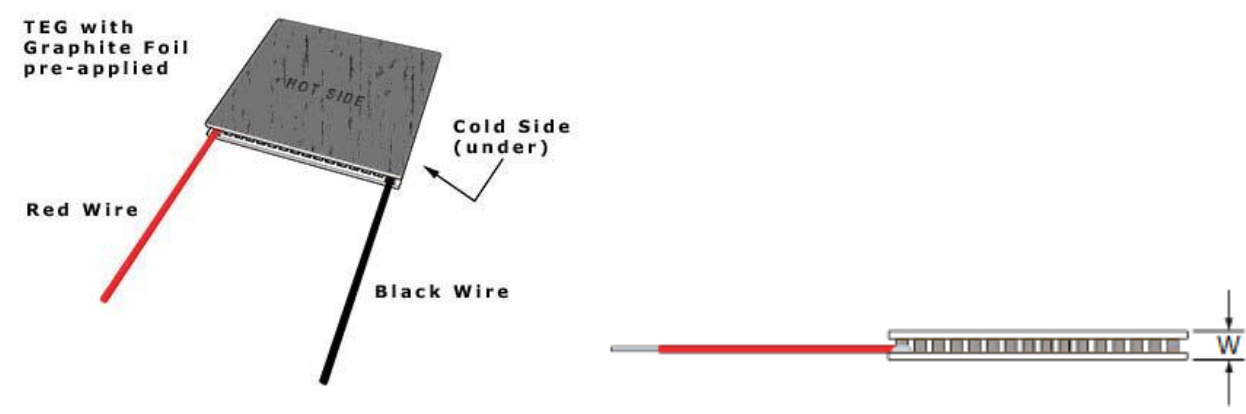

Figure 2.9: Seebeck Thermoelectric Generator

Another thermal interface material was also employed. A thin layer of heat sink compound (thermal paste) was applied between the cold side and the heat sink (water block) in order to increase the thermal conductivity at the interface and, consequently, enhance the heat being transferred to the heat sink.

\subsubsection{Rheostat}

This high power rating potentiometer was purchased in Digi-Key Corporation (see Figure 2.10). As known, in order to get the maximum power output, the load resistance must be equal to the TEG's internal resistance (load matching conditions). For the first tests, on the contrary, the rheostat resistance was set to constant value of $1.7 \mathrm{ohms}$. For further tests, the resistance value was changed trying to match or keep the load resistance higher than the thermoelectric resistance for better results. 


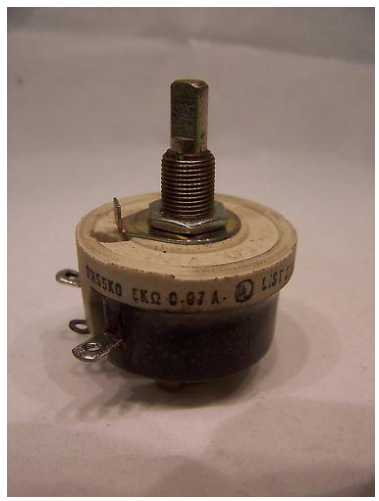

Figure 2.10: Rheostat Used for Thermoelectric Setup

\subsubsection{Hot Plate}

A hot plate, similar to the one displayed in Figure 2.11 was used as part of the third generation of experiments (thermoelectric setup). The hot plate was placed upside down on top of the TEG's hot side surface. The temperature range was $0-600^{\circ} \mathrm{F}$. The temperature was raised and lowered manually using the knob in the hot plate in order to see the effect of the temperature difference on the thermoelectric output voltage as well as the response from the Hall sensor.

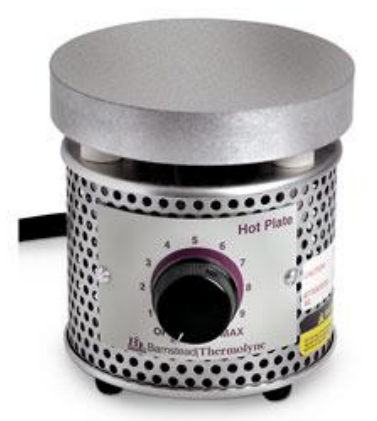

Figure 2.11: Hot Plate Used for Thermoelectric Setup

\subsubsection{Water Block (Liquid Heat Exchanger)}

In order to cool the cold side surface of the TEG and obtain a significant temperature gradient from both surfaces, a water block simulating a liquid heat exchanger was used. The CNC machined aluminum water block was anodized blue in color. The block dimensions were 3.0 in. x 3.0 in x 0.85 in. According to the specifications sheet, the thermal resistance value was $0.011{ }^{\circ} \mathrm{C} / \mathrm{Watt}$, approximately. The block's inlet and outlet were located next to each other as seen below in Figure 2.12. 


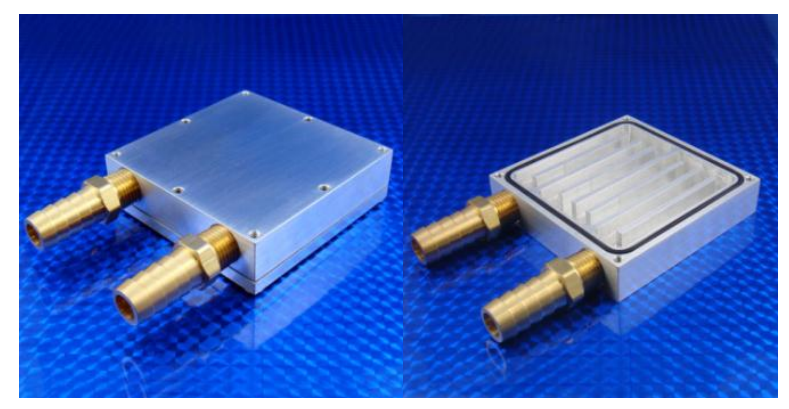

Figure 2.12: Water Block Exterior and Interior

The hose barb fittings were $1 / 2$ in. ID each. According to the thermal resistance and pressure drop data, the volumetric flow rate ratings for the liquid were 0.5-4.0 gpm.

\subsubsection{Diaphragm Water Pump}

The FLOJET water system pump used to drive the water through the water block is shown in Figure 2.13. The polypropylene diaphragm pump's operating pressure was rated between 25 and 35 psi. The volumetric flow rate rating for the fluid was $3.3 \mathrm{gpm}$. The working fluid run by the pump consisted of tap water mixed with a small amount of antifreeze.

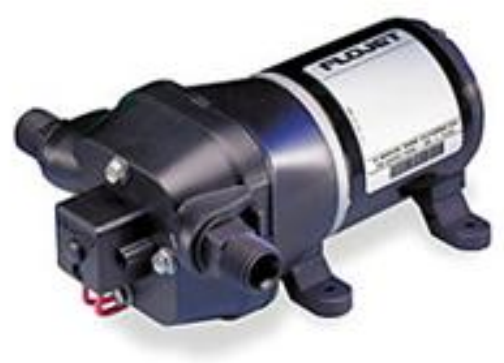

Figure 2.13: Diaphragm Water Pump

\subsubsection{Hall Effect Sensor}

The Hall sensing device A1321 LUA-T used as the receiver in the first and second generation of experiments was used also for the thermoelectric setup. As mentioned previously, a 5.0 mv/Gauss ratiometric linear analog Hall effect sensor (see Figure 2.14) for relatively high temperature operation $\left(\sim 150{ }^{\circ} \mathrm{C}\right)$ was purchased from Alegro MicroSystems, Inc. and was utilized for all the tests. The initial 
sensor's output voltage reading was $2.5 \mathrm{~V}$ when no external magnetic field was generated close to the sensor. The output voltage reading from the sensor changed in accordance to the variations in the perceived magnetic flux density.

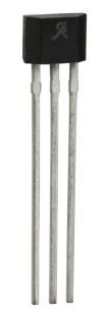

Figure 2.14: Ratiometric linear Hall effect sensor

\subsubsection{Data Acquisition System}

The temperature data, as well as the output voltage readings from the Hall sensing device and the TEG were recorded via LabVIEW 9.1 software. The interface, in turn, was the National Instruments data acquisition board NI PCI-6221.

\subsubsection{Experimental Procedure}

At this stage, temperature was added to the experiment as a critical variable for the subsequent tests. The thermoelectric generator was tested using a hot plate in order to heat the hot side, reaching a maximum temperature of $300{ }^{\circ} \mathrm{C}$. On the cold side of the TEG a water block was placed, maintaining a temperature between $27^{\circ} \mathrm{C}$ and $90^{\circ} \mathrm{C}$.

The coil used in previous tests was attached to the thermoelectric leads. Two k-type thermocouples were placed at the edges of the TEG-hot plate and TEG-water block interfaces. The temperature gradient from the hot and cold sides of the thermoelectric was made possible heating the hot side with the hot plate and at the same time cooling the other side with a water block. The moving fluid (10 Liters of water mixed with 0.5 Liters of automobile's antifreeze) was driven by the diaphragm water pump described in previous sections. The fluid was pre-cooled before in the container and was allowed to run inside the water block for two minutes before the heater (attached to the hot side) was turned on. As the heat was being transferred from the TEG's hot side to the cold side, the temperature of the heat sink was raised and different values for $\Delta T$ were obtained. Also, diverse values for temperature 
gradients were acquired varying the hot plate's surface temperature. The coil attached to the thermoelectric leads was attached to the air cylinder's rod (as in the previous generation of experiments) and tested in a static position for initial tests. The output voltage from the Hall sensor (also defined as relative signal intensity), as well as the induced voltage and temperature gradient on the TEG, were recorded in LabVIEW. The experiment was conducted varying the resistance of the load with the help of the rheostat in order to get a current close to 4.3 Amperes, as in the case for the first two generation of experiments. It is important to note that not only the resistance of the load was varied but the internal resistance of the thermoelectric element varied in accordance to the temperatures at which it was exposed. The chart from which the TEG's internal resistance was determined is found in the specifications sheet and is presented in Figure 2.15 [27]. For instance, if the hot side of the thermoelectric is at $200{ }^{\circ} \mathrm{C}$ and the cold side is held at $30{ }^{\circ} \mathrm{C}$, the average temperature would be $115^{\circ} \mathrm{C}$. Looking at the graph, this temperature corresponds to a TEG resistance value of 0.675 ohms. This means that if the rheostat resistance value is varied and matches the TEG resistance, the maximum power will be obtained. The resistance values in the rheostat $(1.7 \mathrm{ohms})$ were determined from the average temperature of both hot and cold sides in order to match the ones corresponding to the thermoelectric generator at such temperatures. However, the desired current of $4.3 \mathrm{~A}$ was difficult to obtain due to the non-constant rate of the temperature and temperature difference increments on both sides of the thermoelectric generator and the added resistance of the solenoid's wire to the system. 


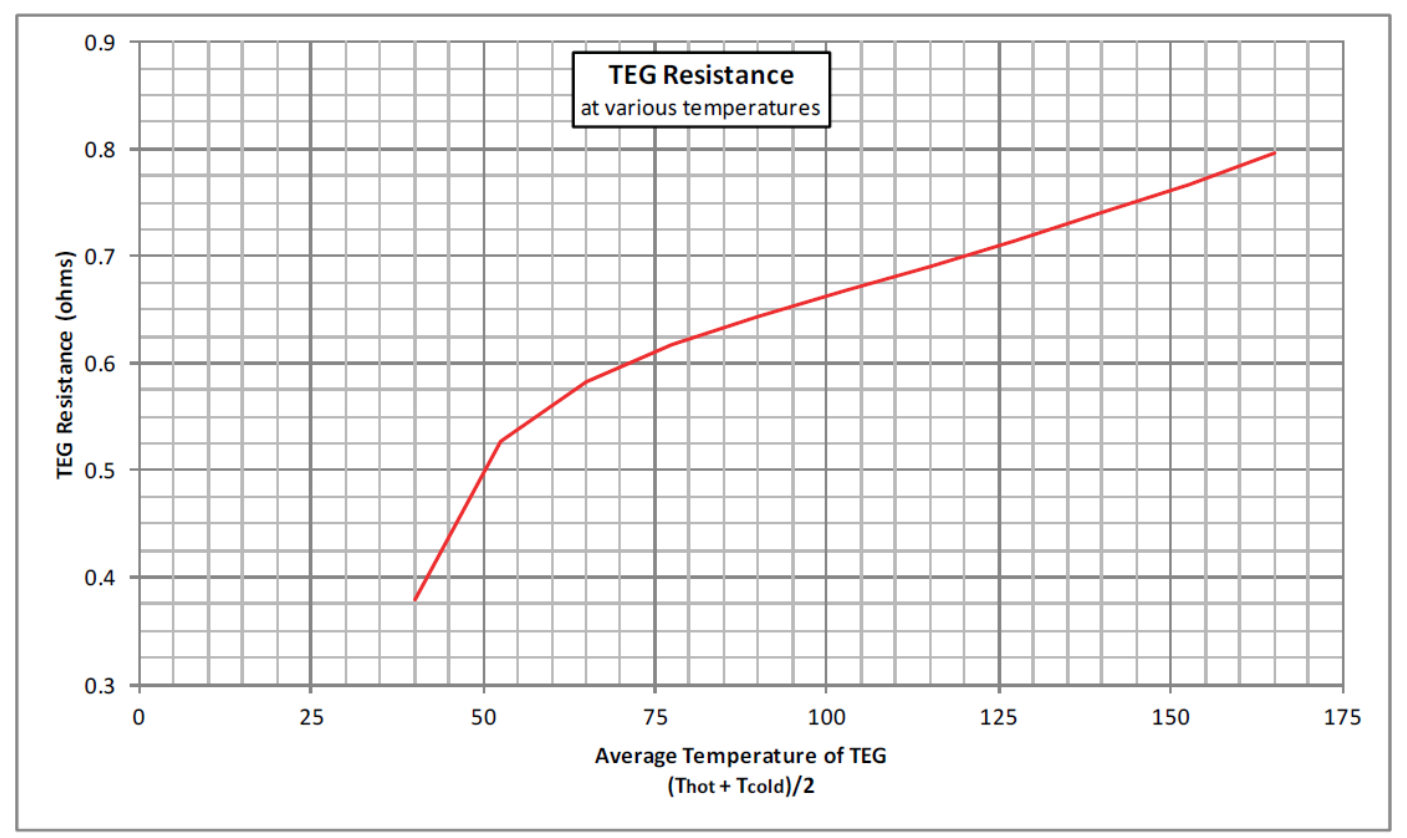

Figure 2.15: TEG resistance values at various temperatures

Due to the sudden changes in temperature of the hot and cold sides of the thermoelectric, load matching conditions were difficult to obtain.

Once the tests were completed with the coil in a stationary position, the coil was allowed to move attached to the cylinder rod back and forth for thirty seconds. The acquired values for thermal gradient, output voltage readings from the Hall sensor and output voltage from the thermoelectric were recorded and correlated simultaneously. Furthermore, the values for the induced current were determined and presented. These values were correlated with the specification sheet charts of the TEG used.

As a final step, the filtering process of the relative signal intensity was applied to the results obtained in order to remove external noise. The results obtained from the first, second, and third generations of experiments are presented in the next chapter.

\subsection{Safety Precautions}

The acknowledgement of the importance of a safe environment in the lab is essential and required before the experimentation takes place, at the time the experiments are conducted, and after 
their completion. Some of the most common hazards that any person can be exposed to by conducting the presented experiments for the three generation of experiments include, but are not limited to: electric shocks, burns, some type of hearing loss due to noise of air cylinder and visual impairment if eye contact is made directly on the laser. Also, danger from impact shock might be present due to the high pneumatic cylinder momentum. A hazard analysis with the respective prevention techniques for each hazard is presented in Table 2.1 .

Table 2.2: Hazard Analysis Table

\begin{tabular}{|c|c|c|c|c|c|c|}
\hline $\begin{array}{c}\text { Hazard } \\
\text { No. }\end{array}$ & System & Hazard & Severity & Likelihood & $\begin{array}{c}\text { HA } \\
\text { Index }\end{array}$ & Mitigation \\
\hline 1 & Wiring & Electric shock & Catastrophic & Unlikely & 2 & $\begin{array}{l}\text { Wear proper } \\
\text { safety rubber } \\
\text { gloves }\end{array}$ \\
\hline 2 & Heater/Coil & Fire/Burns & Significant & Unlikely & 2 & $\begin{array}{l}\text { Avoid touching } \\
\text { the electric } \\
\text { heater or coil } \\
\text { directly }\end{array}$ \\
\hline 3 & $\begin{array}{c}\text { Pneumatic } \\
\text { cylinder/Valve }\end{array}$ & Hearing Impairment & Moderate & Unlikely & 2 & $\begin{array}{l}\text { Wear proper } \\
\text { earplugs when } \\
\text { running tests }\end{array}$ \\
\hline 4 & Laser & Visual Impairment & Moderate & Unlikely & 1 & $\begin{array}{l}\text { Avoid direct } \\
\text { eye exposure }\end{array}$ \\
\hline 5 & Pneumatic cylinder & Impact shock & Significant & Unlikely & 3 & $\begin{array}{l}\text { Avoid standing } \\
\text { close to the } \\
\text { cylinder during } \\
\text { operation }\end{array}$ \\
\hline
\end{tabular}




\section{Chapter 3: Results and Discussion}

The results obtained from the first, second and third generations of experiments are contemplated in this chapter. In addition, these results are discussed and an analysis is made in order to prove the applicability of the technologies used in meeting the set objectives.

\subsection{FIRST GENERATION EXPERIMENTAL RESULTS}

The results obtained from the first experimental setup (pendulum) were recorded in LabVIEW and are presented in the following figures. Figure 3.1 shows the output voltage recorded in the first seconds as the pendulum moved repeatedly in front of the static Hall sensing device. As displayed, the peaks from the moving solenoid with 4.3 A showed a periodic pattern. Each peak represents the output voltage reading from the Hall sensor at the instant the solenoid attached to the motor-driven pendulum was exactly in front of it.

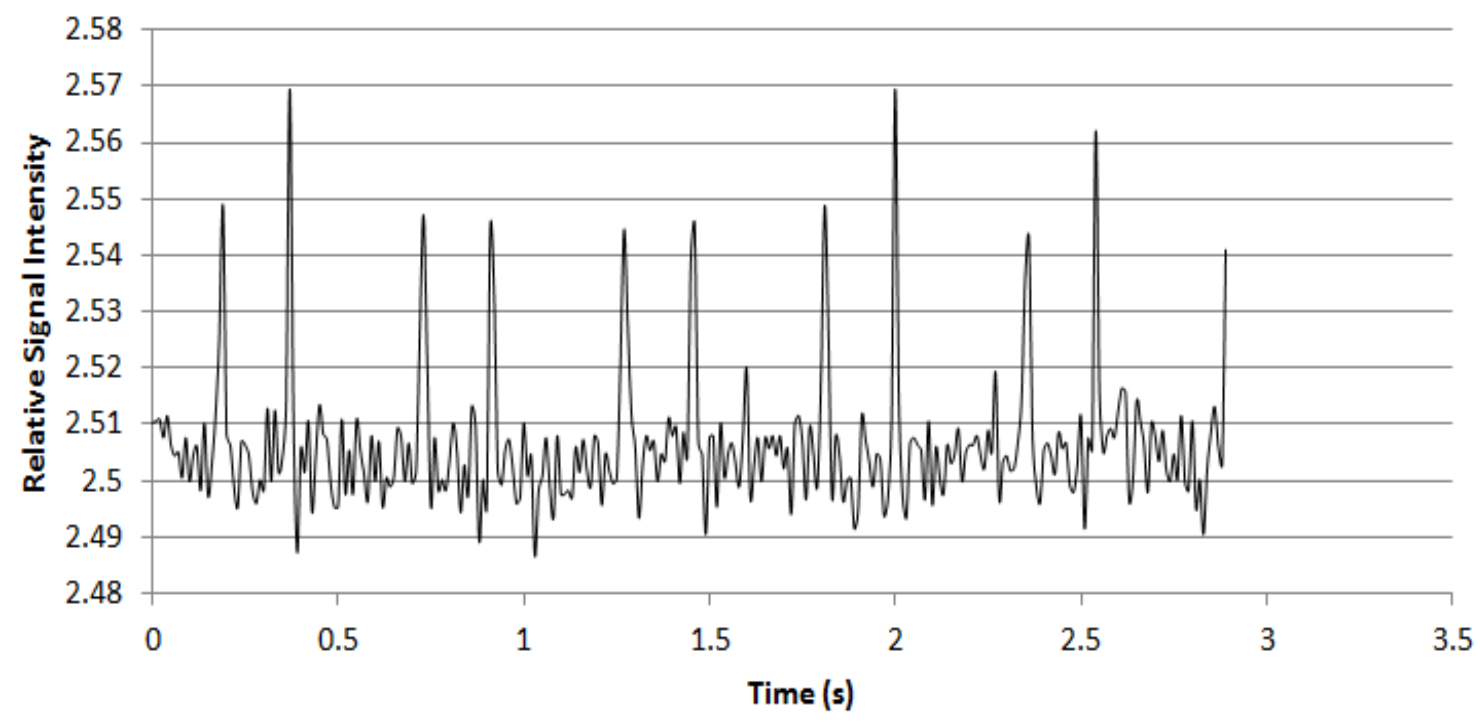

Figure 3.1: Hall sensor output voltage $\left(1^{\text {st }}\right.$ generation $)$

Since the noise found in the measured signal was significant, the filtering method explained in Chapter 2 was applied to the recorded signal. Figure 3.2 shows the spectrum of the frequencies used in the signal filtering process. The first peak occurred at almost $2 \mathrm{~Hz}$, the same value as the pendulum's frequency. The maximum output voltage value obtained was 2.57 in this configuration. Using a Discrete 
Fourier Transform algorithm, up to $60 \%$ of the noise was filtered from the original signal. A comparison between the original and filtered signals is illustrated in Figure 3.3.

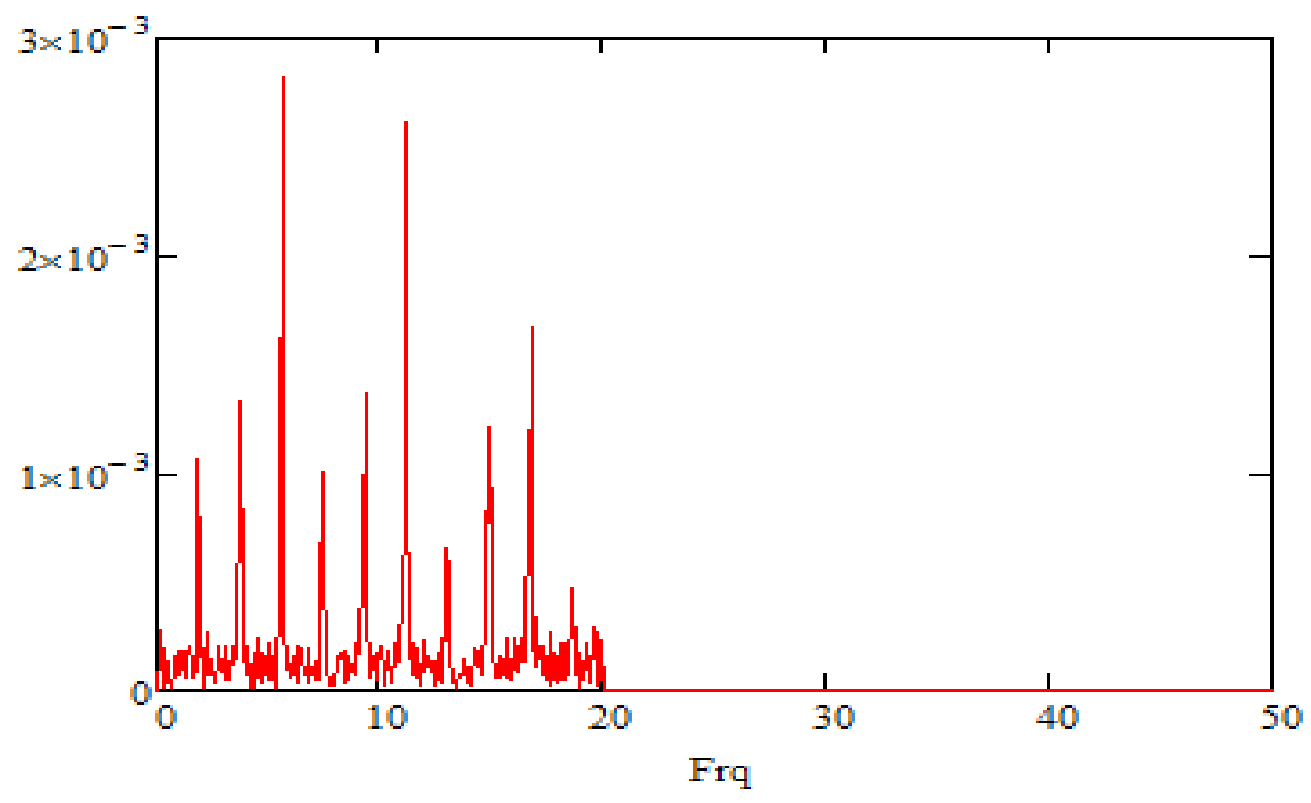

Figure 3.2: Frequency spectrum used for filtering analysis

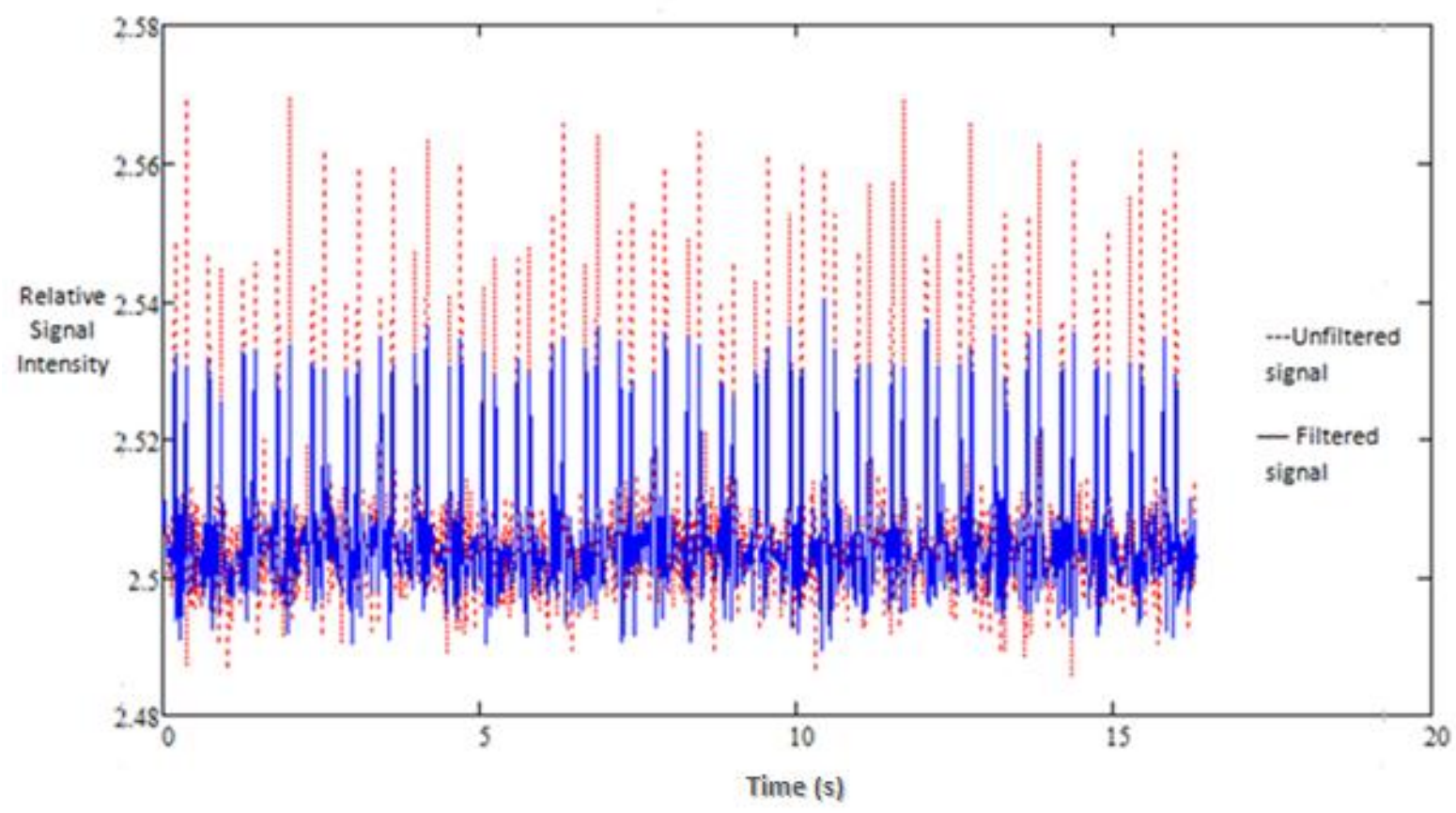

Figure 3.3: Comparison between unfiltered and filtered signals 
Even though the wireless signal was successfully transmitted, the amplitude of the peaks shown was expected to have the same magnitude for each pass in front of the sensor. After repeated measurements and attempts to filter noise it was determined that the pendulum device produced disruptive noise and caused non-repeatable data which was later corrected using the second generation setup.

\subsection{SECOND GENERATION EXPERIMENTAL RESULTS}

Figure 3.4 presents the data obtained from the Hall sensor running the experiments with the second generation setup. As expected from design calculations, the inertial mass of the system and the noise were reduced when moving the coil with the double-action pneumatic cylinder instead of the pendulum system used for the first set of experiments.

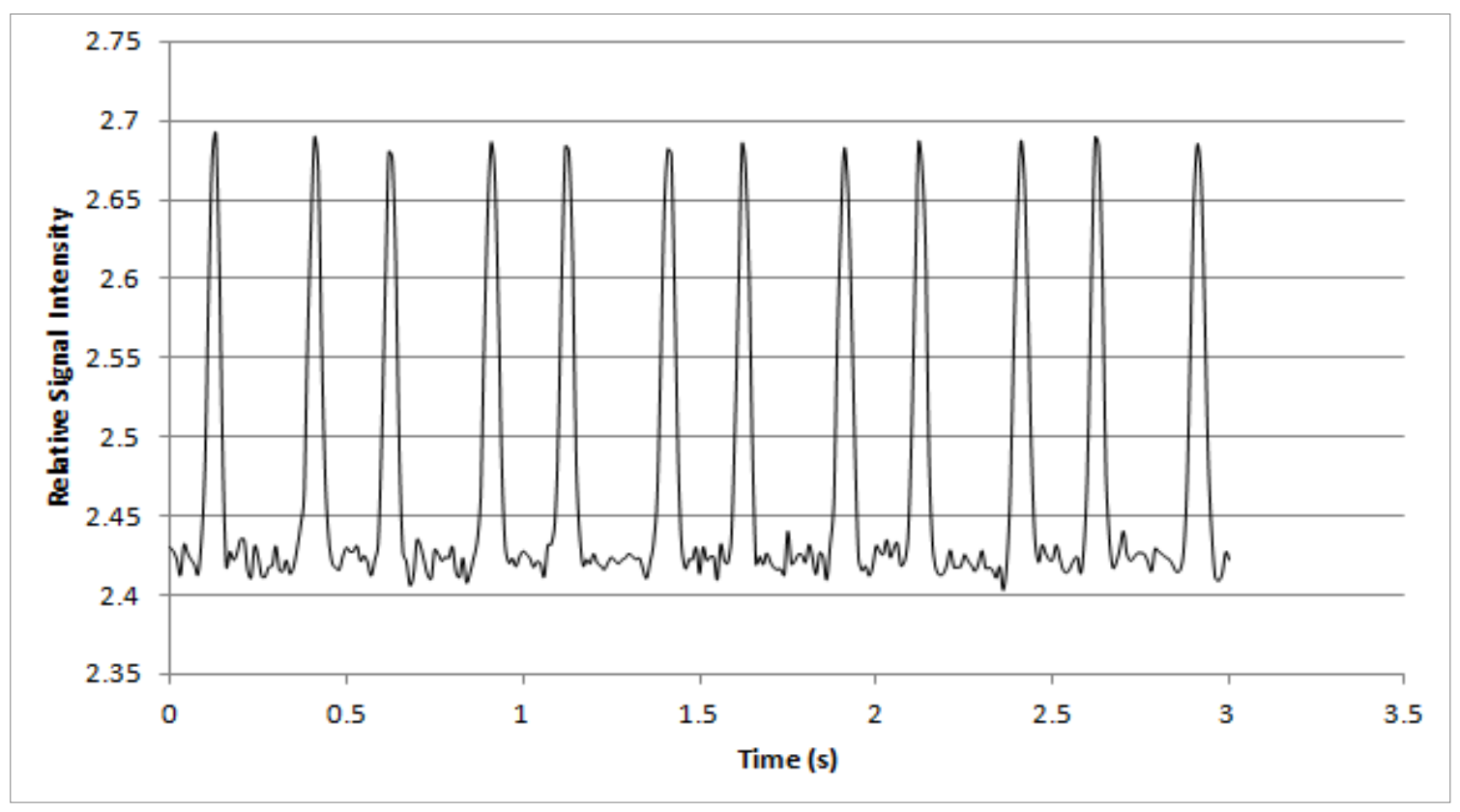

Figure 3.4: Hall sensor output voltage ( $2^{\text {nd }}$ generation)

The peaks' amplitude showed a similar pattern with equal magnitude. Small disturbances from peak to peak were still visible due to fluctuations in the velocity of the accelerating air cylinder and, in a smaller scale, to the change in distance (z-axis) between the cylinder with the attached coil and the static 
sensor caused by minor vibrations in the system. However, many of these effects were filtered. Overall, this successfully showed that a signal from a loop generator could be effectively measured wirelessly. Although no temperatures have been introduced at this point, this shows a proof of concept of the technology. Experimental uncertainty analyses were based on a student-t distribution $95 \%$ confidence interval are presented for the first and second generation of experiments in Appendix A.

\subsection{THIRD GENERATION EXPERIMENTAL RESULTS}

\subsubsection{Static System}

Once the sensor, filtering, and measurement technologies were sufficiently developed, subsequent experiments were run adding a thermoelectric device to the circuit and connecting its leads to the loop coil on the pneumatic cylinder held at first in a stationary position.

\section{Open circuit}

As the temperature difference was increased on the thermoelectric device voltage measurements were taken using the Hall sensor. Figure 3.5 show the results obtained connecting the leads to the solenoid and varying the temperature of the hot plate. As could be observed, the highest temperature obtained was $\sim 270^{\circ} \mathrm{C}$. The temperature from the hot plate was allowed to increase until thermoelectric's hot side reached almost $250{ }^{\circ} \mathrm{C}$.

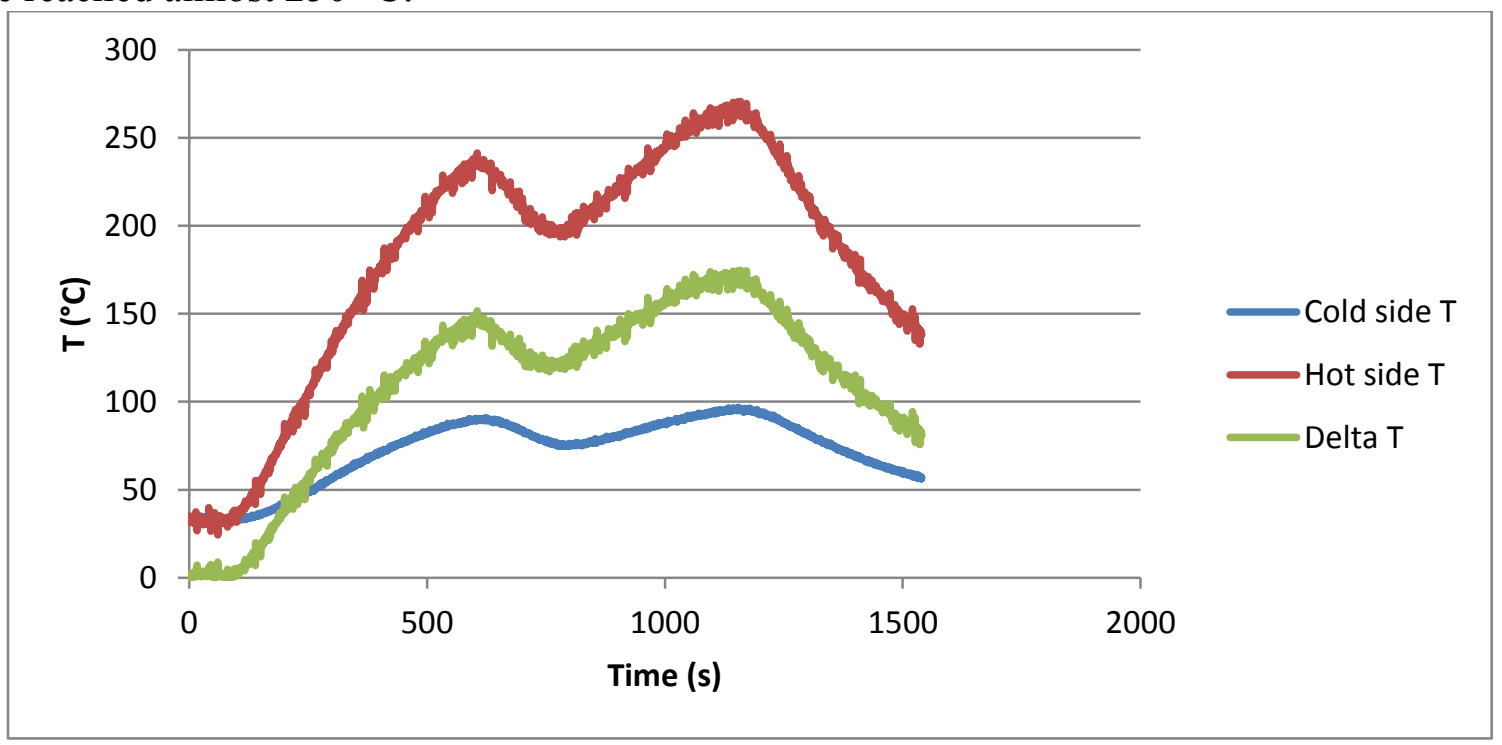

Figure 3.5: Temperatures on surfaces of heated thermoelectric element 
Figures 3.6 and 3.7 show the response obtained by the Hall sensor and the output voltage generated by the thermoelectric device, respectively. The maximum thermoelectric and Hall sensor's output voltage recorded were 1.2 and $2.62 \mathrm{~V}$, respectively. As seen from the plots, the same pattern in the peaks shows the direct relation between the temperature gradient and the generated voltage. Likewise, the response from the sensor behaves in a similar way as expected.

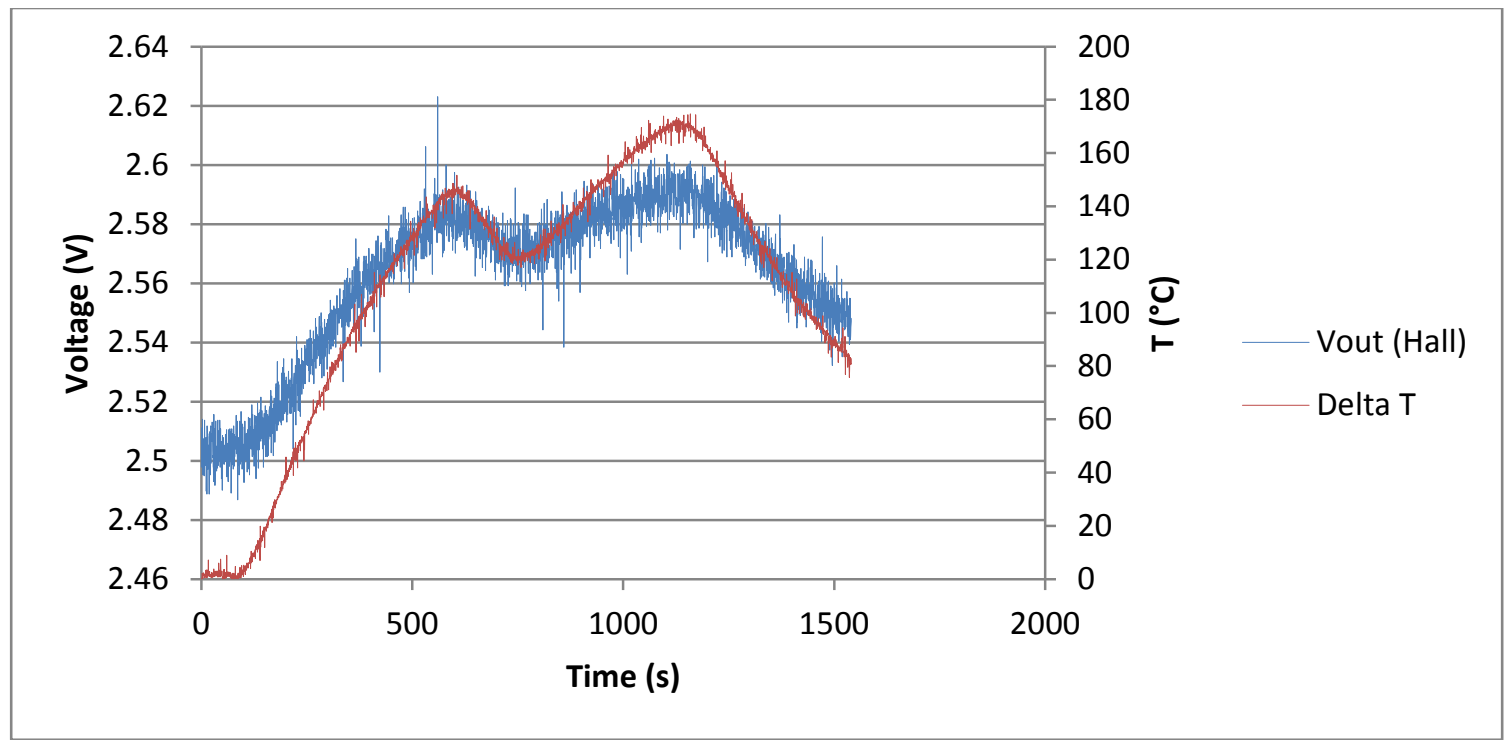

Figure 3.6: Hall sensor output voltage and temperature gradient ( $3^{\text {rd }}$ generation)

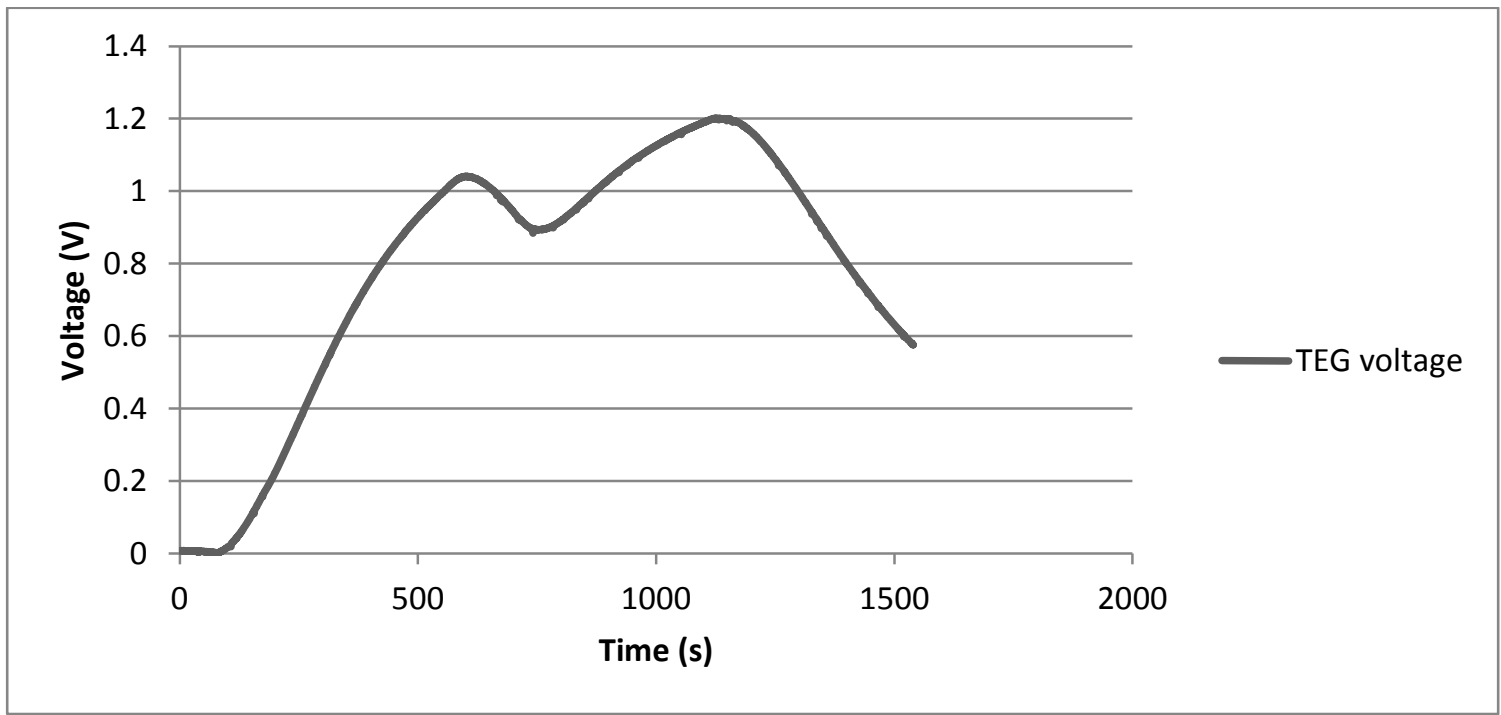

Figure 3.7: Open-circuit output voltage of TEG ( $3^{\text {rd }}$ generation $)$ 


\section{Closed circuit}

The results obtained adding a rheostat to the circuit and setting its resistance to a constant value of $1.7 \mathrm{ohms}$. The temperature values for the hot and cold sides and their difference can be appreciated in Figure 3.8 as the hot plate was being heated and cooled at different settings over time. The maximum temperature difference obtained in the initial states was $191{ }^{\circ} \mathrm{C}$.

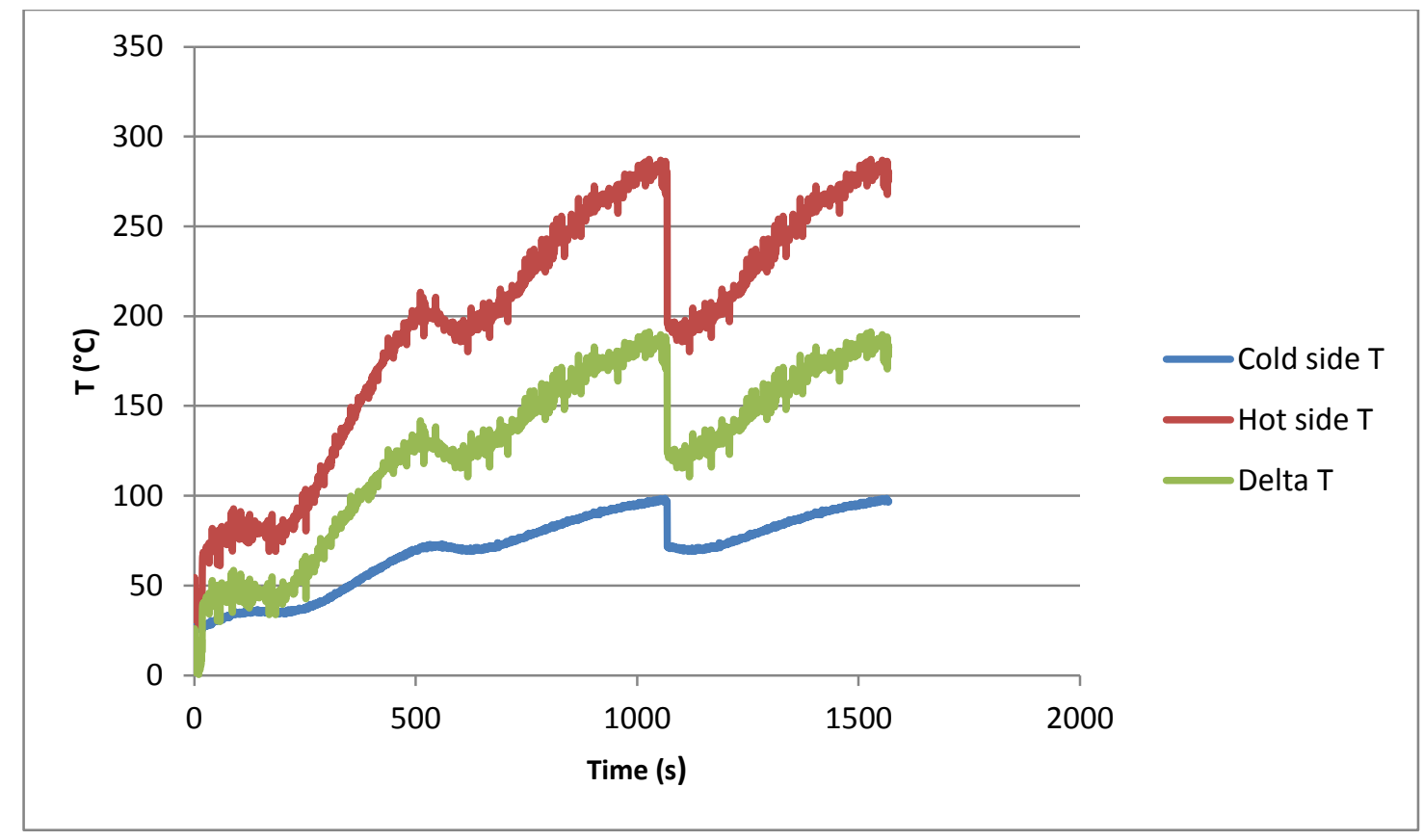

Figure 3.8: Temperatures on surfaces of heated thermoelectric element

The recorded output signal readings from the Hall sensor are presented in Figure 3.9. A relation can be seen between the output voltage and temperature gradient. An increase in the voltage is positively correlated with a temperature gradient increase. The generated voltages from the TEG at different temperature gradients are shown in Figure 3.10. 


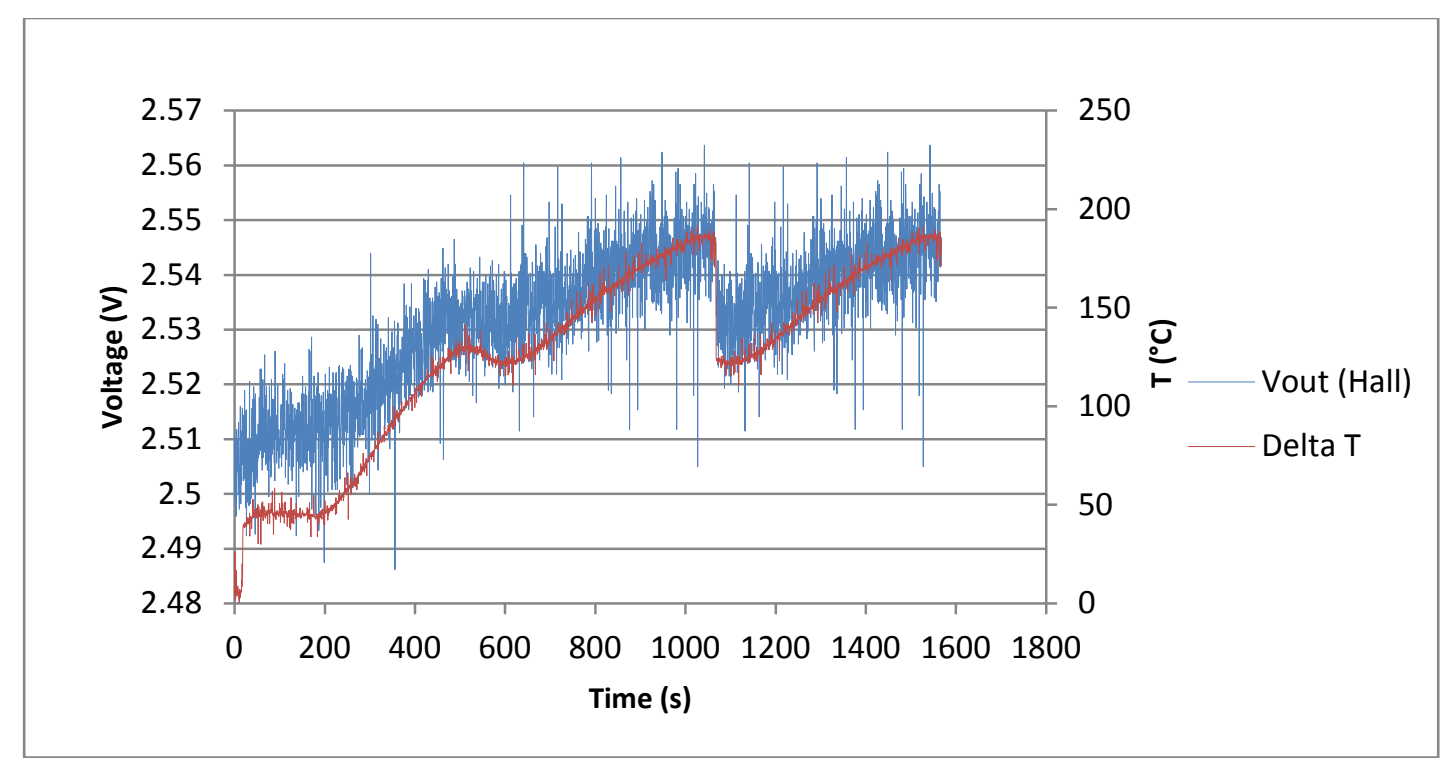

Figure 3.9: Hall sensor output voltage and temperature gradient $\left(3^{\text {rd }}\right.$ generation)

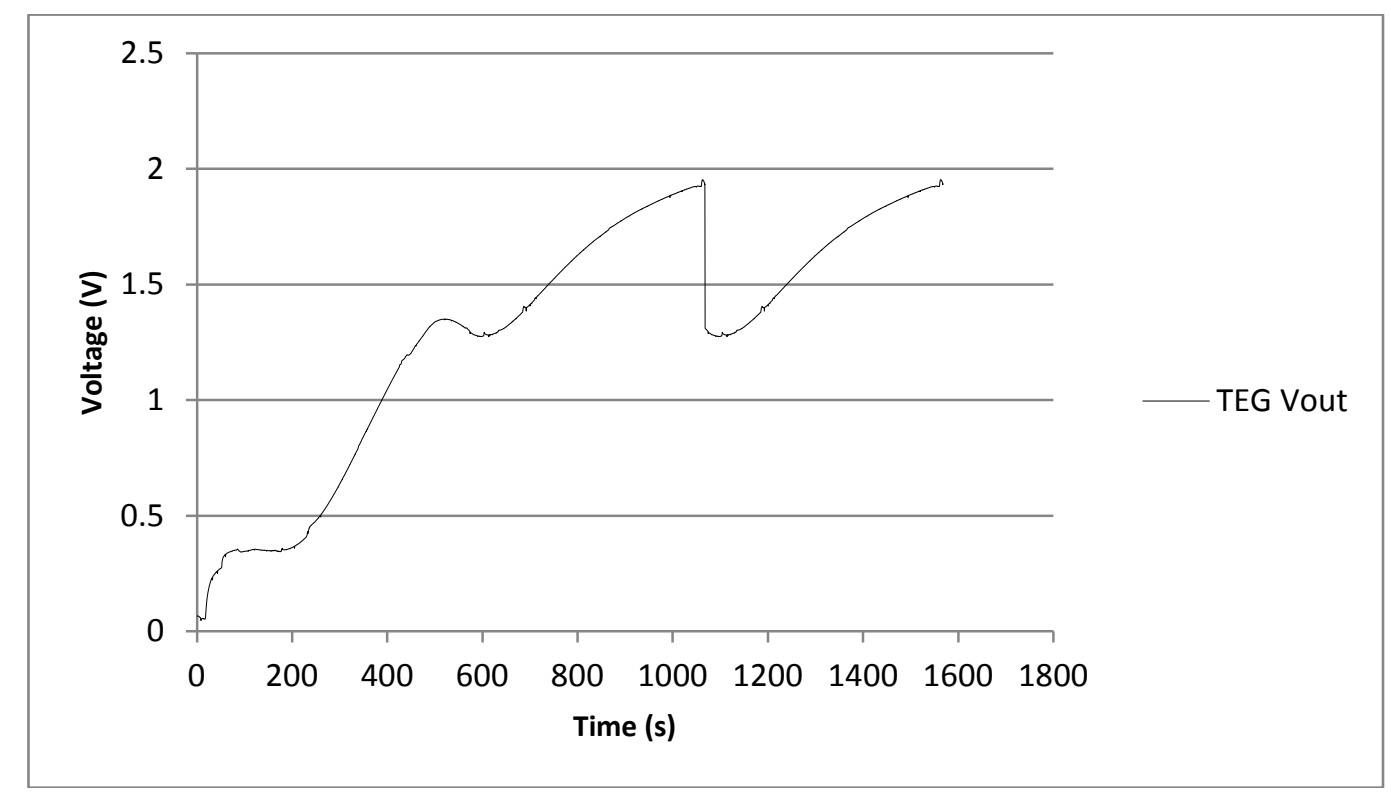

Figure 3.10: Open-circuit output voltage of TEG $\left(3^{\text {rd }}\right.$ generation $)$

The recorded values of the voltage generated by the thermoelectric at different temperatures were correlated with the results obtained by Love et al. [6] in which an exhaust heat recovery system was simulated. Even though the experimental setup and the objectives of his study are different from the ones in this study, similarities were noticed for the values obtained. From both studies, similar temperature differences from the hot and cold side of a thermoelectric device were selected and the 
recorded values of the generated voltage were compared. Table 3.1 presents a comparison of the values obtained from a single thermoelectric generator device.

Table 3.1: Measured values for the voltage generated from a single thermoelectric element

\begin{tabular}{ccc}
\hline $\boldsymbol{T}\left({ }^{\circ} \mathrm{C}\right)$ & Love et al. [6] & Present study \\
Voltage & Voltage \\
\hline 60 & 0.664 & 0.511 \\
70 & 0.712 & 0.669 \\
80 & 0.865 & 0.703 \\
90 & 1.044 & 0.92 \\
100 & 1.419 & 1.174 \\
\hline
\end{tabular}

As seen in Table 3.1, the voltage values obtained during this project were similar to the results presented by Love et al. in his study for the selected temperature difference range. Some differences were noticed, however, due to the different conditions and features of the thermoelectric device itself (figure of merit ZT, variations in the Seebeck coefficient of the material with temperature, surface area and dimensions of the device, etc).

\subsubsection{Dynamic System}

The results presented in this paper show the applicability of the Hall sensor and the solenoid attached to the thermoelectric leads as well as the relation between the temperature gradients, the generated voltage by the thermoelectric generator and the response from the sensing device in a static system. However, these results may be used in a future for temperature sensing applications in nonstationary elements (e.g. gas turbine blades) of power generation units. For this reason, similar tests are to be conducted in dynamics systems to test the ability of the sensor in detecting the changes in the magnetic flux density produced by the variations in the temperature differences of the thermoelectric element. The block diagram and front panel of the VI used to control the 4-way air valve and the rate at 
which it opened and closed in order to drive the pneumatic cylinder is presented in Figure 3.11, along with the input parameters established. Figure 3.12 shows the circuit diagram representation for the control valve system. The same input parameters in LabVIEW were used for the second and third generation of experiments.

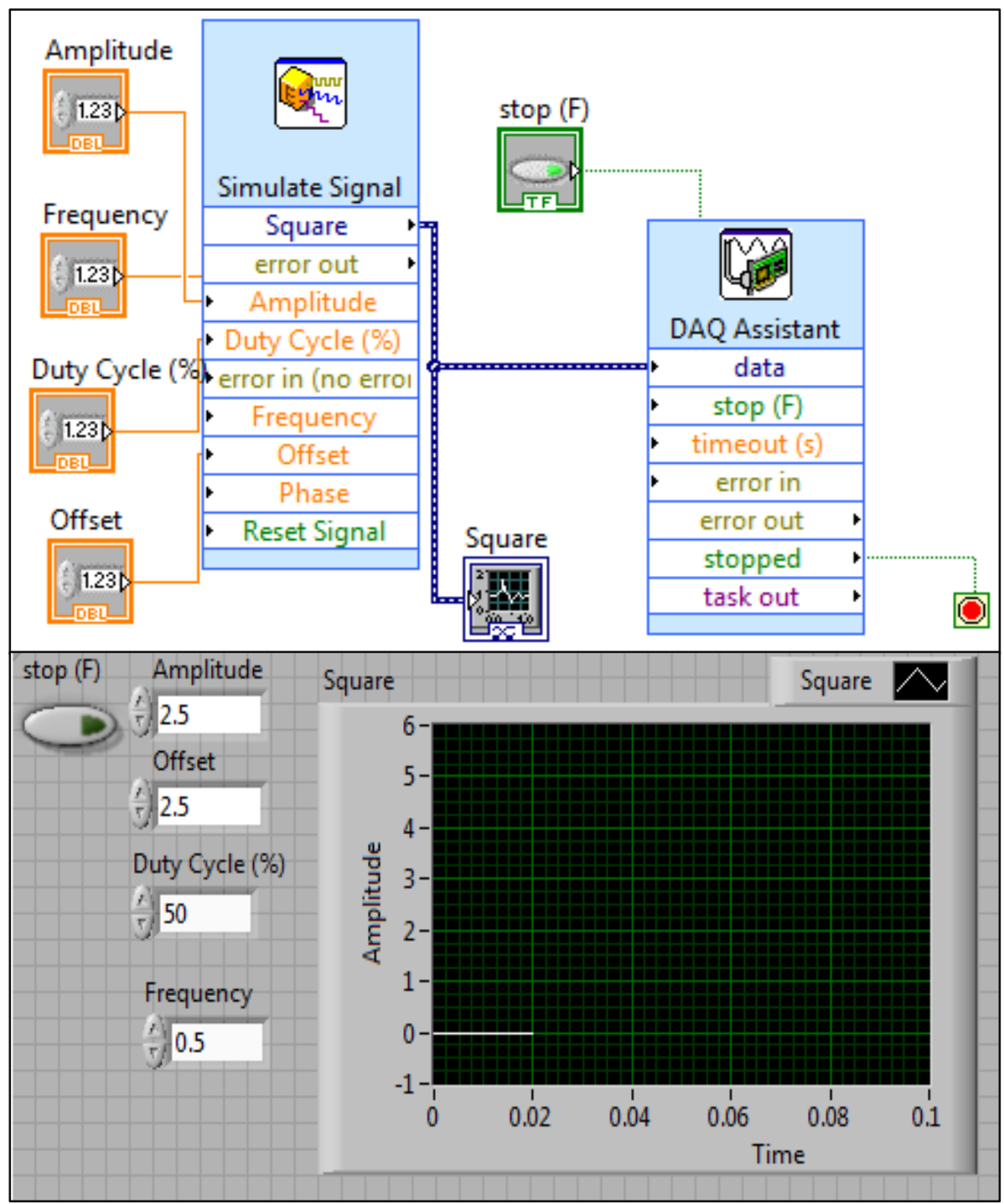

Figure 3.11: LabVIEW VI block diagram of 4-way valve system 


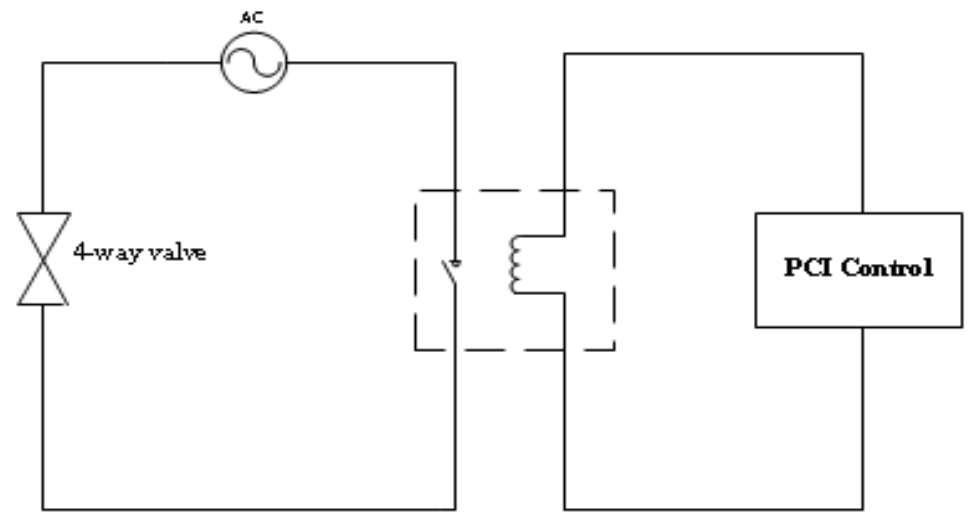

Figure 3.12: Circuit diagram for 4-way control valve

\section{Open circuit}

The same procedure used in the static system was executed. The following plots show the results obtained from the open-circuit voltage system and allowing the solenoid connected to the thermoelectric element to move continuously back and forth from its original position in the horizontal direction. Figure 3.13 shows the temperature and temperature gradients recorded. The highest temperature difference obtained was $\sim 180{ }^{\circ} \mathrm{C}$ Figures 3.14 and 3.15 , in turn, show the receiver's response and the generated voltage from the thermoelectric.

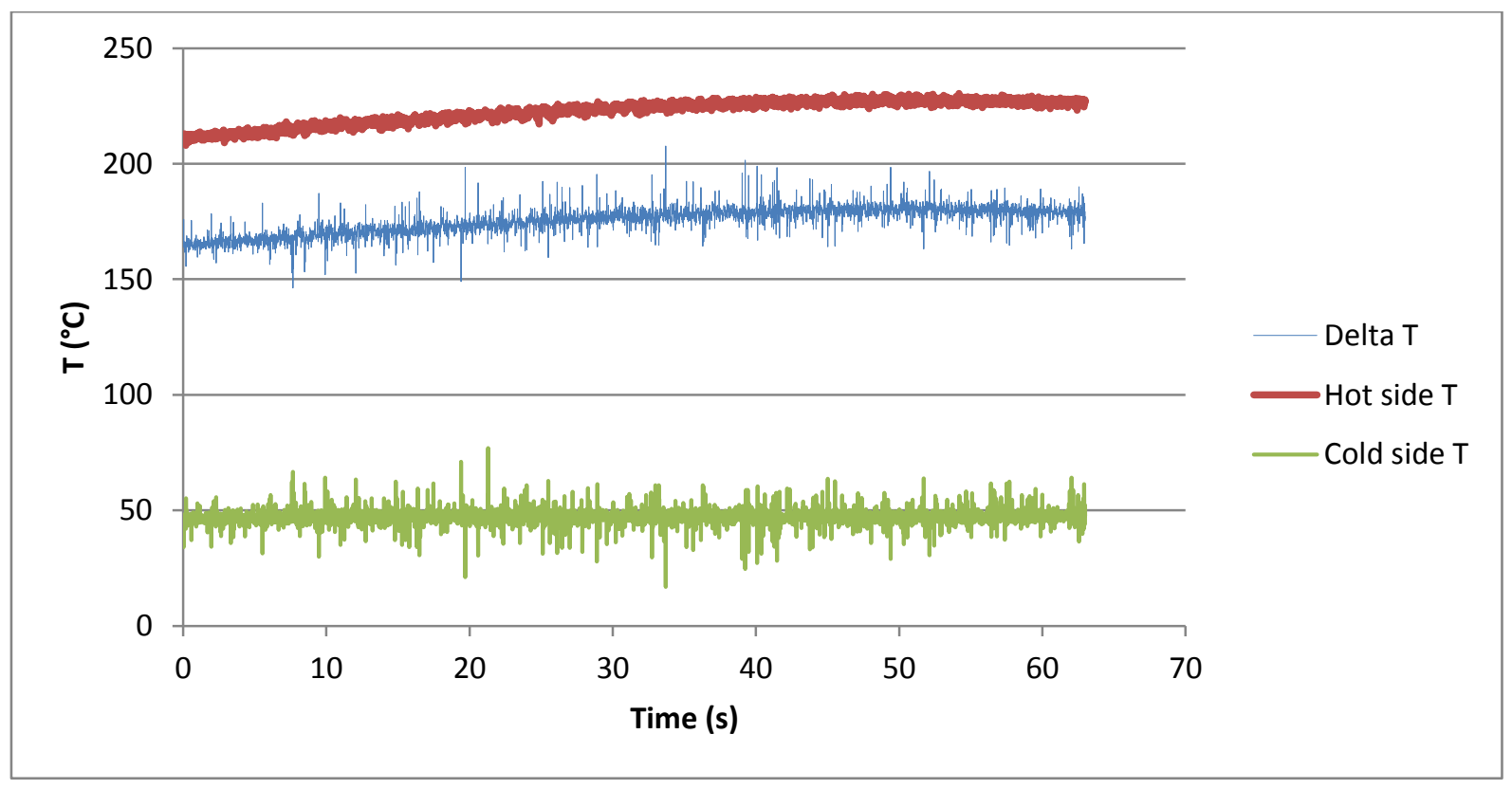

Figure 3.13: Temperatures on surfaces of heated thermoelectric element 


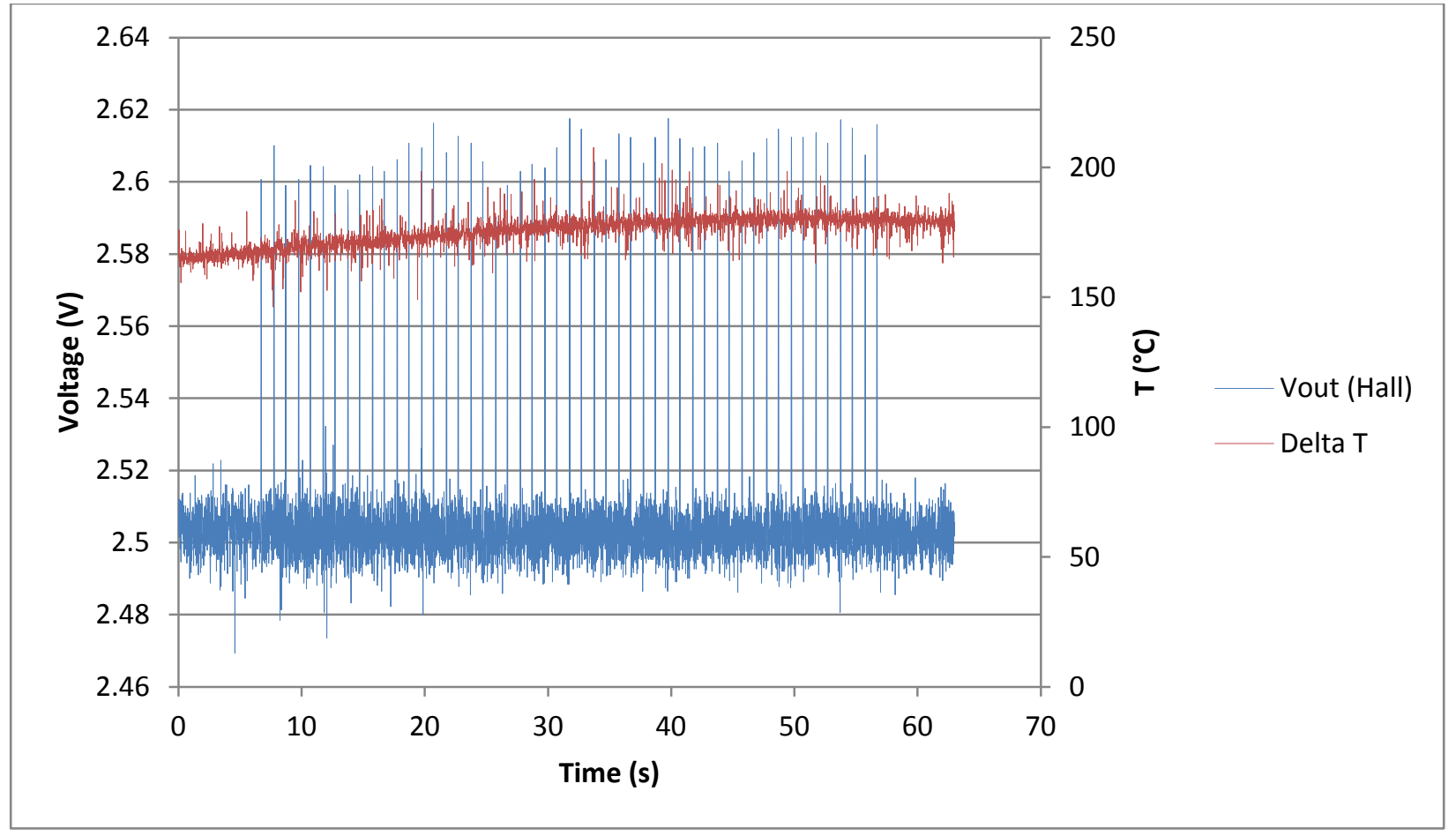

Figure 3.14: Hall sensor output voltage $\left(3^{\text {rd }}\right.$ generation, dynamic system)

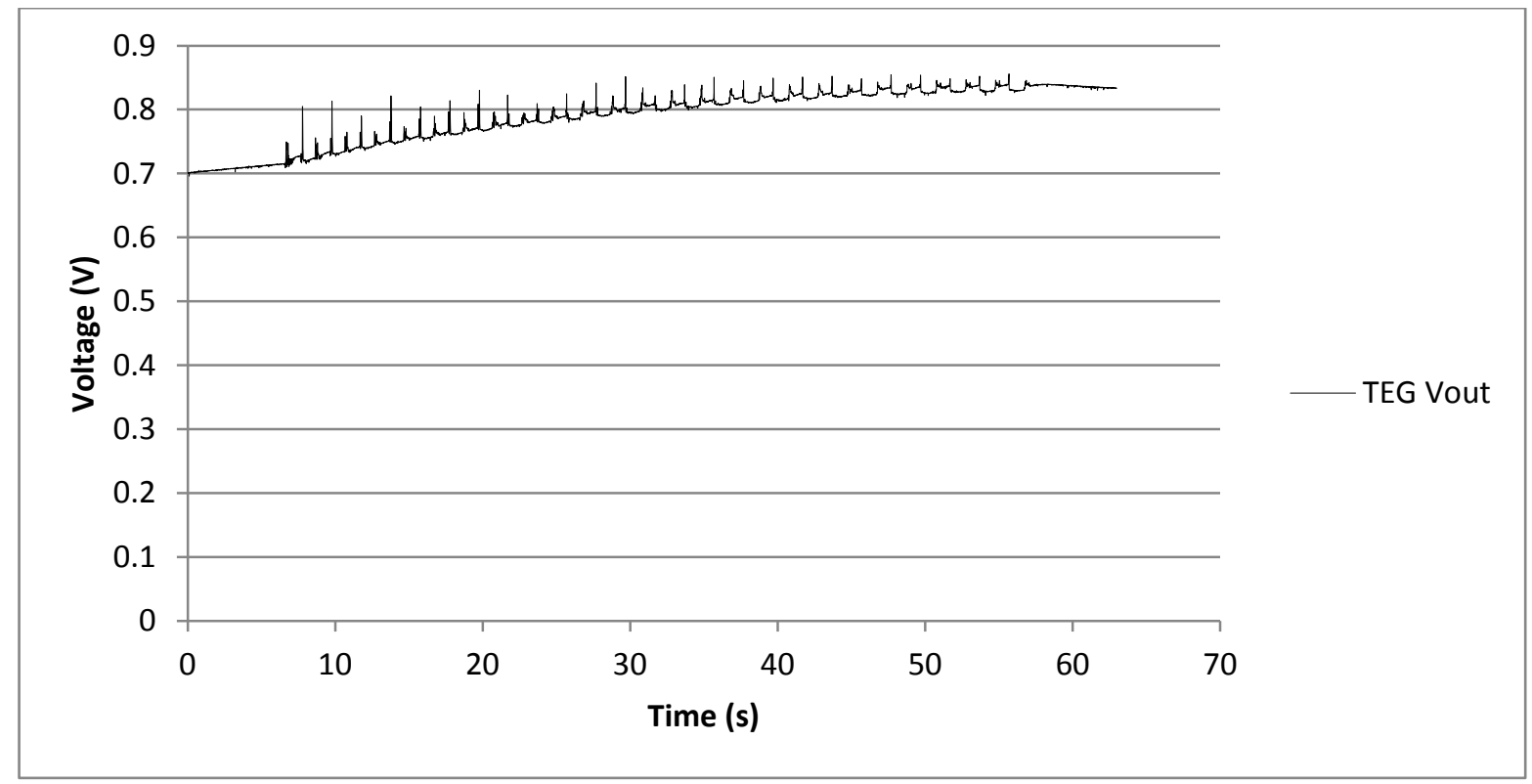

Figure 3.15: Open-circuit output voltage of TEG ( $3^{\text {rd }}$ generation, dynamic system) 


\section{Closed circuit}

Adding the rheostat's resistance into the circuit, the following results were obtained. Figure 3.16 shows the temperature and temperature difference plots. Figure 3.17 shows the relative signal intensity or voltage output recorded from the Hall sensor, and Figure 3.18 the recorded voltage generated by the TEG.

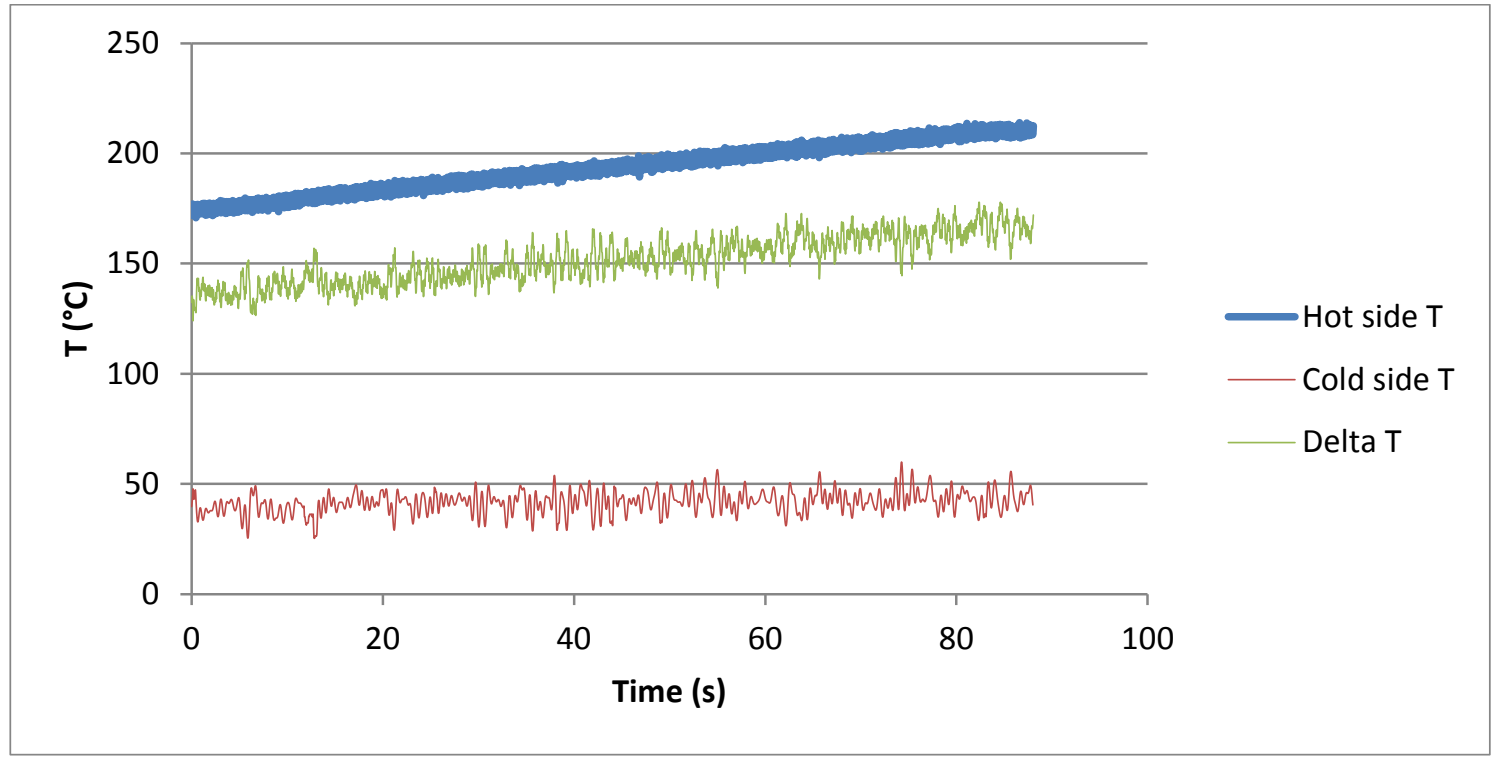

Figure 3.16: Temperature on surfaces of heated thermoelectric element

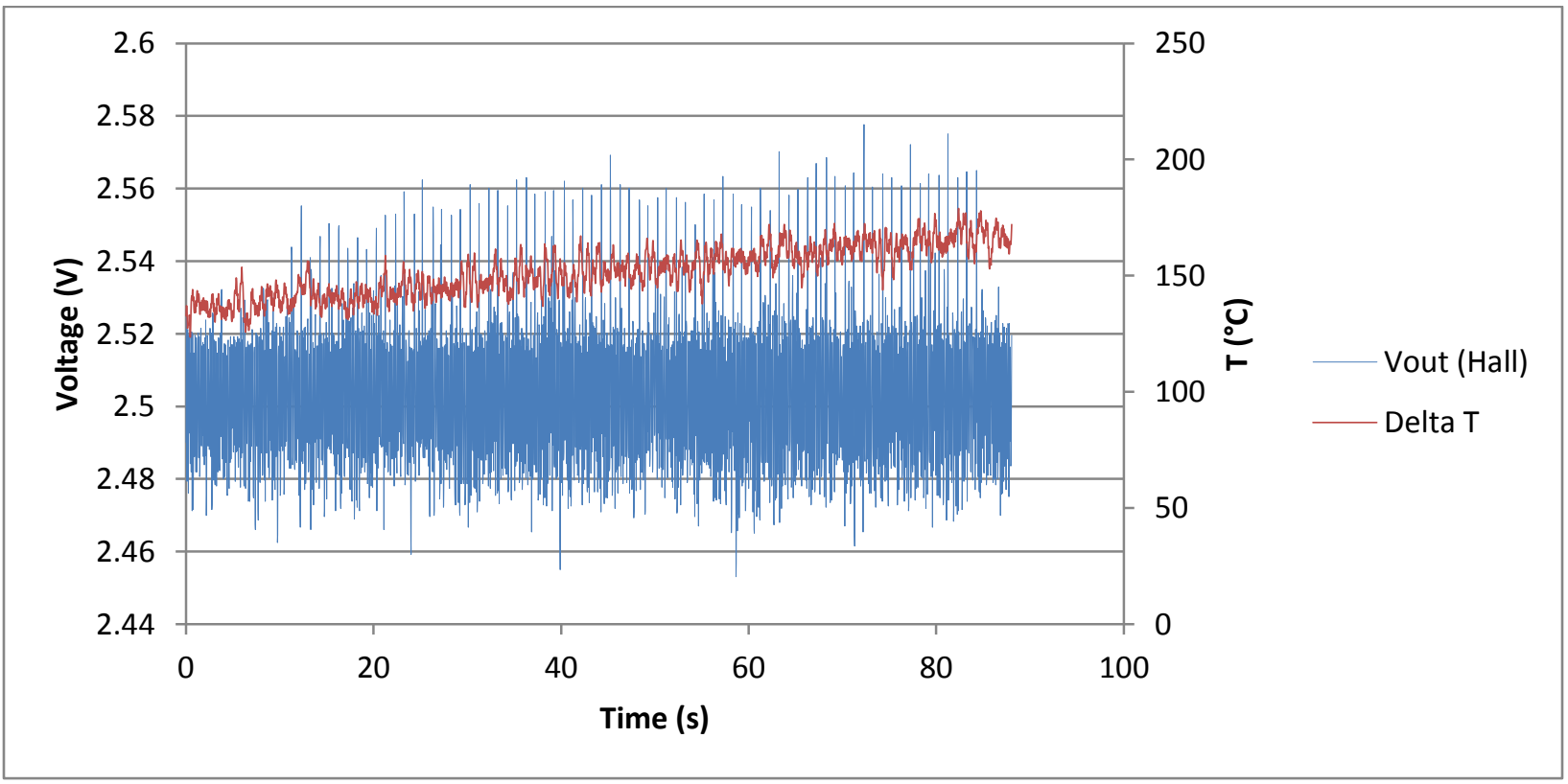

Figure 3.17: Hall sensor output voltage ( $3^{\text {rd }}$ generation, dynamic system) 


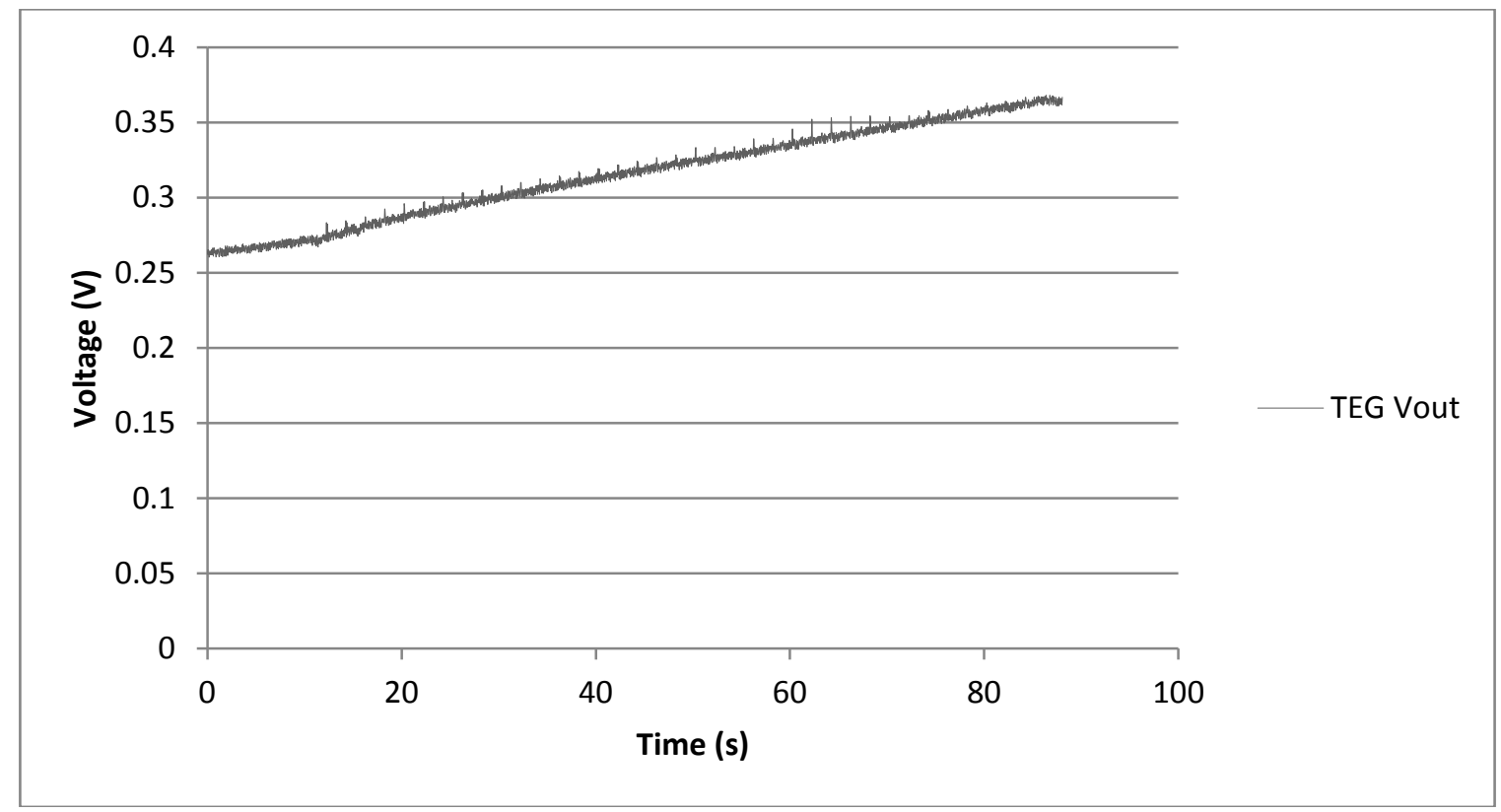

Figure 3.18: Closed circuit voltage of TEG $\left(3^{\text {rd }}\right.$ generation, dynamic system $)$

As seen from the plots, the upwards trend is noticeable even for the small temperature range at which readings were recorded for the open voltage and closed circuits in the dynamic system. In the closed circuit, the behavior is more evident for the Hall sensor recorded values as the temperature difference was increasing on both sides of the thermoelectric element. For both cases in the dynamic system, a significant amount of noise was perceived from the vibrations as the cylinder rod was moving in front of the sensor. 


\section{Chapter 4: Conclusion}

The value of a real time temperature sensor data obtained from a turbine blade or other power generation device can provide both an overall quick real-time assessment of component health or help improve overall efficiencies of a system. Based on this, the overall goal of this study was to demonstrate that temperature or temperature difference measurements may be recorded on the surface of a material. This paper presented the use of thermoelectric loops for this purpose.

The first and second generations of experiments were setup and tested with the intention to prove the Hall sensor's applicability as the signal receiver and the created solenoid as the transmitter. The pendulum and the double action pneumatic cylinder were used to move the solenoid repeatedly in order to simulate a dynamic system such as gas turbine blades or any of the moving parts on power generation units. For the first and second setups, the current was supplied to the solenoid and the response of the sensor was measured.

Finally, simulating a thermoelectric system in the third generation rig and inducing magnetic flux in the solenoid, wireless signals were measured using the Hall sensor. For the third setup, the current induced to the solenoid varied according to temperature differences on the heated thermoelectric device.

\subsection{SUMMARY AND CONCLUDING REMARKS}

From the present study the following conclusions can be made:

1) The need of a better characterization of temperature measurements in power generation units in order to prevent degradation and damage that develops gradually over time in hot section components, along with the constant demand of higher efficiencies of such systems have led to develop a variety of sensors which can help solve these issues.

2) A novel study is emerging in which thermoelectrics are not used only for cooling/heating or power generation (including providing power to the temperature sensors currently used), but as an enabling technology in which they are utilized as sensing devices themselves for temperature measurements, and in a wireless configuration. 
3) The developed system in this study addresses this issue characterizing and testing a wireless and self-powered thermoelectric sensor, which consists of a thermoelectric device and a solenoid as the signal transmitter, and a Hall sensor as the receiver.

4) The results obtained from the first generation set of experiments prove the Hall sensor's capacity in detecting the magnetic flux density changes, however, due to vibrational movements inherent in the controllable pendulum setup repeatable data using this rig was not obtainable.

5) Using a second generation setup comprised of a pneumatic cylinder, fewer vibrations were detected. This allowed for the initial proof of concept and demonstrated that this technology is feasible and that repeatable measurements are possible used in conjunction with the developed filtering mechanism.

6) The results were also presented for the third generation or thermoelectric setup and showed a correlation between thermoelectric temperature gradient and voltage measured by the sensor. As expected, the maximum response from the sensor was obtained at the time the greatest difference between the hot and cold sides of the thermoelectric was reached. The maximum temperature obtained at the hot side of thermoelectric device was $\sim 270{ }^{\circ} \mathrm{C}$ while the cold side temperature remained between $30-50{ }^{\circ} \mathrm{C}$ for most cases. The maximum output voltage obtained from the recorded sensor readings during the last set of experiments was $2.61 \mathrm{~V}$. The maximum voltage generated by TEG at the highest temperature difference was $0.86 \mathrm{~V}$.

7) The plots showed in the results from the first, second and third generation of experiments showed the expected behavior with maximum voltage values obtained at maximum temperature gradients.

8) Noticeable similarities were found comparing the results obtained during this study with the recorded output voltages from a single thermoelectric device in Love et al. study at selected temperature ranges. 
9) The developed filtering mechanism using a Discrete Fourier Transform algorithm allowed for a significant reduction of noise in the system (up to 60\%) for the three generations of experiments.

\subsection{RECOMMENDATIONS FOR FUTURE WORK}

In order to make a better analysis of the whole thermoelectric system, it is important to minimize the number of variables in it in order to simplify the system. For instance, keeping the hot side of the thermoelectric at a more constant temperature and reducing the range of the temperature in the cold side, less variations in the thermoelectric output voltage and current, as well as less changes in the thermoelectric resistance will be obtained.

Improvements in the current setup can also be made for an increased accuracy in the results obtained. Amplifications in the signal are required so that the signal receiver is able to detect the magnetic field induced at the center of the solenoid at a further distance from it.

Now that the applicability of the Hall sensor has been proved to detect the magnetic flux densities of the solenoid and give an output voltage proportional to it in response, this system can be applied in components of power generation units such as turbine blades. Similar tests have to be performed on real units in order to prove the complete applicability of the system developed in this study on real-time performance in actual size components.

Furthermore, since calculations were based on a supposedly spray casted turbine blade with the thermoelectric material impacted onto the solid substrate. In order to follow this approach, an optimum spray casting technique is required based on the effectiveness of the thermoelectric properties the material has made with the surface of the substrate to which it is intended to be embedded. 


\section{References}

[1] D. M. Rowe, Thermoelectrics Handbook: Macro to Nano, CRC, 2005.

[2] S. B. Riffat and X. Ma, "A review of present and potential applications," Applied Thermal Engineering, vol. 23, no. 8, pp. 913-935, 2003.

[3] D. Crane and S. Jackson, "Optimization of cross flow heat exchangers for thermoelectric waste heat recovery," Energy Conversion and Management, vol. 45, no. 9-10, pp. 1565-1582, June 2004.

[4] M. Mori, T. Yamagami, N. Oda, M. Hattori, M. Sorazawa and T. Haraguchi, "Current possibilities of thermoelectric technology relative to fuel economy," in SAE World Congress \& Exhibition, SAE Paper No. 2009-01-0170, Detroit, MI, USA, April 2009.

[5] B. I. Ismail and W. H. Ahmed, "Thermoelectric power generation using waste-heat energy as an alternative green technology," Recent patents on electrical engineering, vol. 2, pp. 27-39, 2009.

[6] N. Love, J. Szybist and C. Sluder, "Effect of heat exchanger material and fouling on thermoelectric exhaust heat recovery," Applied energy, vol. 89, pp. 322-328, 2012.

[7] C. Baker and L. Shi, "Experimental and modeling study of a heat exchanger concept for thermoelectric waste heat recovery from diesel exhaust," SAE Technical Paper 2012-01-0411, 2012.

[8] J. Schilz, "Applications of thermoelectric infrared sensors (thermopiles): gas detection by infrared absorption; NDIR," PerkinElmer Optoelectronics GmbH, 2000.

[9] T. Torfs, V. Leonov and R. J. Vullers, "Pulse oximeter fully powered by human body heat," Sensors \& Transducers Journal, vol. 80, no. 6, pp. 1230-1238, June 2007.

[10] V. Leonov, "Wearable self-powered wireless devices with thermoelectric energy scavangers," in Integration Issues of Miniaturized Systems - MOMS, MOEMS, ICS and Electronic Components (SSI), 2008 2nd European Conference \& Exhibition on, Leuven, Belgium, April 2008.

[11] S. Dalola, "Characterization of thermoelectric modules for powering autonomus sensors," IEEE Transactions on Instrumentation and Measurement, vol. 58, no. 1, pp. 99-107, January 2009.

[12] E. Sardini and M. Serpelloni, "Self-powered wireless sensor for air temperature and measurements with energy harvesting capability," IEEE Transactions on Instrumentation and Measurement, vol. 60, no. 5, pp. 1838-1844, May 2011.

[13] E. Sordiashie, "Electromagnetic harvesting to power energy management sensors in the built environment," University of Nebraska-Lincoln, 2012.

[14] T. A. Cartens, M. L. Corradini, J. P. Blanchard and Z. Ma, "Thermoelectric powered wireless sensors for spent fuel monitoring," IEEE Transactions on Nuclear Science, vol. 59, no. 4, pp. 14081413, August 2012.

[15] M. Romdhane, C. Gourdon and G. Casamatta, "Thermoelectric sensor for ultrasonic intensity measurement," Ultrasonics, vol. 33, no. 2, pp. 139-146, 1995.

[16] F. Völklein, G. Min and D. M. Rowe, "Modelling of a microelectromechanical thermoelectric cooler," Sens. Actuators A, vol. 75, no. 2, pp. 95-101, 1999.

[17] T. Haruyama, "Performance of Peltier elements as a cryogenic heat flux sensor at temperatures of down to 60 K," Cryogenics, vol. 41, no. 5-6, pp. 335-339, June 2001.

[18] M. S. El-Genk, H. H. Saber and T. Caillat, "A performance comparison of SiGe and skutterudite based segmented thermoelectric devices," AIP Conference Proceedings, vol. 608, pp. 1007-1015, February 2002. 
[19] O. Gregory, J. Conkle and T. Birnbaum, "Wireless sensors for gas turbines engines," 56th International Instrumentation Symposium, 2010.

[20] J. LaGrandeur, D. Crane, S. Hung, B. Mazar and A. Eder, "Automotive waste heat conversion to electric power using skutterudite, TAGs, PbTe and BiTe," in 25th International Conference on Thermoelectrics, Irwindale, CA, August 2006.

[21] S. R. Brown, S. M. Kauzlarich, F. Gascoin and G. J. Snyder, "Yb14MnSb11: new high efficiency thermoelectric material for power generation," American Chemical Society, vol. 18, no. 7, pp. 18731877, March 2006.

[22] G. J. Snyder and E. S. Toberer, "Complex thermoelectric materials," Nature Materials, vol. 7, pp. 105-114, 2008.

[23] J. Gilbert and R. Dewey, "Linear Hall-Effect sensor IC's. Allego MicroSystems, Inc.," [Online]. Available: www.allegromicro.com/ /media/Files/Technical-Documents/an27702-Linear-HallEffect-Sensor-ICs.ashx . [Accessed May 2012].

[24] L. I. Berger, Semiconductor materials, 1st ed. CRC Press, 1996.

[25] M. Plonus, Applied electromagnetics, McGraw-Hill Higher Education, 1978.

[26] R. K. Schaevitz, J. E. Roth, S. Ren, O. Fidaner and D. Miller, "Material properties of Si-Ge/Ge Quantum Wells," IEEE Journal of Selected Topics in Quantum Electronics, vol. 14, no. 4, July/August 2008.

[27] "Custom Thermoelectric, 1261G-7L31-24CX1 Power generation module," Custom Thermoelectric, 2009-2012. [Online]. Available: http://www.shop.customthermoelectric.com/1261G-7L31-24CX1Power-Generation-Module-1261G-7L31-24CX1.htm. [Accessed February 2012]. 


\section{Appendix A}

- Sample Calculations

- Assuming Si-Ge Quantum wells thermoelectric with properties described in Chapter 2 (hypothetical analysis),

$$
\begin{gathered}
\mathrm{R}=\frac{\mathrm{l}}{\sigma \mathrm{A}}=\frac{0.45 \mathrm{~m}}{833 \times 10^{3} *(0.0015)}=\mathbf{3 . 4 8} \times \mathbf{1 0}^{-4} \boldsymbol{\Omega} \\
\mathrm{I}=\frac{\mathrm{S}}{\mathrm{R}}=\frac{1500 \times 10^{-6}}{3.48 \times 10^{-4}}=\mathbf{4 . 3 \mathrm { A }}
\end{gathered}
$$

- Magnetic field calculations (actual experimental setup analysis),

$$
\frac{\mu_{0} K}{2}\left\{\frac{1-\frac{2(z)}{l}}{\left[\left(\frac{2 r}{l}\right)^{2}+\left(\frac{2(z)}{l}-1\right)^{2}\right]^{1 / 2}}+\frac{1+\frac{2(z)}{l}}{\left[\left(\frac{2 r}{l}\right)^{2}+\left(\frac{2(z)}{l}+1\right)^{2}\right]^{1 / 2}}\right\}=\frac{1000\left(V_{B}-V_{0}\right)}{\operatorname{Sens}}
$$

where $\mu_{0}=4 \pi^{*} 10^{-7}$

$$
\begin{aligned}
& \mathrm{K}=N I / l=155 * 4.3 / 0.02 \\
& z=0.013 \mathrm{~m} \\
& r=0.014 \mathrm{~m} \\
& \text { Sens }=0.005 \mathrm{~V} / \text { Gauss } \\
& V_{0}=2.5 \mathrm{~V}
\end{aligned}
$$

$$
\frac{4 \pi \times 10-7}{2}\left\{\frac{1-\frac{2(0.013)}{0.02}}{\left[\left(\frac{2 * 0.014}{0.02}\right)^{2}+\left(\frac{2(0.013)}{0.02}-1\right)^{2}\right]^{1 / 2}}+\frac{1+\frac{2(0.013)}{0.02}}{\left[\left(\frac{2 * 0.014}{0.02}\right)^{2}+\left(\frac{2 * 0.013}{0.02}+1\right)^{2}\right]^{1 / 2}}\right\}=\frac{1000\left(V_{B}-2.5\right)}{0.005}
$$

\section{$\mathrm{B}=135$ Gauss $=0.014 \mathrm{~T}$}

Solving for $\mathrm{V}_{\mathrm{B}}$, 


$$
V_{B}=\left\{(\text { Sens }) \frac{\mu_{0} K}{2}\right\} \frac{\left\{\frac{1-\frac{2(z)}{l}}{\left[\left(\frac{2 r}{l}\right)^{2}+\left(\frac{2(z)}{l}-1\right)^{2}\right]^{1 / 2}}+\frac{1+\frac{2(z)}{l}}{\left[\left(\frac{2 r}{l}\right)^{2}+\left(\frac{2(z)}{l}+1\right)^{2}\right]^{1 / 2}}\right\}}{1000}+V_{0}
$$

$\mathrm{V}_{\mathrm{B}}=\mathbf{2 . 8 3 \mathrm { V }}$

- Experimental uncertainty (95\% confidence interval)

\begin{tabular}{|c|c|c|}
\hline & $1^{\text {st }}$ generation & $2^{\text {nd }}$ generation \\
\hline Output Voltage & $2.538 \pm 0.006$ & $2.681 \pm 0.001$ \\
\hline
\end{tabular}

e.g. $\left(1^{\text {st }}\right.$ generation $)$

No. of samples for analysis, $N=8$

$x=2.535,2.542,2.537,2.534,2.536,2.538,2.534,2.544$

$\bar{x}=2.538$

$S_{x}=\sqrt{\frac{\sum(x-\bar{x})^{2}}{N-1}}=0.003$

$$
\alpha=0.05, \quad \alpha / 2=0.025, \quad t_{\alpha / 2}=2.365, \quad \gamma=10-1=9
$$

$$
\begin{aligned}
& R=t_{\alpha / 2}\left(\frac{s_{x}}{\sqrt{N}}\right) \\
& R=2.365\left(\frac{0.003}{\sqrt{8}}\right)=0.006
\end{aligned}
$$

Experimental uncertainty $=\bar{x} \pm \mathrm{R}=\mathbf{2 . 5 3 8} \pm \mathbf{0 . 0 0 6}$ 


\section{Appendix B}

- Filtering System in Mathcad

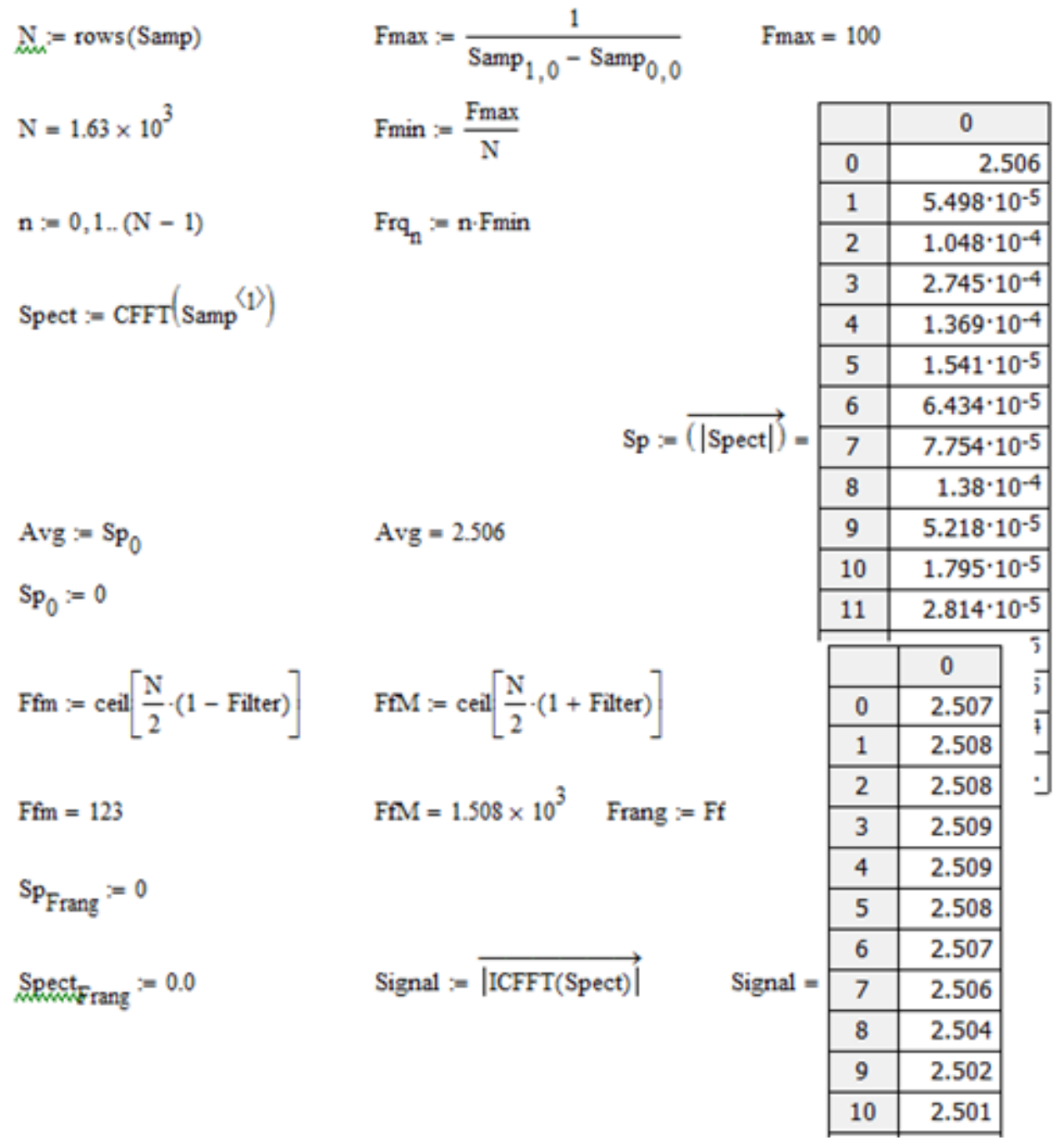




\title{
Appendix C
}

\section{Development of Thermoelectric Temperature Sensors}

\author{
Jennifer J. Kuchle ${ }^{1}$, Rodolfo Aguirre ${ }^{1}$, Norman Love ${ }^{2}$ \\ Center for Space Exploration Technology Research (cSETR) \\ Department of Mechanical Engineering \\ The University of Texas at El Paso \\ El Paso, Texas 79968
}

\begin{abstract}
Temperature measurements in power generation systems can provide useful information on the performance parameters of the unit. This paper presents conceptual measurement technique using a simulated thermoelectric loop (transmitter). The transmitter simulates the induced current and magnetic field emanating from the center of an n\&p loop. The receiver used in this study is a Hall effect sensor and measures the magnetic flux produced by the transmitter. Two experimental setups were designed and built for the measurements. The first setup used a pendulum to move a coil simulating a loop thermoelectric generator thereby creating a magnetic flux. A second generation setup was also constructed that produced more accurate and repeatable results. Initial results are also presented using a heated thermoelectric generator in a loop configuration. Results show that measurements of temperature wirelessly using thermoelectrics are feasible and may be used in future advanced power generation technologies.
\end{abstract}

$\begin{array}{ll}\mathrm{A} & =\text { area } \\ \mathrm{I} & =\text { current } \\ \mathrm{l} & =\text { length } \\ \mathrm{N} & =\text { number of turns } \\ \mathrm{S} & =\text { Seebeck coefficient } \\ \mathrm{T} & =\text { temperature } \\ \mathrm{V} & =\text { voltage } \\ \mathrm{Z} & =\text { thermoelectric figure of merit } \\ \lambda & =\text { thermal conductivity } \\ \mu_{0} & =\text { permeability of free space } \\ \varphi & =\text { magnetic flux } \\ \sigma & =\text { electrical conductivity }\end{array}$

\section{Introduction and Background}

1 hermoelectric elements can be used to improve the efficiency of current land based power-generating gas turbines or other power generation equipment through the close monitoring of active temperatures and temperature differences. Thermodynamics dictates that for a heat engine, higher efficiencies can be obtained at higher operating temperatures. However, the materials used to build engines impose some practical limits on operating conditions. High temperatures and heavy thermal cycling can cause premature and possibly catastrophic failure of engine components. Based on these constraints, the trade-off between high performance and high reliability has historically been met by designing for a

\footnotetext{
${ }^{1}$ Graduate Research Assistant, Student Member AIAA

${ }^{2}$ Assistant Professor, Member AIAA
} 
temperature safety margin. This safety margin is met by operating the engine at a lower than optimal temperature to prevent fatigue and failure. When operating temperatures are not well cKicterized, this safety margin must be large. However, when accurate temperatures and temperature gradients can be monitored in real time, the safety margin can decrease allowing for possible use of higher operating temperatures and improved performance. Therefore, developing a method that can provide temperature data while equipment is working will be an advantage in terms of efficiency and operational parameters. This paper presents the use of thermoelectric elements for this purpose. A brief literature review of thermoelectric technologies is given here.

Traditional usage of thermoelectrics are for waste heat recovery applications. Love et al. ${ }^{3}$, used several thermoelectric devices on a heat recovery system simulating an automotive exhaust. A similar study was also conducted by Baker and $\mathrm{Shi}^{4}$, where the heat transfer characteristics of a conceptual heat exchanger design were investigated for thermoelectric waste heat recovery from a diesel exhaust. Implementing thermoelectric technology can increase efficiencies of many systems in this configuration. Several other studies involving the use of thermoelectrics for exhaust waste heat recovery can be found in Ref 3.
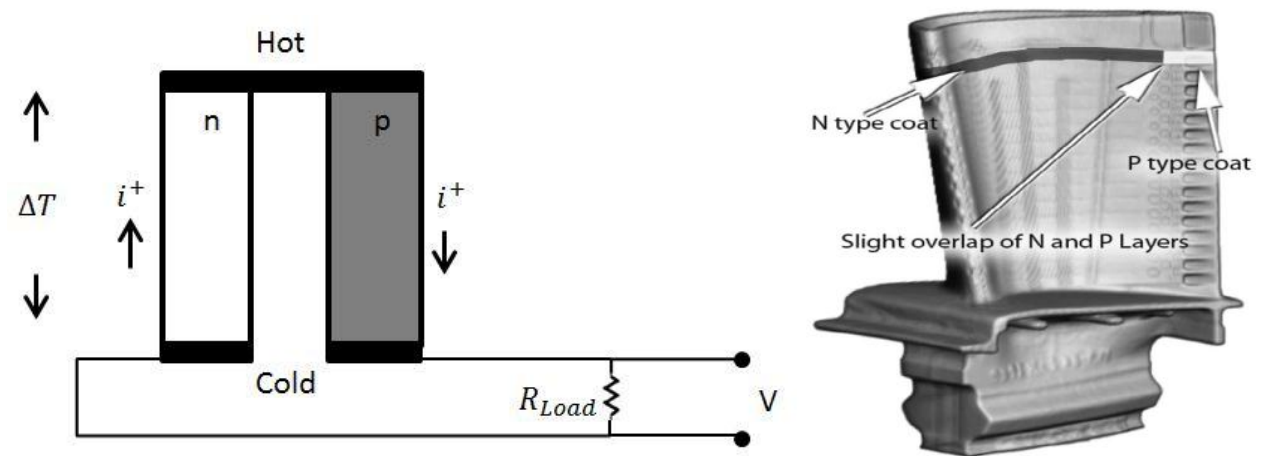

Figure 1. (Left) Typical thermoelectric system ${ }^{2}$ (Right) Concept of how this technology may be applied to a surface of a blade.

Other applications for thermoelectrics more related to this study have also been found in literature. For instance, research was conducted on the use of thermoelectric generators to power radio frequency sensor modules and consequently, monitor the fuel being spent during dry-cask storage in nuclear power plants ${ }^{5}$. Similar studies have also been conducted in order to conceptually monitor the temperature in a gas turbine using a variety of sensors. A detailed list of other works relevant to the current study is presented in Table 1.

Table 1. Summary of studies involving thermoelectric sensor devices

\begin{tabular}{|l|l|l|}
\hline \multicolumn{1}{|c|}{ Authors } & \multicolumn{1}{|c|}{ Experimental Technique } & \multicolumn{1}{c|}{ Findings } \\
\hline Sardini and Serpelloni (2009) & $\begin{array}{l}\text { Passive and self-powered } \\
\text { autonomous sensors for remote } \\
\text { measurements }\end{array}$ & $\begin{array}{l}\text { Power harvesting system } \\
\text { supplied by an electromagnetic field } \\
\text { used as communication support in } \\
\text { order to obtain the electric } \\
\text { power required to make the sensor } \\
\text { work }\end{array}$ \\
\hline Gregory et al. (2010) & $\begin{array}{l}\text { Wireless sensors for gas turbine } \\
\text { engines }\end{array}$ & $\begin{array}{l}\text { Passive sensor, integrated circuit } \\
\text { embedded on the gas turbine blade. } \\
\text { Further implementation is being } \\
\text { investigated }\end{array}$ \\
\hline Sordiashie (2012) & $\begin{array}{l}\text { Electromagnetic harvesting to power } \\
\text { energy management sensors in the } \\
\text { built environment }\end{array}$ & $\begin{array}{l}\text { Development of a small } \\
\text { electromagnetic energy harvesting } \\
\text { device by estimating the magnetic } \\
\text { field strength around the current } \\
\text { carrying conductors }\end{array}$ \\
\hline Schilz(2000) & $\begin{array}{l}\text { Thermoelectric infrared sensors for } \\
\text { remote temperature measurements }\end{array}$ & $\begin{array}{l}\text { Incident IR radiation induces a } \\
\text { change in electrical conductivity } \\
\text { which is measured and used as the } \\
\text { sensing signal for the incident power }\end{array}$ \\
\hline
\end{tabular}

The value of real time temperature sensor data obtained from a turbine blade can provide both an overall quick real-time 
assessment of engine health and help to improve overall efficiencies of a system. There are many challenges to overcome as has been found in other studies ${ }^{5-9}$. These challenges include the selection of a temperature sensor technology capable of surviving the hostile environment in a turbine, ability to transfer data to an externally located real time receiver, be capable of being implemented on high-speed moving engine components, and must be sufficiently small so as not to interfere with the combustion processes in the combustor.

In many of the aforementioned studies thermoelectrics were used to power sensor devices whereas the overall goal of this study is to demonstrate that temperature measurements may be recorded on the surface of a material using thermoelectric technology itself. This paper presents a novel study that investigates the potential for using thermoelectric loops for temperature and temperature difference measurements. As a proof of concept study the paper presents a method to measure the temperatures signals wirelessly.

\section{Theory}

Thermoelectric phenomena arise out of the intercoupled electrical and thermal currents in a material. Temperature gradients applied to the conductor cause a voltage gradient. This phenomenon of a temperature gradient causing a voltage gradient is characteristic of all conductors and is a bulk phenomenon. The open circuit voltage $(\Delta \mathrm{V})$ that is generated in a given conductor is proportional to the temperature difference $(\Delta \mathrm{T})$ across that conductor. The constant of proportionality relating these two quantities is the Seebeck coefficient or thermopower, S, yielding an equation for generated voltage shown in Eq. (1).

$$
\Delta V=S \Delta T
$$

Two additional material properties of interest when analyzing a thermoelectric material include the electrical conductivity, $\sigma$, and the thermal conductivity, $\lambda$. These material properties govern thermoelectric performance and are often expressed as a numerical value that provides an indication of the electrical conversion efficiency of a device. The thermoelectric figure of merit $\mathrm{Z}$ is presented in Eq. (2). The parameter ZT is often used to compare alternative thermoelectric choices since properties $\sigma, \mathrm{S}$ and $\lambda$ are temperature dependent parameters.

$$
Z=\frac{\sigma S^{2}}{\lambda}
$$

A thermocouple, which is the simplest form of a thermoelectric generator, can be formed by making an electrical connection of an N-type conductor with a P-type conductor. When $\mathrm{T}_{2}>\mathrm{T}_{1}$, the P-type and N-type conductors generate voltages of $\mathrm{V}_{1}$ and $\mathrm{V}_{2}$ respectively. By shorting the ends of the thermocouple, as in Fig. 2, a continuous loop that is temperature dependent circulates current in response to the temperature difference between the two connection points. The magnitude of the current, $\mathrm{I}$, is proportional to the magnitude of the temperature difference $\Delta \mathrm{T}=\mathrm{T}_{1}-\mathrm{T}_{2}$. The present study looks to simulate this ring thermoelectric generator using an electric coil and later using an actual thermoelectric device. The circulating current and the induced magnetic flux in the center of the loop will produce a measureable quantity that will simulate temperature differences between $\mathrm{T}_{1}$ and $\mathrm{T}_{2}$.

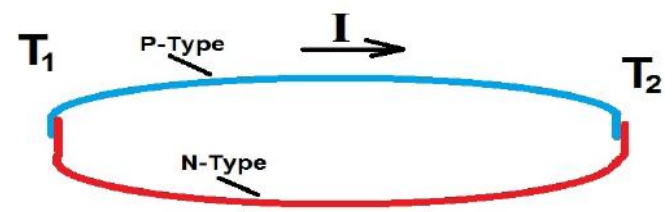

Figure 2. Schematic diagram of a thermoelectric loop

If this current loop has a velocity, a magnetic field will be generated at a magnitude proportional to the current I (simulated $\Delta \mathrm{T}$ ) as seen in Eq. (3) ${ }^{10}$. By using a fixed receiver that is located away from the loop the magnetic flux can be detected wirelessly which is what this study attempts to show.

$$
\varphi=\frac{\mu_{0} N I A}{l}
$$




\section{Experimental Method}

This section presents three experimental setups used for testing: a first generation setup, a second generation rig based on lessons learned from the first, and a third using a heated thermoelectric to produce a measureable current.

\section{A. First Generation Experimental Rig}

For the first generation experimental setup, a winded coil simulating a current loop was placed at the end of a motor controlled pendulum. The pendulum movement simulated a moving component in a power generation unit and was necessary to generate a magnetic flux. A continuous current of $4.3 \mathrm{~A}$ was supplied by a power supply to the coil which circulated as in Fig. 2. The value of 4.3A was done assuming $\mathrm{N}$-type and P-type thermoelectric strips were $1 \mathrm{~mm}$ in height, $5 \mathrm{~mm}$ in width and $10 \mathrm{~cm}$ in length (circumference of $20 \mathrm{~cm}$ ) and have a thermopower of $189 \mu \mathrm{V} /{ }^{\circ} \mathrm{C}$ and an electrical conductivity of $8.95 \mathrm{x}$ $10^{4} \Omega^{-1} \mathrm{~m}^{-1}$ and a temperature difference between the two leads of $1000^{\circ} \mathrm{C}$ which is a typical temperature expected in a combustor or energy producing device. The equation below shows the calculation:

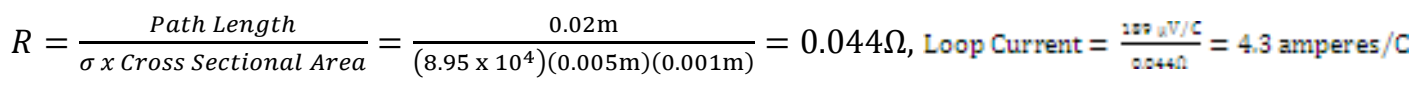

The pendulum speed was then adjusted to produce a magnetic flux based on the motion and magnitude of the current supplied. The pendulum with the attached coil was allowed to move in front of the receiver. In this study, a $5 \mathrm{mV} / \mathrm{Gauss}$ radiometric linear analog Hall effect sensor was used. The initial output voltage of this sensor is set as half of the supply voltage ( 2.5 Volts) and varied in accordance to the strength of the magnetic field. A schematic diagram of the setup is shown in Fig. 3.

The sensor was tested several times at a distance of $1.3 \mathrm{~cm}$ away from the electromagnet. The data obtained was recorded using LabVIEW. Due to vibrations associated with movements with the pendulum a filtering system was also developed. A Discrete Fourier Transform (DFT) function was used for the filtering process and 1,630 samples were evaluated. The cutoff frequency and bandwidth were determined by the lowest allowable frequency (pendulum's frequency) and the third highest frequency obtained. These values were 2 and $20 \mathrm{~Hz}$, respectively. Under this function, $60 \%$ of the noise was filtered, without any compromise in fidelity.

For this system the peaks' amplitude were not equal each time the coil passed in front of the Hall sensor, thus the vibrations were significant despite attempts to eliminate with the filtering code. This is discussed more in the results section of this paper.

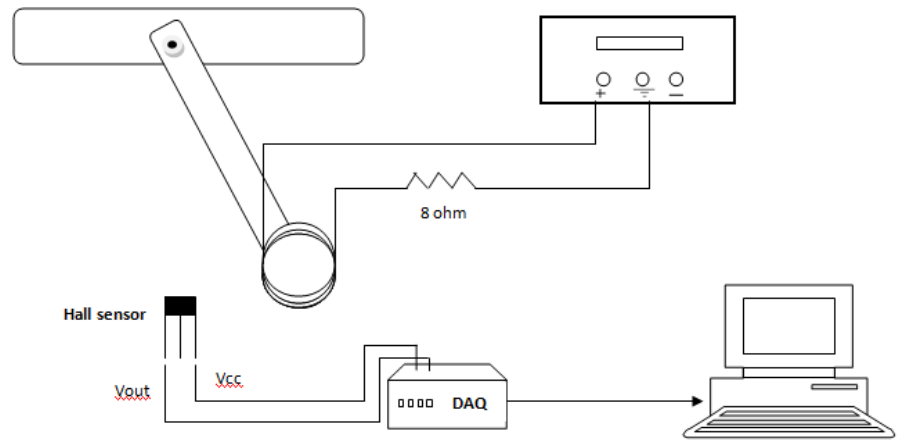

Figure 3. Schematic diagram of first generation experimental setup.

\section{B. Second Generation Experimental Rig}

For the second generation of experiments a similar setup was utilized. The second generation setup, Fig. 4, consisted of a double-action pneumatic cylinder, a solenoid air control valve, a $5 \mathrm{~V}$ input relay, Hall effect sensor, DC power supply, and high pressure air delivery line. The pneumatic piston device was selected since vibrational effects were significantly reduced using this configuration. Additionally the velocity of the piston could be monitored for any given instant using a laser displacement sensor which was mounted on the Hall sensor's bench. 
The 4-way valve used with the pneumatic cylinder was configured to operate at a frequency of $0.5 \mathrm{~Hz}$. The Hall sensor signal which represented the magnetic flux generated by a heated thermoelectric loop was recorded in LabVIEW. Using the velocity data from the displacement sensor accurate signals were measured. Each test was run several times for a duration of ten seconds. Experimental uncertainty was found to be with $1 \%$ of the mean.

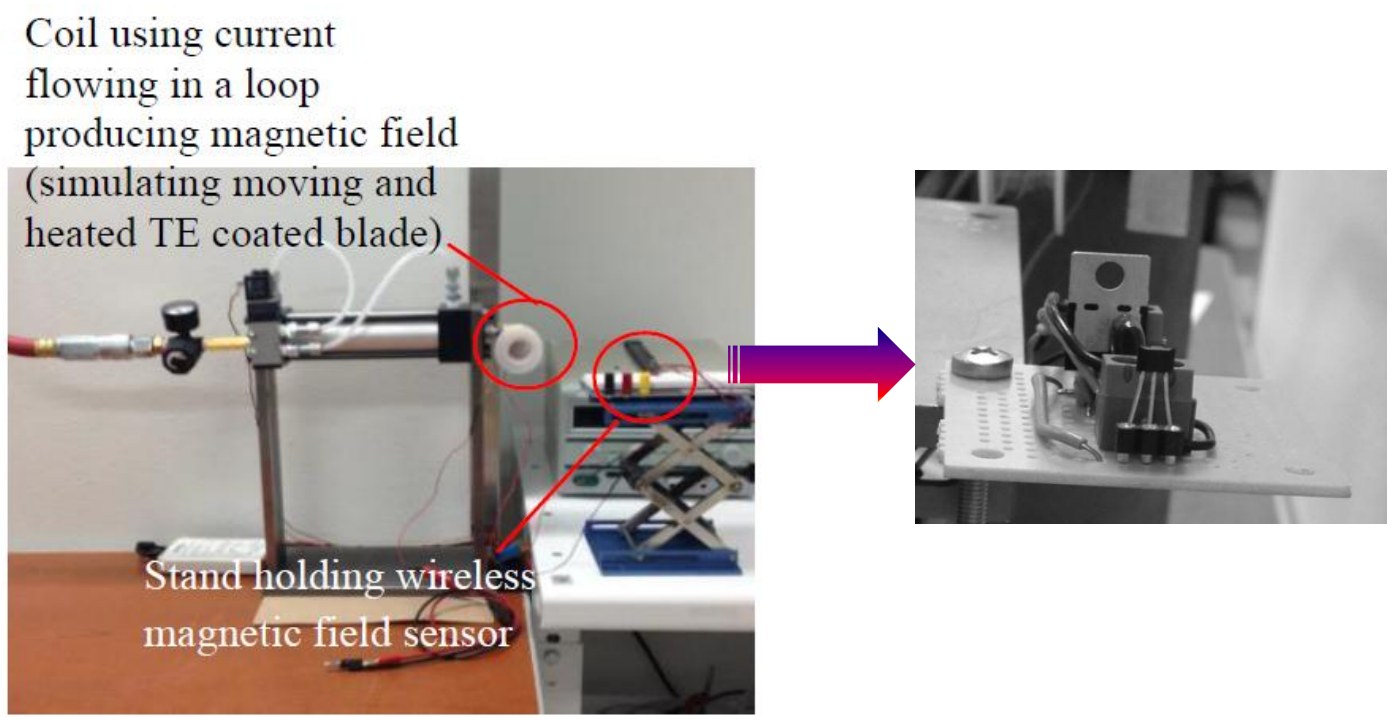

Figure 4. Experimental setup using double action pneumatic cylinder along with close up of the Hall sensor

\section{Thermoelectric Setup}

Once the measurement technique was established using the second generation setup with wireless sensor and filtering system some other components were also added to test for the effect of temperature. A bismuth telluride thermoelectric element was heated using a hot plate heater connected to a rheostat $(0-3 \Omega, 25 \mathrm{~W})$. The rheostat was employed to vary the load's resistance and match the TEG's internal resistance in order to obtain the desired induced current in the coil (4.3A). The cool side of the thermoelectric was connected to a water block to produce the temperature difference across the device. Water was pumped through the cooling block using a diaphragm water pump.

For these experiments the thermoelectric leads were attached to the ends of the coil seen in Figs. 3 and 4. Temperatures on both sides of the thermoelectric element, as well as output voltages of both Hall and thermoelectric were recorded. Some of the initial results obtained setting the load's resistance to $1.7 \Omega$ are presented in the results section.

\section{Results and Discussion}

\section{A. First Generation Experimental Results}

The results obtained from the first experimental setup and the filtered signal using a DFT algorithm are shown in Figs. 6 to 8 . Figure 6 shows the output voltage recorded in the first seconds as the pendulum was moving. As seen, the peaks from the moving coil with $4.3 \mathrm{~A}$ showed a periodic pattern. Each peak represents the output voltage reading from the Hall sensor at the instant the coil attached to the moving pendulum was in front of it. Figure 7 shows the spectrum of the frequencies used in the signal filtering process. The first peak occurred at $\sim 2 \mathrm{~Hz}$, the same value as the pendulum's frequency. The maximum output voltage value obtained was 2.57 in this configuration. The filtered signal using a DFT algorithm is shown in Figure 8 . Although the wireless signal was successfully transmitted, these data should have equal magnitude for each pass in front of the sensor. After repeated measurements and attempts to filter noise it was determined that the pendulum device produced disruptive noise and caused non-repeatable data which was later corrected for using the second-generation setup. 


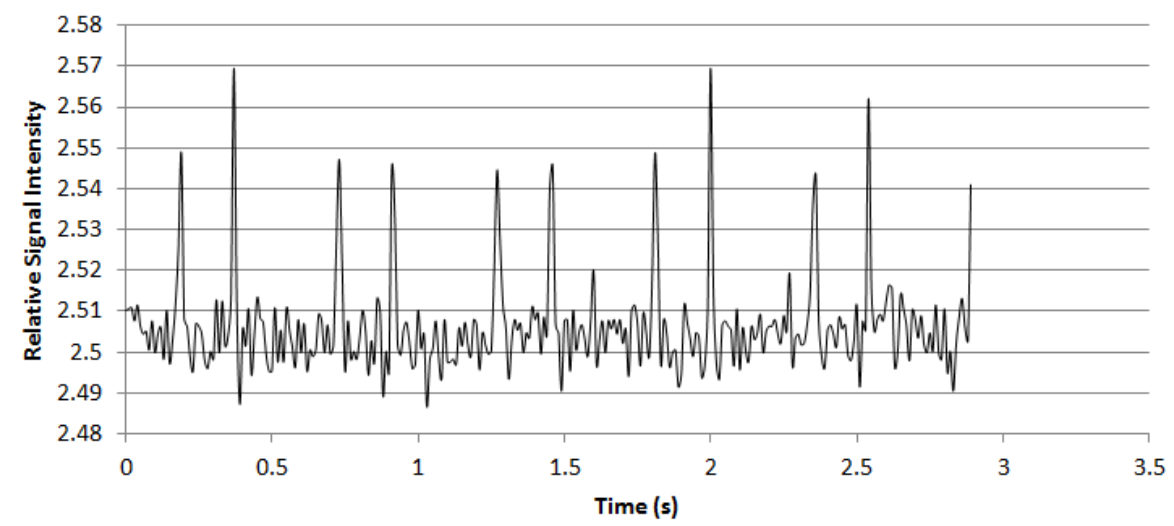

Figure 6. Relative signal intensity vs time

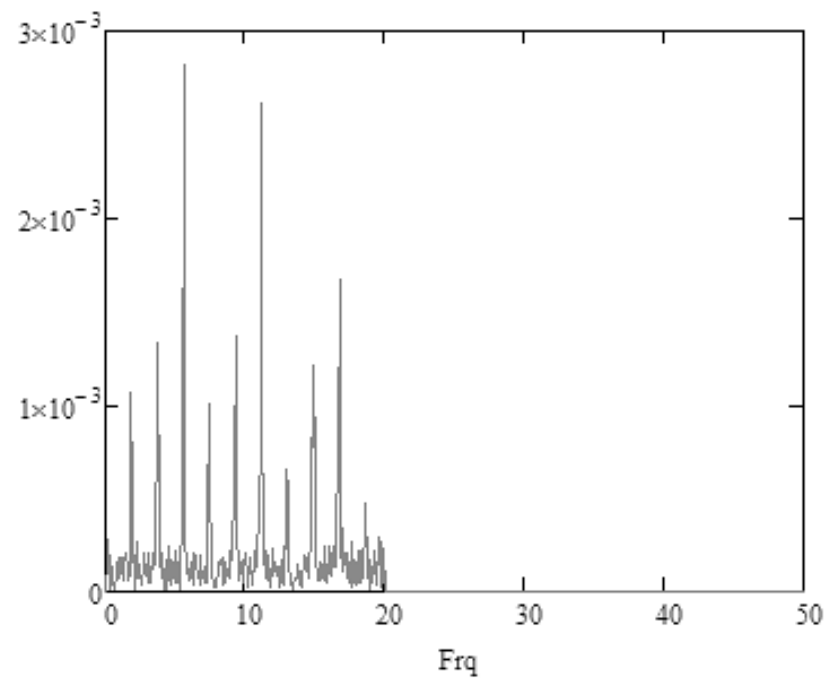

Figure 7. Frequency spectrum used for filtering analysis

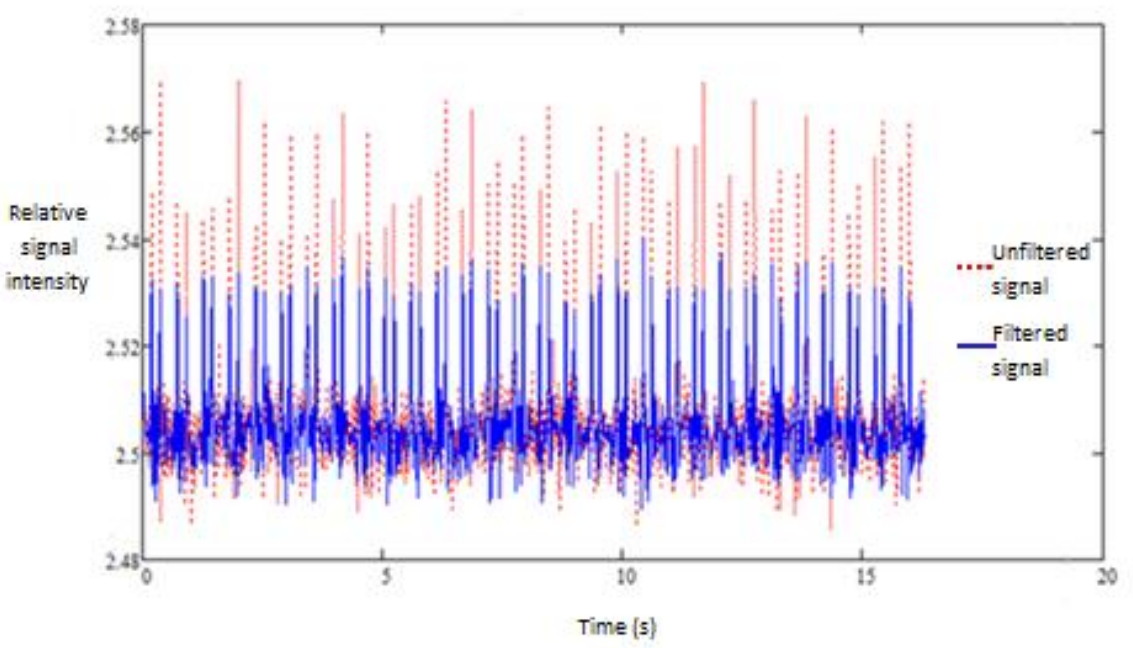

Figure 8. Comparison between unfiltered and filtered signals

\section{B. Second Generation Experimental Results}

Figure 9 presents the data obtained from the Hall sensor running the experiments with the second generation setup. As expected from design calculations, the inertial mass of the system and the noise were reduced when moving the coil with the 
double-action pneumatic cylinder. The peaks' amplitude showed a similar pattern with equal magnitude. Small disturbances from peak to peak were still visible due to fluctuations in the velocity of the accelerating air cylinder and, in a smaller scale, to the change in distance (z-axis) between the cylinder with the attached coil and the static sensor caused by minor vibrations in the system. However, many of these effects were filtered; the result can be seen in Fig. 9. Overall, this successfully showed that a signal from a loop generator could be effectively measured wirelessly. Although no temperatures have been introduced at this point, this shows a proof of concept of the technology.

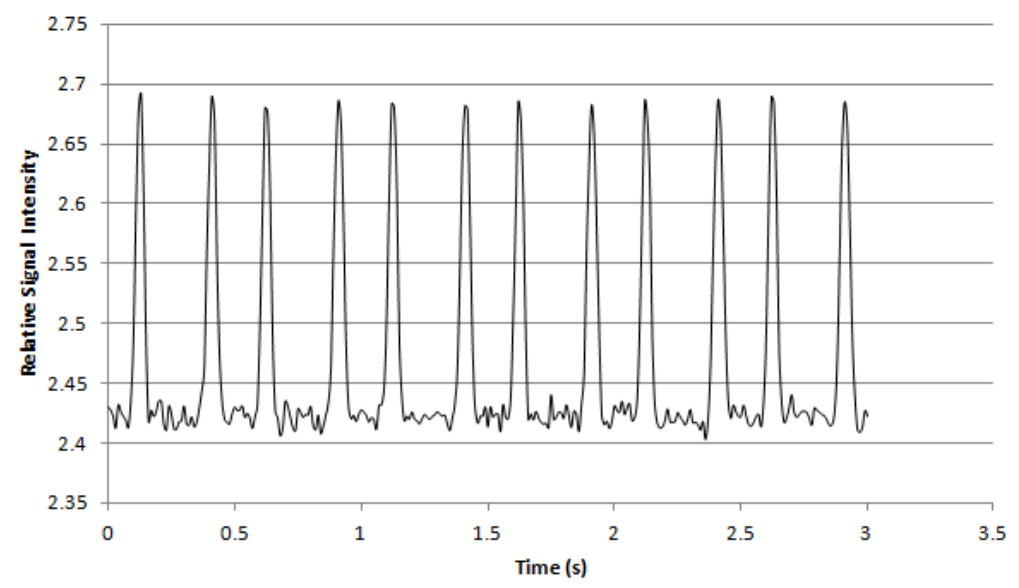

Figure 9. Relative signal intensity vs. time for second generation setup

\section{Thermoelectric Experimental Results}

Once the sensor, filtering, and measurement technologies were sufficiently developed, a heated thermoelectric's leads were connected to the loop coil on the moving pneumatic cylinder. As the temperature difference was increased on the thermoelectric device voltage measurements were taken using the Hall sensor. Figures 10 and 11 show some of the initial results obtained. The temperature values for the hot and cold sides and their difference can be appreciated in Fig. 10 as the hot plate was being heated and cooled at different settings over time. The maximum temperature difference obtained in the initial states was $\sim 190{ }^{\circ} \mathrm{C}$.

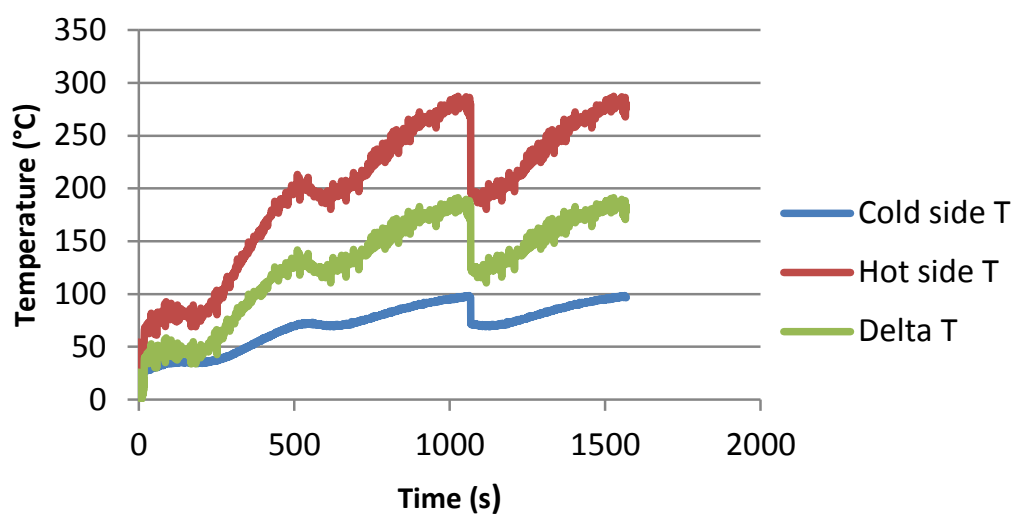

Figure 10. Temperature on surfaces of heated thermoelectric element

The recorded output signal readings from the Hall sensor are presented in Figure 11. A relation can be seen between the output voltage and temperature gradient. An increase in the voltage is positively correlated with a temperature gradient increase. Currently more extensive set of tests are currently being run using the heated thermoelectric in order to obtain a relation between temperature gradient, magnetic flux density, and the Hall sensor's output. 


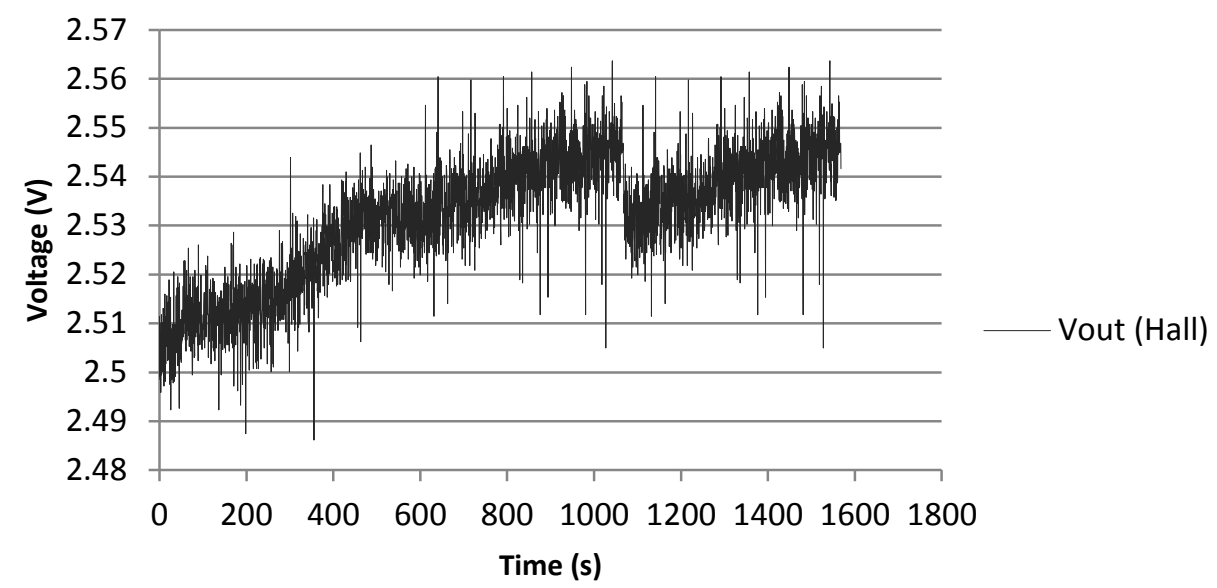

Figure 11. Relative signal intensity vs. time ( $2^{\text {nd }}$ generation).

\section{Summary and Conclusion}

The value of a real time temperature sensor data obtained from a turbine blade or other power generation device can provide both an overall quick real-time assessment of component health or help to improve overall efficiencies of a system. Based on this, the overall goal of this study was to demonstrate that temperature or temperature difference measurements may be recorded on the surface of a material. This paper presented the use of thermoelectric loops for this purpose. Using a simulated a magnetic flux from a coil, wireless signals were measured using a Hall sensor. Some initial data using a heated thermoelectric to generate a signal was also presented. The findings from the paper are summarized in the points below:

1) The results obtained from the first generation set of experiments prove the Hall sensor's capacity in detecting the magnetic flux density changes, however, due to vibrational movements inherent in the controllable pendulum setup repeatable data using this rig was not obtainable.

2) Using a second generation setup comprised of a pneumatic cylinder fewer vibrations were detected. This allowed for the initial proof of concept and demonstrated that this technology is feasible and that repeatable measurements are possible used in conjunction with the developed filtering mechanism.

3) Preliminary results were also presented using a thermoelectric generator device and showed a correlation between thermoelectric temperature and voltage measured by the sensor. Currently more tests are being performed to produce a direct relation between the thermoelectric output and temperature.

\section{Acknowledgments}

The authors acknowledge the generous support of the A. Loya innovation fund.

\section{References}

${ }^{1}$ Kasap, S. Thermoelectric effect in metals: thermocouples. E-Booklet. 1997.

${ }^{2}$ California Institute of Technology, Thermoelectrics, Caltech Materials Science http://www.its.caltech.edu/ jsnyder/thermoelectrics/

${ }^{3}$ Love, N., Szybist, J., and Sluder, C. Effect of heat exchanger material and fouling on thermoelectric exhaust heat recovery. Applied Energy. Vol. 89. 2012. pp. 322-328.

${ }^{4}$ Baker, C. and Shi, L. Experimental and Modeling Study of a Heat Exchanger Concept for Thermoelectric Waste Heat Recovery from Diesel Exhaust. SAE Technical Paper. 2012-01-0411, 2012, doi:10.4271/2012-01-0411.

${ }^{5}$ Cartens, T. A., Corradini, M. L., Blanchard, J. P. and Ma, Z. Thermoelectric Powered Wireless Sensors for Spent Fuel Monitoring. 2012. 
${ }^{6}$ Sardini, E., Serpelloni, M. Passive and Self-Powered Autonomus Sensors for Remote Measurements. Department of Electronics for Automation. University of Brescia/ V. Branze 38, 25123 Brescia, Italy. 2009, 9, 943-960; doi: $10.3390 / \mathrm{s} 90200943$

${ }^{7}$ Gregory, O., Conkle, J., Birnbaum, T. Wireless Sensors for Gas Turbine Engines-56 ${ }^{\text {th }}$ International Instrumentation Symposium. 2010.

8 Sordiashie, E. Electromagnetic Harvesting to Power Energy Management Sensors in the Built Environment. University of Nebraska-Lincoln. 2012.

9 Schilz, J. Applications of Thermoelectric Infrared Sensors (Thermopiles): Gas Detection by Infrared Absorption; NDIR. PerkinElmer Optoelectronics GmbH. 2000.

${ }^{10}$ Kasap, S. Thermoelectric effect in metals: thermocouples. E-Booklet. 1997.

${ }^{11}$ Honeywell. Hall effect sensing and application. MICRO SWITCH Sensing and Control. URL: http://content.honeywell.com/sensing/prodinfo/solidstate/technical/hallbook.pdf [cited May 7 2012]

3.

${ }^{12}$ Hamwell, G. P., Principles of electricity and electromagnetism, $2^{\text {nd }}$ ed., McGraw-Hill Book Co., New York, 1949, Ch.

${ }^{13}$ Gilbert, J. and Dewey R. Linear Hall-Effect Sensor IC's. Applications Information. URL: www.allegromicro.com/ /media/Files/Technical-Documents/an27702-Linear-Hall-Effect-Sensor-ICs.ashx [cited May 9 2012]. 


\section{Appendix D}

- Nomenclature

\begin{tabular}{ll} 
A & Area \\
$\mathrm{I}$ & Current \\
$\mathrm{I}$ & Length \\
$\mathrm{N}$ & Number of turns \\
$\mathrm{R}$ & Resistance \\
$\mathrm{r}$ & Radius of solenoid \\
$\mathrm{S}$ & Seebeck coefficient \\
$\mathrm{T}$ & Temperature \\
$\mathrm{V}$ & Voltage \\
$\mathrm{V}_{0}$ & Initial voltage \\
$\mathrm{V}_{\mathrm{B}}$ & Output voltage \\
$\mathrm{Z}$ & Thermoelectric figure of merit \\
$\lambda$ & Thermal conductivity \\
$\mu_{0}$ & Permeability of free space \\
$\varphi$ & Magnetic flux \\
$\sigma$ & Electrical conductivity \\
\hline & Distance from Hall sensor and solenoid coil \\
\hline &
\end{tabular}




\section{Vita}

Jennifer Jazmin Kuchle Ituarte was born in Ciudad Juarez, Chihuahua, Mexico on February $28^{\text {th }}$, 1988 to Clemente Kuchle Olivas and Maria Teresa Ituarte Salvatierra. She was raised in Ciudad Juarez and studied at local schools in the same city. She graduated from Instituto Tecnologico y de Estudios Superiores de Monterrey High School Campus Ciudad Juarez in 2006 from which she was awarded a diploma for academic excellence. She continued her studies at The University of Texas at El Paso where she earned her Bachelor of Science in Mechanical Engineering in 2010. During the summer of the same year, she worked as an intern at the Army High Performance Computing Research Center (AHPCRC) at Stanford University performing aerodynamic analyses within the computational fluid dynamics area.

After the completion of her Bachelor's degree, she continued her education pursuing a Master's degree in Mechanical Engineering as well. She joined the center for Space Exploration Technology Research (cSETR) at UTEP in 2011. She was also awarded a teaching assistantship for one year for the Thermofluids and Solid Mechanics labs courses. She will graduate with her Master's of Science in Mechanical Engineering in 2012.

Permanent address: 6427 Jarudo Sur

Ciudad Juarez, Chihuahua, MX 32659

This thesis was typed by Jennifer Jazmin Kuchle Ituarte. 